\title{
Coordinated studies of the geospace environment using Cluster, satellite and ground-based data: an interim review
}

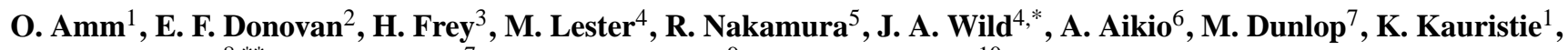 \\ A. Marchaudon ${ }^{8, * *}$, I. W. McCrea ${ }^{7}$, H. J. Opgenoorth ${ }^{9}$, and A. Strømme ${ }^{10}$ \\ ${ }^{1}$ Finnish Meteorological Institute, Space Research, P.O. Box 503, FIN-00101 Helsinki, Finland \\ ${ }^{2}$ Department of Physics and Astronomy, University of Calgary, Calgary, T2N 1N4, Canada \\ ${ }^{3}$ Univ. of California, Space Sci. Lab., Centennial Drive at Grizzly Peak Boulevard, Berkeley, CA 94720-7450, USA \\ ${ }^{4}$ Radio Space Plasma Physics Group, Department of Physics Astronomy, University of Leicester, Leicester LE1 7RH, UK \\ ${ }^{5}$ Space Research Institute, Austrian Academy of Sciences, Schmiedlstraße 6, 8042 Graz, Austria \\ ${ }^{6}$ University of Oulu, Department of Physical Sciences, P.O. Box 3000, FIN-90014 University of Oulu, Finland \\ ${ }^{7}$ Space Science and Technology Department, Rutherford Appleton Laboratory, Chilton, Didcot, Oxfordshire, OX11 0QX, UK \\ ${ }^{8}$ CETP/IPSL/UVSQ, 4 avenue de Neptune, 94107 Saint-Maur-des-Fossés Cedex, France \\ ${ }^{9}$ Solar and Solar Terrestrial Missions Division, ESTEC (SCI-SH), P.O.Box 299, 2200 AG Noordwijk, The Netherlands \\ ${ }^{10}$ Auroral Observatory, University of Troms $\varnothing$, N-9073 Troms $\varnothing$, Norway \\ *now at: Space Plasma Environment and Radio Sci. group, Dept. of Communication Systems, InfoLab 21, Lancaster Univ., \\ Lancaster, LA1 4WA, UK \\ ** now at: Mullard Space Sci. Lab., Univ. College London, Holmbury St. Mary, Dorking, Surrey, RH5 6NT, UK
}

Received: 21 December 2004 - Revised: 18 April 2005 - Accepted: 3 May 2005 - Published: 15 September 2005

\begin{abstract}
A little more than four years after its launch, the first magnetospheric, multi-satellite mission Cluster has already tremendously contributed to our understanding about the coupled solar wind - magnetosphere - ionosphere system. This is mostly due to its ability, for the first time, to provide instantaneous spatial views of structures in the system, to separate temporal and spatial variations, and to derive velocities and directions of moving structures. Ground-based data have an important complementary impact on Clusterrelated research, as they provide a larger-scale context to put the spacecraft data in, allow to virtually enlarge the spacecrafts' field of view, and make it possible to study in detail the coupling between the magnetosphere and the ionosphere in a spatially extended domain. With this paper we present an interim review of cooperative research done with Cluster and ground-based instruments, including the support of other space-based data. We first give a short overview of the instrumentation used, and present some specific data analysis and modeling techniques that have been devised for the combined analysis of Cluster and ground-based data. Then we review highlighted results of the research using Cluster and ground-based data, ordered into dayside and nightside processes. Such highlights include, for example, the identification of the spatio-temporal signatures of the different modes of reconnection on the dayside, and the detailed analysis of the electrodynamic magnetosphere-ionosphere coupling of
\end{abstract}

Correspondence to: $\mathrm{O}$. Amm

(olaf.amm@fmi.fi) bursty bulk flows in the tail plasma sheet on the nightside. The aim of this paper is to provide a "sourcebook" for the Cluster and ground-based community that summarises the work that has been done in this field of research, and to identify open questions and possible directions for future studies.

Keywords. Ionosphere (Auroral ionosphere) - Magnetospheric physics (Magnetosphere-ionosphere interactions; General or miscellanous)

\section{Introduction}

The terrestrial magnetosphere is a cavity carved out of the solar wind by the terrestrial magnetic field. To zeroth order it is a consequence of the high solar wind conductivity, and its dimensions reflect a stress balance between the solar wind dynamic pressure and the magnetic pressure inside the cavity. The magnetosphere is coupled to the solar wind across its outer boundary - the magnetopause - and to the Earth's upper atmosphere via the ionosphere and thermosphere. Key processes at work at the magnetopause are magnetic reconnection, particle entry, and large- and small-scale waves that arise at and around this boundary. Electric currents couple the magnetosphere and ionosphere, and large-scale convection within the magnetosphere drives ionospheric currents, and has significant effects on the motion of the neutral atmosphere at thermospheric altitudes. The energy that powers 


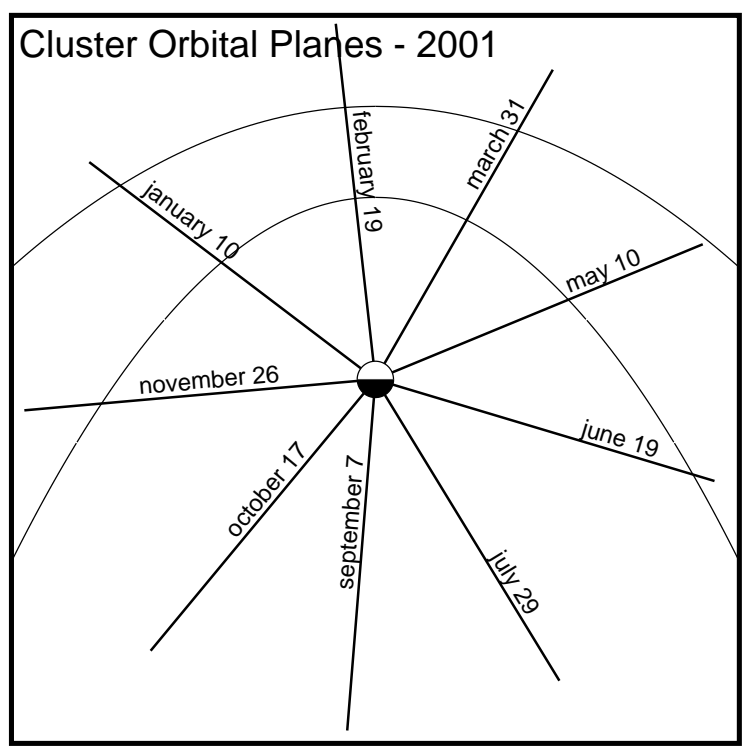

Fig. 1. The meridian of the Cluster orbit clocks through all local times of the year supporting dayside, flank, and nightside investigations.

the large-scale currents and convection is extracted from the solar wind. The dominant mechanism through which this energy is extracted is reconnection on the dayside and the motion of flux tubes past the Earth that are magnetically coupled to the magnetosphere via "open" magnetic field lines. The magnetospheric plasma is replenished by the direct entry of solar wind plasma, and electrons and ions of ionospheric origin.

Closure of important unanswered questions in space physics demands novel instruments and/or missions that extend our observational capabilities in ways tailored to those questions. For example, ground-based remote sensing of electric and magnetic fields, and imaging of the aurora from space and the ground provide us a macro-scale or even sometimes a global perspective of the ionospheric projection along magnetic field lines of the magnetospheric electric fields and particle populations. With these larger-scale or global measurements we can separate temporal and spatial variations, but only in this two-dimensional projection. Our ability to project this information outwards to infer magnetospheric quantities and to track magnetospheric dynamics, suffers from limitations in our understanding of the magnetic field topology, and poorly understood parallel and inductive electric fields that can electrically decouple the magnetosphere and ionosphere. On the other hand, in-situ satellite observations provide essential information about charged particle distribution functions, electric and magnetic fields, and a host of plasma waves, but typically do not provide simultaneous observations in different magnetospheric regions nor the ability to separate temporal variations from spatial gradients. The recognition of these limitations is the motivation for the development of multi-satellite constellation-, and cluster-class missions, both of which represent bold advances that will allow us to explore fundamentally new physics and bring closure to central questions in our field.

In a constellation-class mission, multiple similarly instrumented spacecraft will simultaneously probe different geospace regions, with the scientific motivation of exploring the physics of macroscale geospace processes, such as, substorms, fast plasma flows, and flux transfer events. Clusterclass missions, on the other hand, involve several similarly instrumented spacecraft flying in close formation with the following objectives:

- To explore the physics of small-scale geospace structures. An example is magnetic reconnection. Single satellites, such as Polar and Geotail, have identified signatures of reconnection, such as ion diffusion and fast flows on the dayside magnetopause and in the nightside mid-tail CPS (e.g. Bale et al., 2002). A close formation of appropriately instrumented satellites probe the structure of an X-line.

- To measure gradients, curls, and field-line curvatures. These quantities appear in terms in virtually all of the equations describing geospace phenomena. For example, any studies of ballooning in the inner magnetosphere require knowledge of field-line curvature and the gradients in the (non-isotropic) pressure.

- To measure the source regions and propagation characteristics of waves and structures. For example, the Cluster quartet can measure the characteristics of surface waves, for example, Kelvin-Helmholtz waves, on the magnetopause, as recently demonstrated by Hasegawa et al. (2004).

- To measure the orientation and motion of magnetospheric boundaries. For example, Cluster observations of magnetopause motion have been used to characterize the response of the dayside magnetopause to changes in the solar wind parameters (Bosqued et al., 2001).

The first cluster-class mission is the appropriately named the European Space Agency's Cluster-Mission, which was launched in summer 2000. The Cluster mission concept is described in Escoubet et al. $(1997,2001)$. Cluster consists of four identically instrumented satellites. The spacecraft separation, orbit, and instrumentation were selected to facilitate studies of small-scale plasma processes in key geospace regions, such as the bow shock, magnetopause, magnetotail and auroral zone (see Figs. 1, 2a and b). The orbits of the four spacecraft are adjusted through subtle maneuvers in such a way that they form a tetrahedron at pre-specified locations near apogee, for example, in and above the cusp, or in and around the magnetotail. Consequently, orbital dynamics lead to a "string-of-pearls" configuration at and near perigee, for example, in the interior cups and the auroral zones. The separations range from several hundred $\mathrm{km}$ up to several Earth radii. The orbit is polar, with $4 R_{E}$ perigee and $19.6 R_{E}$ apogee both roughly in the magnetospheric equator. The orbital plane rotates in local time over one year, so that six 
months after apogee is on the dayside, it is on the nightside (see Figs. 1, 2a and b). Each Cluster satellite carries the same set of eleven instruments that allow for the detection of electron and ion distribution functions at spin resolution, and the measurement of electric and magnetic fields at higher time resolution, from DC to high frequencies. A brief description of the instrument complement is given in Sect. 2.1 below. Although the instrument complement is truly state-of-the-art, and includes several novel instrument types, an even larger impact of Cluster on the international space science community is derived from the fact that it is the first cluster-class mission.

Well before the Cluster launch, it was widely recognized that the mission's scientific impact could be greatly enhanced by a complementary ground-based program (see the proceedings of the NATO 1991 Svalbard workshop). Three major observational contributions that ground-based observations can provide were highlighted by Opgenoorth and Lockwood (1997):

- Resolution of spatial and temporal variations in dynamic events, such as the expansive phase of substorms.

- Placing satellite observations in context. Ground-based observations are widely used, for example, for the identification of convection and auroral boundaries and the cross polar cap potential, and their spatial and temporal dynamics.

- The provision of ionospheric boundary conditions, such as conductivities which are important for Alfvén wave reflection and magnetosphere-ionosphere coupling during substorms, and within active dayside reconnection events and low altitude cusp processes.

In these ways, science, motivated by the satellite measurements, would be enhanced through the context that groundbased and other remote sensing of the ionosphere provide. In turn, Cluster observations enhance ground-based observations in important ways, several of which we list here: Cluster can measure boundary motions. Repeated magnetopause crossings, for example, could signify surface waves that can be related to poleward moving auroral forms or magnetic pulsations. Starting from the Cluster observations such features can be identified in otherwise hard to interpret global network ground-based data. Cluster can confirm, for example, the existence of an X-line in the plasma sheet during a substorm, and point the way to new ground-based observations related to such features. Alternatively, confirmation by Cluster that reconnection is occurring on the dayside magnetopause at the same time that it is occurring as specific cusp precipitation is an essential step in the development of proxy signatures for such processes that can later be used in statistical studies.

In the "string-of-pearls" configuration, Cluster can provide in-situ observations that can relate, for example, changing physical conditions in the auroral zone to observed changes in the auroral distribution.
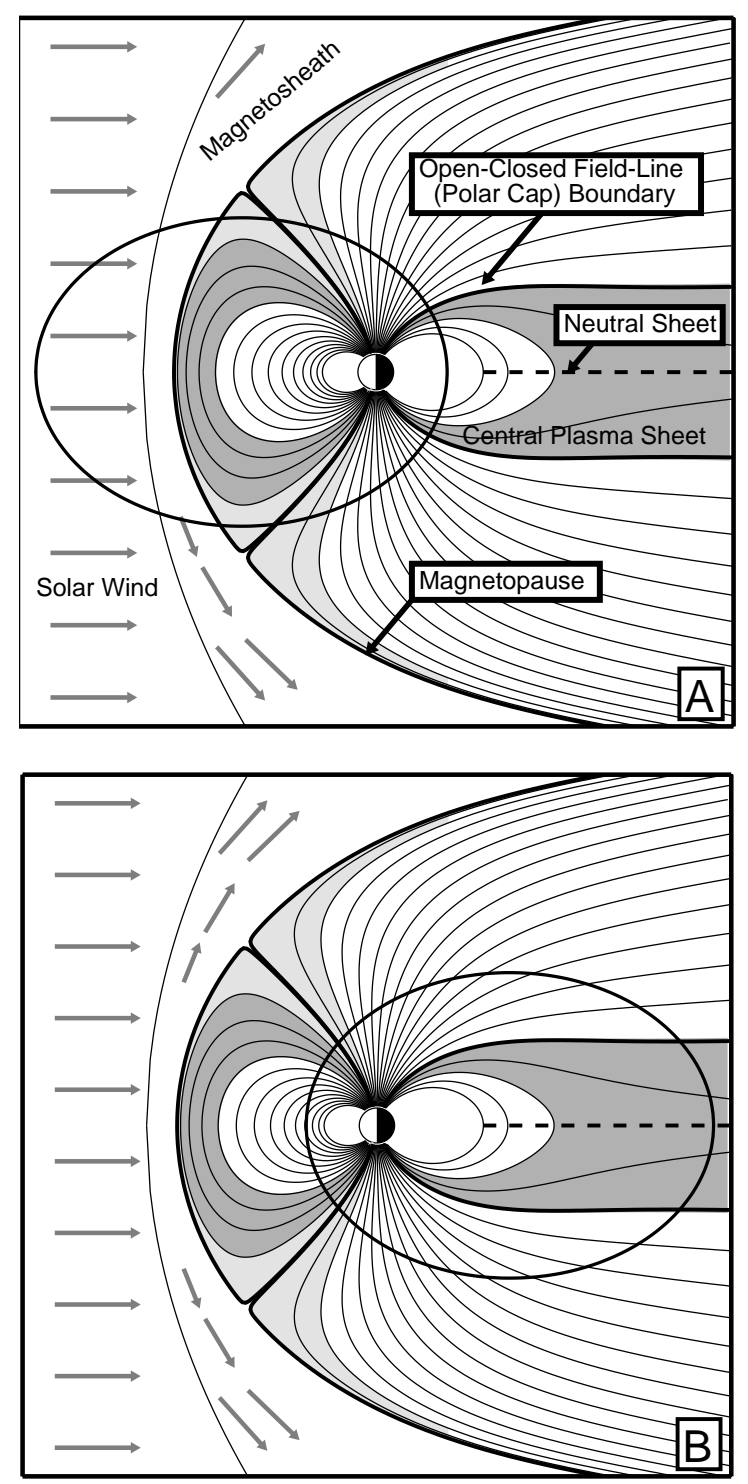

Fig. 2. (a) The orbit of Cluster was selected to maximize the opportunities to study cusp, magnetosheath, and bow shock processes during periods of dayside apogee. (b) Nightside apogee takes Cluster through the CPS in the mid-tail reconnection region, ideally suited for studies of substorms, and thin current sheets.

Close coordination between the two research communities provides synergy, and opens the door to research not previously possible. For example, coordinated Cluster groundbased observations have made possible the first real crossscale coupling studies. Cluster can provide, for example, insitu observations of the micro-physics of reconnection on the dayside magnetopause. The simultaneous global view provided by ground-based observations allows us then to explore how and through what other mechanisms such small-scale processes couple to larger scale dynamics, as seen in global convection, current and precipitation patterns. Such studies are impossible without both the ground-based and Clustertype data. 
To give a structure to the Cluster ground-based program, and to coordinate the work of the rather large and previously quite disparate international ground-based observation community, the Cluster Ground-based Working Group was formed in 1991 as a formal coordinating body. The initial chair of this group, H. Opgenoorth, was recognized by ESA with a membership in the Cluster Science Working Team (SWT), giving the ground-based program the status of an instrument on the spacecraft (the SWT is made up of the 11 instrument PIs, and the ground-based coordinator).

The initial prescription for action by the Working Group was straightforward: it was to identify ground-based assets, develop protocols for data archiving and summary presentation via the World Wide Web that would facilitate the use of ground-based data in conjunction with Cluster data, and develop tools for identifying useful ground-based Cluster conjunctions (see, e.g. Opgenoorth and Lockwood, 1997). This largely technical work was successful, and has led to significant advances in data formats and the integrated use of data from different instrument arrays and types, and it has also significantly improved coordination between different ground-based programs (see Lockwood et al., 1997).

In order to ensure that ground-based observations will do more than simply provide context for the satellite measurements, the Working Group adopted a strategy of identifying Cluster related science that not only required the use of ground-based coordinated measurements, but was driven by the ground-based research itself. It also defined a broadened mandate by extending its efforts to include global MHD and empirical modelling to more meaningfully connect ground and in-situ observations. Further, the Working Group recognized that global imaging of the aurora from space, geosynchronous particle and magnetic field observations, and particle observations from low altitude satellites like DMSP and FAST all provide data that are utilized in ways analogous to ground-based remote sensing data. Note therefore, that for such purposes, space-based global imaging, geosynchronous particle and field, and low-altitude particle observations have been included under the overall heading of "ground-based" data. The common characteristic of these types of data is that they provide ionospheric observations with essentially no uncertainty in terms of localization.

The overall theme became rather "specification of the ionospheric electrodynamics and precipitation distribution", as compared to simply "observations made from the ground". In the end, the Working Group has brought together a blend of global modelling, global ground-based, and geosynchronous and low-altitude satellite observations capable of almost complete specification of the electrodynamics, convection, and precipitation in the ionosphere on a global scale for hours at a time.

In this paper we review scientific results derived from the coordinated use of Cluster and ground-based data. While this effort grew out of the Cluster Ground-Based Working Group, we have not restricted our attention to research by that group. The team surveyed published work that used both ground-based and Cluster data and tried to identify sci- entific highlights to be included in this review. In Sect. 2 we briefly describe the relevant ground-based and Cluster instruments, pointing the reader to key recent references, and outline value-added data analysis, empirical models, data assimilation, and global models, all of which are relevant to coordinated Cluster ground-based work. The Cluster groundbased work that we review falls into three categories. In Sects. 3 and 4 we review dayside (i.e. cusp processes, FTEs, and magnetic reconnection) and nightside (i.e. substorms, fast flows, and auroral arcs) processes. In our discussion, we outline how the coordinated use of Cluster and groundbased data has advanced our understanding of geospace phenomena, and what major contributions are expected in the future not only from this program, but also from the coordinated use of ground-based data and upcoming constellation and cluster-class missions.

\section{Instrumentation, techniques and models}

In this section, we present the relevant instruments and techniques used to relate measured quantities to the physical quantities of interest, and some issues related to the empirical models most commonly used for mapping. We finish this section with a discussion of physics-based and assimilative models, which are now coming to the fore as important tools for studying the geospace system. We use a broad-brush here, for brevity sake, and we are in no way trying to present a complete review of this important aspect of geospace science. Rather, we limit our attention to instruments and techniques used in studies discussed in this paper.

\subsection{Instruments}

On the ground, the international community operates an extensive and diverse collection of instruments, such as fluxgate and induction coil magnetometers, VLF (Very Low Frequency) receivers, coherent (High Frequency, HF, and Very High Frequency, VHF) and incoherent scatter radars, meridian scanning photometers (MSPs), spectrographs, all-sky imagers (ASIs), and imaging and integrating riometers. These instruments are operated individually and as part of national and even international networks. They extend from the heart of Antarctica to near the geographic north pole. Nations from every continent are involved in this global effort. In a very real sense these instruments provide us with our only true global measurements. The co-ordinated use of ground-based instruments certainly provides us with our most complete picture of smaller-scale ionospheric electrodynamics. Data from all of these instrument types are widely discussed in the literature. We refer the reader to the "Satellite - GroundBased Coordination Sourcebook" (Lockwood et al., 1997) for reviews of various instrument types, their data, and descriptions of important international observing networks.

Fluxgate magnetometers measure the vector magnetic field on the ground. The sample rate varies, but most systems obtain data at a rate of roughly $1 \mathrm{~Hz}$. Magnetometers 
operate continuously, delivering a rather coarse picture of the two-dimensional ionospheric current systems subject to fundamental limitations imposed by ground-induced currents and the smoothing effect of the $100 \mathrm{~km}$ or more distance between the magnetic field sources and the detector. Fluxgate magnetometers are operated as parts of international and national arrays (see, e.g. Rostoker et al., 1995; Engebretson et al., 1995), and individually, and the result is an essentially worldwide array of these instruments (see, e.g. Fig. 1 of Lu et al., 1995). New techniques to maximize the extraction of information from dense magnetometer arrays are discussed in Subsect. 2.2.

MSPs and ASIs are typically used to detect auroral emissions through narrow band-pass filters centered on important auroral emission lines and bands (see, e.g. Deehr and Lummerzheim, 2001, and Syrjäsuo et al., 1998). The spatial resolution afforded by optical data is much better than that of magnetometer data, and the optical data allows one to infer at least some information about the spectrum of precipitating particles (see discussion in Sect. 2.2). The usefulness of optical observations is limited, however, by often poor viewing conditions (i.e. clouds, twilight, etc.), as well as uncertainties in the emission height and hence in the location of the source for off-zenith observations.

Riometers measure HF radio wave absorption due to enhanced ionization in the lower ionosphere. This absorption is a quantitative proxy for the precipitation of high energy diffuse and discrete auroral electrons and very high energy solar protons. Riometers give little, if any, information about the spectrum of the precipitating particles, but can map out the two-dimensional evolution of the inner magnetospheric, high-energy electron population under favorable circumstances (Baker et al., 1981).

The Super Dual Auroral Radar Network (SuperDARN) is a network of HF coherent scatter radars which encircle the northern and southern polar regions (Greenwald et al., 1995). The overlapping fields of view (FOVs) of SuperDARN cover much of the auroral and polar cap regions in both the Northern and Southern Hemispheres. These radars normally scan in 16 successive directions, with 75 range gates which are $45 \mathrm{~km}$ in extent. Each radar measures the backscatter power from ionospheric irregularities, the Doppler or line-of-sight (LOS) velocity of the irregularities, and a parameter termed the spectral width, which is a measure of the decorrelation time of the irregularities. Pairs of radars with overlapping fields of view can provide vector measurements of the ionospheric drift velocity. VHF radars, such as STARE ("Scandinavian Twin Auroral Radar Experiment"), operate at higher frequencies, and obtain echoes from E-region waves (see, e.g. Greenwald et al., 1978). The Doppler velocity can be related, with some caveats, to the local velocity in the Eregion. The VHF radars provide a higher spatial resolution map of ionospheric convection than the SuperDARN radars, although their ability to obtain echoes is more sensitive to the magnetic aspect angle and they have smaller FOVs.

Incoherent scatter radars (ISRs) utilize powerful highfrequency $(>\sim 50 \mathrm{MHz})$ transmitters, and plain or phase- coded pulses. Ionospheric electrons oscillate in response to the electric field of the radar transmitted wave, and these oscillating electrons, in turn, radiate electromagnetic waves, the frequency of which changes according to the movement of each electron. ISRs observe signals from many electrons simultaneously. In the ionospheric plasma the electrons partly follow the motion of the much heavier ions, and the backscatter observed by the radars comes not from the individual electrons, but from collective processes (Langmuir and ionacoustic waves) arising from the natural oscillatory modes of the plasma. Since the scattering process depends on the properties of both electrons and ions, the received signal is rich in physical content. From the power and the shape of the spectrum one can determine electron density, electron temperature, ion temperature, ion drift speed and the collision frequency between ions and molecules along the radar line-of-sight. Bi-static or tri-static radars combine such scatter information from a given ionospheric volume as obtained from two or three radar stations. From these basic incoherent scatter parameters, several quantities can be calculated, for example: ionospheric electric field, ionospheric electric currents, energy and flux of the precipitating particles, conductivities, heating rates, neutral winds, temperatures, etc.. This ability to measure or to infer so many of the fundamental parameters of the ionosphere and upper atmosphere makes incoherent scatter a uniquely powerful technique in the study of the geospace plasma environment. Specifically, to support Cluster observations of the cusp, cleft, magnetosheath, and bow shock, a new incoherent scatter radar facility was constructed on Svalbard.

The EISCAT (European Incoherent Scatter) Svalbard radar has been operational since 1996. Just one of its many unique advantages is that it is at a high enough geographic latitude so that it has a view of the dark cusp for several months of the year. Consequently, optical experiments, such as photometers, spectrometers, and a surprising number of all-sky imagers, have sprouted up around this facility, making it the preeminent cusp research facility in the world. Observations by Cluster, in conjunction with high power radio wave transmitters and heaters, such as the EISCAT Heater (Stubbe et al., 1982), SPEAR (Wright et al., 2000) or HAARP (Bell et al., 2004), have also been undertaken. The HAARP facility was able to trigger waves in the ionosphere which were subsequently detected, at the highest altitude ever, by Cluster (Bell et al., 2004). It is likely that such studies will form a major new area of research during the remainder of the Cluster mission.

As discussed in the Introduction, in space physics, global auroral images from space are utilized in essentially the same fashion as is ground-based data. The NASA IMAGE (National Aeronautics and Space Administration Imager for Magnetopause-to-Aurora Global Exploration) satellite was launched in March of 2000. IMAGE carries two global auroral imaging instruments which together comprise the Far Ultraviolet Instrument (FUV). The Wideband Imaging Camera (WIC) provides global images of primarily the $\mathrm{N}_{2} \mathrm{LBH}$ (Lyman-Birge-Hopfield) band. The Spectroscopic Imager 
Table 1. Cluster instruments, instrument PIs, and relevant references.

\begin{tabular}{lll}
\hline Instrument name & Instrument PI & Reference \\
\hline ASPOC (Spacecraft potential control) & K. Torkar (IRF, A) & Torkar et al. (2001) \\
CIS (Ion composition) & H. Rème (CESR, F) & Rème et al. (2001) \\
EDI (Plasma drift velocity) & G. Paschmann (MPE, D) & Paschmann et al. (2001) \\
FGM (Magnetometer) & A. Balogh/E. Lucek (IC, UK) & Balogh et al. (2001) \\
PEACE (Electrons) & A. Fazakerley (MSSL, UK) & Johnstone et al. (1997) \\
RAPID (High energy electrons and ions) & P. Daly (MPAe, D) & Wilken et al. (2001) \\
DWP (Wave processor) & H. Alleyne (Sheffield, UK) & Wooliscroft et al. (1997) \\
EFW (Electric field and waves) & M. André (IRFU, S) & Gustafsson et al. (2001) \\
STAFF (Magnetic and electric fluctuations) & N. Cornilleau (CETP, F) & Cornilleau-Wehrlin et al. (2003) \\
WBD (Electric field and wave forms) & D. Gurnett (IOWA, USA) & Gurnett et al. (2001) \\
WHISPER (Electron density and waves) & P. Décréau (LPCE, F) & Décréau et al. (2001) \\
\hline
\end{tabular}

(SI) provides global images of emissions via two channels. The SI12 channel is sensitive to the Doppler shifted Hydrogen Lyman-alpha, and provides the first truly global images of the proton aurora. The SI13 channel is sensitive to the $135.6 \mathrm{~nm}$ OI doublet. The WIC and SI13 instruments are primarily electron auroral imagers, but it is important to recognize that precipitating protons, via secondary processes, can give rise to these emissions, as well (see, e.g. Frey et al., 2001). The FUV instrument package is described in detail by Mende et al. (2000).

Of course, the complement to the ground-based instrumentation are the in-situ instruments carried on board Cluster. Each Cluster satellite carries the same set of eleven instruments that allow for the measurement of electric and magnetic fields from DC to high frequencies, and the detection of electron and ion distribution functions at spin resolution. An overview of this instrument complement is given by Escoubet et al. (1997, 2001). The individual instruments, their respective Principal Investigators (PIs), and references for the description of the instruments, are listed in Table 1.

\subsection{Techniques}

The instruments described in Sect. 2.1 measure physical quantities that must be further analysed in order to generate the information needed for a particular application. While the bulk of this subsection is devoted to techniques that are applied to ground-based data, we begin with a brief comment about satellite data analysis. Many of the techniques used in multi-spacecraft data analysis have been described in Paschmann and Daly (1998). While most can be applied to single spacecraft data, such as spectral analysis and the measurement of the moments of the plasma velocity distribution, some can only be applied to multi-spacecraft observations, such as discontinuity analysis and spatial gradient measurements. Two such techniques that have been widely utilized in coordinated Cluster-Ground based studies are the Curlometer (Dunlop et al., 2002a) and the discontinuity anal- yser (Dunlop et al., 2002b). The Curlometer estimates the average current density in the vicinity of the satellites. It can be used at the magnetopause, to determine the magnetopause current, or in the tail to determine the evolution of the tail current. The discontinuity analyser, on the other hand estimates the motion, geometry and orientation of a boundary or discontinuity, such as the magnetopause, the plasma sheet boundary, or the tail current. Both techniques are inherently multi-spacecraft (i.e. there is no single satellite equivalent measurement) and provide important information for solar wind-magnetosphere-ionosphere coupling and substorm studies.

We start the discussion of ground-based techniques with the quantitative inversion of auroral images which is based on the brightness ratio of two emissions which are either excited or absorbed differently. Many investigations use the ratio between the visible oxygen red ${ }^{3} \mathrm{P}-{ }^{1} \mathrm{D}$ transition $630.0 \mathrm{~nm}$ duplet and the blue ${ }^{1} \mathrm{~N} \mathrm{~N}^{2+}$ band emission at $427.8 \mathrm{~nm}$. The red oxygen emission is primarily excited by low energy $(<1 \mathrm{keV})$ electrons. At high altitudes $(>180 \mathrm{~km})$ this emission is mostly undisturbed while at lower altitudes $(<130 \mathrm{~km})$ the excited oxygen atoms are often deexcited by collisions with other atmospheric constituents. The blue emission of nitrogen molecules is mostly excited by higher energy $(>1 \mathrm{keV})$ electrons at lower altitudes. The ratio of the red/blue emission is therefore a measure of the mean energy of precipitating electrons (Rees and Luckey, 1974; Kaila, 1989; Janhunen, 2001).

In the ultraviolet regime, which is applicable to imagers flown on spacecraft, such as Polar and IMAGE, there are auroral emissions from the oxygen OI transitions at 130.4 and $135.6 \mathrm{~nm}$, the nitrogen molecule Lyman-Birge-Hopfield (LBHs) band at $120-250 \mathrm{~nm}$, and several strong nitrogen atom emissions, for instance, at 149.5 and $174.3 \mathrm{~nm}$. The molecular oxygen absorption in the Schumann-Runge band strongly absorbs below $160 \mathrm{~nm}$ and reduces the amount of photons that could be observed from an imager in space 
(Germany et al., 1997). The region of LBHs emission at $140-160 \mathrm{~nm}$ that undergoes strong atmospheric absorption is generally referred to as the $\mathrm{LBH}$ region. The mostly undisturbed, higher wavelength region of LBH emissions at 160$190 \mathrm{~nm}$ is generally referred to as the $\mathrm{LBH}$ region. The $\mathrm{LBH}$ emission is excited by direct electron impact on nitrogen molecules, and the different wavelength emissions are only determined by the branching ratios of $\mathrm{N}_{2}$ (Vallance-Jones, 1974). The ratio between LBHs and LBHl is therefore intrinsically fixed, however, depending on the altitude where the emission is excited this ratio can change with electron energy. As high energy electrons penetrate deeper into the atmosphere (below $120 \mathrm{~km}$ ) their excited LBHs emission undergoes strong absorption while the LBHl remains mostly undisturbed. Therefore, the LBHl band can then be used to determine the input energy flux (Germany et al., 1997). A similar approach uses the strongly absorbed 135.6-nm emission to $\mathrm{LBH}$ ratio, yet this has the additional complication of the unknown atmospheric $\mathrm{O} / \mathrm{N}_{2}$ ratio (Frey et al., 2003a). Knowing the global distribution of precipitating electron energy, their energy flux can lead to a global estimate of ionospheric conductance (Robinson et al., 1987; Germany et al., 1994; Semeter and Doe, 2002).

The assimilative mapping of ionospheric electrodynamics (AMIE) procedure (Richmond and Kamide, 1988) is one of the most commonly used methods for deriving global distributions of ionospheric electrodynamics. For all input data sets used with this technique, exact or empirical relations to the ionospheric electric field distribution are devised. The electric field is then solved as a primary output, using an optimisation approach. This gives AMIE the flexibility to utilize many different types of data sets, such as ground magnetic data, ionospheric electric field data from radars or satellite measurements, optical data and particle precipitation data. Not every input data set has to cover the full analysis region, as it is required for forward methods that are based on the solution of algebraic or differential equations. On the other hand, "a priori" information from statistical models of the ionospheric Hall and Pedersen conductances (e.g. FullerRowell and Evans, 1987) and of the ionospheric convection (e.g. Foster et al., 1986) need to be used in areas where no measurements are available. This limits the ability of the technique to adequatly describe single events, and it is difficult to estimate the uncertainty of the results in regions where the density of actually measured data is sparse. With the combined set of "a priori" data, measured data, and the electric field output distribution, the full set of macroscopic ionospheric electrodynamic parameters can be calculated. Until now, AMIE has been only available for global-scale analyses, and has, for example, been successfully used in order to analyse the response of the ionospheric electrodynamics to different conditions of the interplanetary magnetic field (IMF) (e.g. Lu et al., 1995, 2002).

The KRM (Kamide-Richmond-Matsushita-Mishin) technique (Kamide et al., 1981) also provides global distributions of the ionospheric electric potential by combining ground magnetometer data and a model of the ionospheric conduc- tances, in order to solve a second-order differential equation for the potential. While this approach has been successfully used on a global scale for regional analyses, the unknown boundary conditions cause substantial uncertainty in the results (Murison et al., 1985).

Two methods for deriving ionospheric electrodynamics from combined ground-based and multi-satellite observations have been specifically developed for use with Cluster data: The Elementary Current Method (ECM; Amm, 2001) and the field-aligned current (FAC)-based method of characteristics (Amm, 2002). Both methods use the FAC derived from the four Cluster satellites, mapped to the ionosphere, as an input, in order to derive a spatial distribution of the ionospheric FAC. The way in which this is done depends on the geometry of the satellites' magnetic footprints in the ionosphere, and on whether or not a stationary ionospheric structure can be assumed to be moving through the area under analysis (see Amm, 2001, for more details). It is most suitable to apply these techniques when the spacing of Cluster's magnetic footprints in the ionosphere is comparable or larger than the spacing of the ground-based data points. Both methods are forward methods, i.e. no optimisation procedures are used but algebraic or differential equations are solved with the data as input.

The ECM method combines the FAC with ionospheric equivalent currents, as derived from ground-based magnetometer data (see below) as inputs. Its primary outputs are the true ionospheric currents. The ECM method makes use of the fact that the divergence-free part of the true currents equals the ionospheric equivalent currents, and their curl-free part can be derived from the FAC. Spherical elementary current systems (Amm, 1997) are used to expand both parts of the currents, with their sum being the true currents. If ionospheric electric field data are available (e.g. from VHF or HF radar measurements), the ionospheric conductances can be also derived directly using Ohm's law in the ionosphere.

The FAC-based method of characteristics combines the FAC with data of the ionospheric electric field. Using an estimate of the Hall to Pedersen conductance ratio, the Hall conductance is calculated by solving a first-order differential equation, from which, together with the input data set and the estimate of the conductance ratio, the remaining macroscopic ionospheric electrodynamic parameters can be calculated. While depending on the structure of the electric field, unknown boundary values may affect the solution on parts of the area to be analysed; these areas are known and an error estimate is inherently available. The FAC-based version of the method of characteristics does not require ground magnetic field data. This method has, for example, been used by Marchaudon et al. (2004a) to analyse the electrodynamics of an auroral spiral.

The FAC-based method of characteristics is mathematically very similar to the older JEQ (equivalent current)based method of characteristics (Inhester et al., 1992; Amm, 1995, 1998), which combines ionospheric equivalent currents and electric field data, in order to yield the same output as the FAC-based version. Since the JEQ-based version 
uses ground-based data only, it can also be applied also if the magnetic footprint geometry makes it impossible to derive two-dimensional FAC distributions from Cluster. The results of the method can be compared quantitatively with the Cluster observations, as has been done by Amm et al. (2003) (see also Sect. 4.2).

The ECM method and the JEQ-based method of characteristics require as an input the ionospheric equivalent currents which can be calculated from the ground magnetic disturbance data measured by magnetometers. An advanced technique to perform this magnetic field upward continuation is the Spherical Elementary Current Method (SECS; Amm and Viljanen, 1999). In this method, the ground magnetic field is represented as a sum of the magnetic field effects of a number of divergence-free, ionospheric, elementary current systems. The magnitude of each of the elementary systems is adjusted such that the measured ground magnetic field is optimally matched. Once the magnitude of each elementary system is determined, the ionospheric equivalent currents can directly be expanded as superpositions of these differently weighted elementary current systems.

SuperDARN LOS Doppler velocity measurements are widely utilized to directly infer F-region plasma motions. The worldwide array allows the inference of the global convection pattern, subject to there being an adequate number of scatterers. The LOS velocities from all Northern or Southern Hemisphere radars can be combined using a more sophisticated analysis technique termed the map potential analysis (Ruohoniemi and Baker, 1998). This technique fits a spherical harmonic expansion to the potential pattern associated with the measured ionospheric flow using a model of ionospheric flow, generated from a single Northern Hemisphere HF radar at Goose Bay (Ruohoniemi and Greenwald, 1996) to seed the expansion where there are no data. The model is parameterized by the IMF (Interplanetary Magnetic Field) clock angle and magnitude, while the lower latitude limit of the potential pattern is determined by the lowest latitude Fregion ionospheric scatter. This technique is therefore ideal for providing a large spatial coverage observations of the ionospheric convection, which is near global at times. In addition, the cross polar cap potential can be estimated from the maximum and minimum values. The standard time resolution used is $2 \mathrm{~min}$.

SuperDARN measurements of convection provide us with a global, albeit two-dimensional, time-evolving map of the projection of the magnetospheric convection. This picture is augmented by ionospheric electric field measurements from polar orbiting spacecraft, such as FAST (Fast Auroral Snapshot Explorer) and DMSP, data from magnetometers, digital ionosondes and incoherent scatter radars. The use of ionospheric convection observations to infer magnetospheric convection is limited by our understanding of the magnetic field topology and the relationship between the magnetospheric and ionospheric electric potential distributions. Understanding of the field-aligned potential distribution and the magnetic field topology would allow us to use ionospheric convection measurements to infer the correct magnetospheric convection pattern.

\subsection{Mapping between the ionosphere and magnetosphere}

The question of magnetic mapping is of central importance in virtually all magnetospheric studies involving coordinated use of ionospheric and in-situ observations. Empirical magnetic field models, such as the T87, T89, and T01 models (see Tsyganenko, 1987, 1989, 2002a,b) have been widely used for planning conjunctions, and as a necessary step when placing magnetospheric observations in a more global context, in both cases by providing at least estimates of magnetic footpoint locations. Such empirical models in general, their use in coordinated satellite ground-based studies, and potential pitfalls in their use, are discussed by Pulkkinen et al. (1998) and Hapgood (1998). Empirical models are widely used in the studies reviewed in this paper. As we point out in the following paragraphs, however, Cluster has presented an exciting new opportunity to test the validity of field line mappings and the commonly used assumption that (for mapping purposes) field lines are electric equipotentials.

Provided field-aligned potential drops are small relative to the cross-polar cap potential, it is reasonable to impose the condition that field lines are equipotentials and simply map the convection pattern out to the magnetosphere (Boström, 1967). Even in applications where this assumption is valid, the uncertainties in mapping significantly limit how useful ionospheric convection measurements are in terms of providing information about magnetospheric convection (Donovan and Rostoker, 1991). Of course, in most interesting applications, the assumption of equipotential field lines is highly questionable. Rapidly changing magnetospheric topologies go hand in hand with induced electric fields that do not map to the ionosphere, and a curl in the parallel electric field (i.e. a gradient in the parallel electric field orthogonal to the field line direction) can significantly distort the potential pattern from the one inferred using the equipotential assumption (Newcomb, 1958; Hesse et al., 1997). To date, the only way to explore the limitations in mapping potential distributions between the magnetosphere and ionosphere has been to utilize models and simulations (see, e.g. Hesse et al., 1997).

For several hours on 12 March 2001, the Cluster spacecraft were magnetically conjugate to a region of the ionosphere which was at the time yielding excellent SuperDARN convection measurements. The satellites were outbound over the northern polar regions. Baker et al. (2003) used SuperDARN convection measurements, in conjunction with the "T01" magnetic field model (Tsyganenko 2002a,b), and the aforementioned equipotential field line assumption, to infer transverse electric fields in the vicinity of the spacecraft. They found excellent agreement between the in-situ (EDI) and the mapped (SuperDARN) electric field during much of the interval. There were brief periods of disagreement, however, which were attributed to errors in mapping and the decoupling of the ionospheric and magnetospheric electric potentials due to geomagnetic activity. In a demonstration that mapping errors were a plausible source for some of the 
discrepancies, the authors found that by moving the magnetic footpoints slightly from those determined from the T01 model, they could improve the agreement between the in-situ (EDI) and mapped (SuperDARN) electric fields. This need for "optimization", they argued, reflected ever-present, slight mapping errors. As well, they found that during one of the periods of disagreement, multi-spacecraft FGM and groundbased optical and riometer data showed that Cluster was in the vicinity of field-aligned currents which can reasonably be expected to affect the mapping. The discrepancies also coincided with a series of pseudo-breakups, leading up to a breakup, all of which would produce induced electric fields in the magnetosphere, as well as highly structured parallel electric fields.

The Baker et al. (2003) study was only a first step. The authors present their work as an introduction of an important new technique that needs further testing and that will provide important insights into the connection between the ionospheric and magnetospheric potential patterns. Their results clearly demonstrate that the technique works. Although they only used EDI data from one satellite for the bulk of their study, their results are an important first step in attacking the difficulties that have perennially plagued the use of ionospheric measurements to study magnetospheric convection. They point out that the next step on this research path is to use multi-point EDI data to explore the gradient across the magnetic field direction of the parallel electric field in situations like their event.

\subsection{Numerical models}

While empirical models will remain an essential tool in our field for years to come, there are clearly significant limitations on how much information we can truly glean from them in event studies. Improvements can be made by designing models that are primarily analytical (i.e. like the Tsyganenko models discussed above), but that can be constrained by event-specific parameters. Such event-based modelling was initiated by Pulkkinen et al. (1991). Assimilative models provide the opportunity to blend data from different sources (such as ground-based arrays and global images), together with an empirical model and some physical constraints. The ultimate objective, of course, is to have more physics-based models that are derived from realistic simulations and constrained by data. These models would then provide not only context, but a powerful means for exploring the relevant physics.

Currently there are several functioning MHD (MagnetoHydroDynamic) codes designed to solve the entire solar wind - magnetosphere - ionosphere system. Some of the widely known examples are the Lyon-Fedder-Mobarry code (LFM; Fedder et al., 1995), BAT-R-US code (Powell et al., 1999), Geospace General Circulation Model (GGCM, Raeder et al., 1998), and GUMICS-4 (Janhunen, 1996). The global view of such simulations is a valuable reference in the studies of the mesoscale auroral phenomena. An interesting example are the bursty bulk flows which appear in global
MHD-simulations (Wiltberger et al., 2000) and are currently being investigated extensively with combined ground-based and Cluster observations.

The combination of Cluster and ground-based observations has the potential to provide a new, more direct way to probe a number of problems which have been identified in comparison between model and observations. One particular area where co-ordinated observations could play a crucial role is near perigee, which is close to the altitude of the MHD-regime inner boundary (for most MHD models near $3 R_{E}$ geocentric distance, i.e. close to the Cluster perigee of $4 R_{E}$ ), while ground-based instrumentation would monitor the simultaneous ionospheric conditions. Other models include ionospheric models, such as the TRANSCAR model (Blelly et al., 1996) which is a one-dimensional, timedependent ionospheric model, coupled to a suprathermal electron transport code. Such models have yet to be utilised in terms of Cluster - ground-based research, but their use is foreseen as important to the continued activity in this area.

\section{Dayside processes}

\subsection{Introduction}

Solar wind energy and momentum are predominantly transferred to the terrestrial magnetosphere via coupling processes at the dayside magnetopause. Magnetic reconnection is arguably the most significant of these mechanisms, yet the nature, location and factors controlling the reconnection process remain unclear. The energy transport process begins when interplanetary and terrestrial magnetic field lines first break, then reconnect with one another (sometimes referred to as merging), resulting in the creation of an open magnetic field line anchored at one end to the terrestrial magnetic field, with the other end embedded in the IMF. The coupling of the IMF and terrestrial magnetic field has two crucial implications. Firstly, solar wind plasma can penetrate the magnetopause and enter the magnetospheric cavity. Simultaneously, magnetospheric plasma can escape along the reconnected magnetic field lines. Secondly, reconnected magnetic field lines are dragged tailward by magnetic tension and the anti-sunward motion of the solar wind, resulting in the effective transfer of momentum and energy from the solar wind to the magnetosphere.

The level of coupling between the solar wind/IMF and the magnetosphere is sensitive to the orientation of the IMF. If the IMF is directed purely southward (negative $\mathrm{B}_{Z}$ ), reconnection is expected to occur mainly at the low-latitude magnetopause (in the vicinity of the subsolar point), where the magnetic shear between the southward pointing interplanetary magnetic field and the northward pointing magnetospheric field is the greatest. In this simple case, magnetic reconnection increases the amount of open magnetic flux which must inevitably be incorporated into the Earth's magnetic tail, and increases the size of the open polar cap. This loading of energy into the Earth's magnetotail drives 
the convective Dungey cycle (Dungey, 1961) and is ultimately responsible for many of the nightside phenomena discussed in later sections. Magnetospheric convection is imposed upon the ionosphere, resulting in a twin-cell flow pattern characterised by an anti-sunward flow across the polar cap and a sunward flow at lower latitudes. In the contradictory case, when the IMF is directed northward (positive $\mathrm{B}_{Z}$ ), the magnetic shear at the subsolar point is greatly reduced. However, as northward pointed magnetic field lines are carried anti-sunward by the solar wind, they drape over the nose of the magnetopause. This draping results in a large magnetic shear at some locations, most notably in the region tailward of the magnetic cusps, where draped antisunward, interplanetary magnetic field lines overlay earthward (and sunward) pointing terrestrial fields in the lobes of the magnetotail. Consequently, during northward pointing IMF the reconnection process does not cease. Instead, the reconnection site is thought to shift to higher latitudes. Of course, nature is rarely as simple as the simple northward/southward oriented IMF scenarios introduced here. In reality, the orientation of the IMF is highly variable over short time scales (min) and usually exhibits intermediate orientations. In these cases, the location and rate of reconnection are not clear-cut, and it is likely that some blurring of the northward and southward IMF paradigms occurs, with reconnection possibly occurring at multiple locations over the magnetopause. Previous satellite missions have confirmed that the rate of reconnection is highest during intervals when there is a southward directed component of the IMF. At these times, flux transfer events (FTEs), the characteristic signatures of newly-opened magnetic flux tubes in the vicinity of the dayside magnetopause, were frequently observed at equatorial- and mid-latitudes. However, during intervals when the IMF contained a northward component, FTEs were typically observed at higher latitudes (e.g. Berchem and Russell, 1984; Rijnbeek et al., 1984; Kawano et al., 1992; Russell et al., 1996).

Studies of the magnetospheric cusps have yielded insight into the reconnection process under various IMF orientations. Since the cusps lie at the demarcation point between closed and open magnetic field lines, many signatures of dayside reconnection are naturally focused into a relatively small spatial region, in both the magnetosphere and ionosphere. A still much-debated topic in cusp research is the question of whether cusp structures are predominantly temporal or/and spatial in nature, an issue that is related to the question of whether reconnection is quasi-steady or transient. Attempts to resolve this issue have not proved conclusive. Several prior studies have suggested that observed cusp structures are consistent with time-varying reconnection (e.g. Cowley et al., 1991; Lockwood and Smith, 1989, 1994; Lockwood, 1995; Lockwood et al., 1995) while other studies have suggested spatial, rather than temporal, structuring of the cusp (Trattner et al., 1999, 2002).

Prior to the launch of Cluster, the numerous networks of ground-based instruments and auroral imaging spacecraft described in Sect. 2.1 were employed in order to exploit the conjugacy of magnetospheric structures (observed by satellite) with their ionospheric counterparts. While the often inferior spatial resolution offered by ground-based measurements has been compensated for by massively extended fields-of-view and almost continuous data acquisition, the advent of Cluster has enabled a plethora of truly multi-point, multi-scale investigations of the structure and dynamics of the dayside magnetosphere and ionosphere. We shall therefore organise this section by presenting reviews of Cluster and ground-based investigations of magnetic reconnection under southward and northward IMF orientations, before reviewing those studies concerning the temporal variability of the reconnection process via measurements in the cusp.

\subsection{Dayside reconnection under southward IMF}

Of all the solar wind/magnetosphere coupling scenarios, the southward IMF paradigm is arguably the most developed. The concept of low- and mid-latitude reconnection driving large-scale magnetospheric and ionospheric convection is generally accepted, although the determination of the exact location, extent and temporal variability of the reconnection mechanism continues to stimulate passionate discussion. The potential for Cluster to address these outstanding questions has, unsurprisingly, resulted in a whole raft of studies during intervals of southward IMF.

During the first weeks of the Cluster mission's science phase in February and March 2001, the spacecraft orbited the Earth roughly in the noon-midnight meridian. Since apogee lay in the upstream solar wind, interest from groundbased investigators was focussed upon intervals during which the spacecraft traversed the polar cap, high-altitude cusp, and encountered the high-latitude magnetopause. Wild et al. (2001, 2003) studied one such outbound pass through the post-noon, high-latitude magnetopause between 09:15 and 11:15 UT on 14 February 2001. During the whole period of interest, the IMF was essentially southward and duskward. The Cluster spacecraft observed magnetic field perturbations in the magnetosphere with four clear signatures of FTEs. They then entered into a highly-structured magnetopause boundary layer, followed by 3 successive magnetopause crossings (outbound/inbound/outbound), and definitively entered the magnetosheath where FTEs was also observed. Whilst in the magnetosphere, the magnetic footprint of Cluster was located in the mid-afternoon sector dayside ionosphere at 14:30 MLT. In the Northern Hemisphere, this position fell within the fields-of-view of the CUTLASS SuperDARN radars and the field-aligned beam of the ESR radar (Wild et al., 2001), and within the field-of-view of the Syowa East SuperDARN radar in the Southern Hemisphere (Wild et al., 2003). The SuperDARN radars, at magnetically conjugate locations in both hemispheres, revealed the ionospheric signatures of FTEs.

In the first of this pair of papers (Wild et al., 2001), the Cluster data were limited to the FGM magnetic field measurements. The FTEs were characterised by an increase in the magnetic field amplitude and a bipolar signature in the magnetic field component normal to the magnetopause, as 
previously observed by Russell and Elphic (1978). Subsequent examination of Cluster plasma data allowed the authors to confirm their interpretation of the FTEs in the magnetosphere and in the magnetosheath, characterised by a mixture of magnetospheric and magnetosheath plasma populations (Wild et al., 2003). The field tilting effects associated with each FTE were consistent with a reconnection site located at the dusk magnetopause (in agreement with the positive IMF $B_{Y}$ ), with the resulting newly-opened flux tubes carried in the north-westerly direction in the Northern Hemisphere by magnetic tension and magnetosheath flow.

The Northern Hemisphere radar data during this interval (Wild et al., 2001) comprised ESR and CUTLASS SuperDARN data. The CUTLASS Finland SuperDARN radar, conjugate with Cluster and pointing essentially northward, observed two different regions of echoes, each located westward of the Cluster footprint. The low-latitude region between $74^{\circ}$ and $76^{\circ}$ MLAT was characterised by low ionospheric velocities essentially westward and northward, in agreement with the positive IMF $B_{Y}$, and detailed study of this region revealed pulses of ionospheric flow and of backscatter power. The high-latitude region above 76 MLAT included poleward-moving regions of enhanced flow and backscattered power, signatures characteristic of FTEs (Pinnock et al., 1995) that followed each of the pulses in the low-latitude region. These data are presented in Figs. 3a and b. Examination of the Cluster and SuperDARN data indicated a clear one-to-one correlation between the signatures of magnetospheric FTEs observed by Cluster and the pulsed enhancements of convection and power observed by the Finland radar. These observations suggested that the reconnection events had a large spatial scale and that the low-latitude flow region corresponded to the footprint of newly-opened flux tubes. The poleward convection enhancements observed at higher latitudes were the fossil-like signatures of the reconnected flux tubes in the ionosphere. This inference was supported by enhancements of the electron density (associated with cusp precipitation) observed in the low-latitude region by the ESR radar.

The ionospheric convection geometry provided by the CUTLASS radars confirmed the dusk location of the magnetopause reconnection site inferred from the Cluster data. The subsequent study of magnetically conjugate Syowa East SuperDARN radar observations in the Southern Hemisphere (Wild et al., 2003) again revealed modulations of the convection flow at low latitudes and poleward convection enhancements at high latitudes, as presented in Figs. $3 \mathrm{~b}$ and c. These flow modulations were well correlated with the flow pulsations observed by the SuperDARN Finland radar and with the magnetic perturbations observed by Cluster. As expected, the reconnected flux tubes in the Southern Hemisphere propagated poleward and eastward, the asymmetry between the hemispheres being due to the non-zero $\mathrm{B}_{Y}$ component of the IMF. However, the location of this radar around noon MLT implied that the reconnected flux tubes had to be generated on the dawn magnetopause, in order to propagate duskward though the field-of-view of the radar. Consequently, the re-

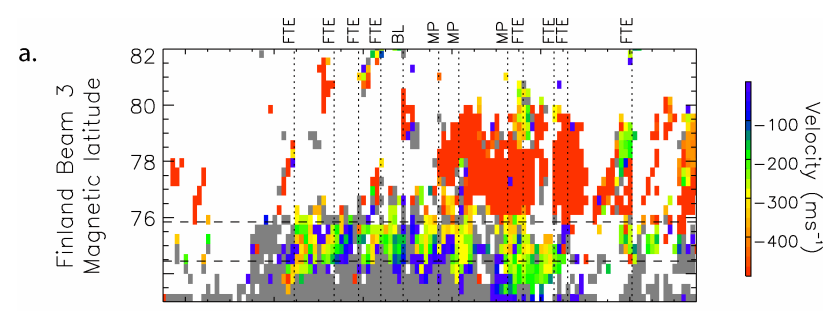

b.
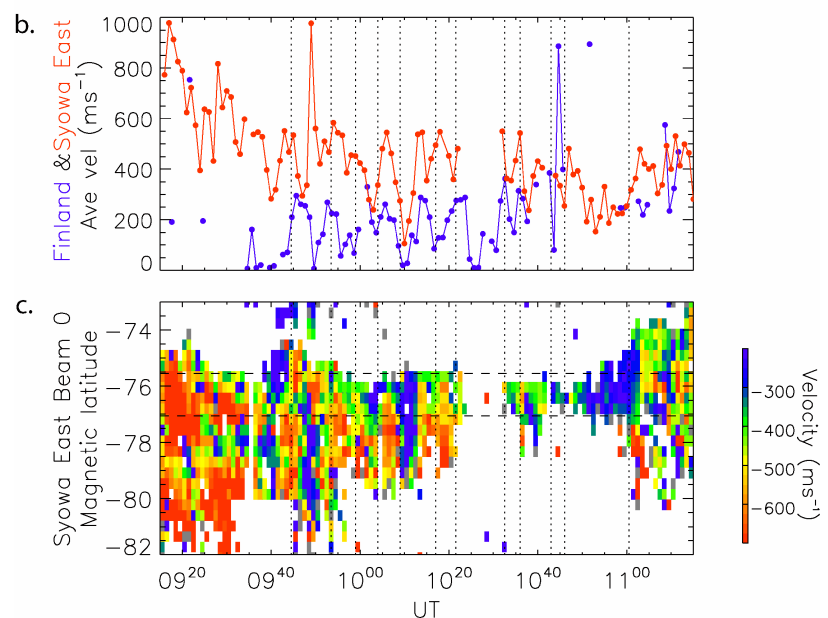

Fig. 3. (a) Line-of-sight velocity data from beam 3 of the SuperDARN Finland radar, colour-coded as indicated in the colour bar. (c) Velocity data from beam 0 of the Syowa East radar, presented in the format of (a), albeit with a different colour scale and a reversed latitude axis. (b) The mean velocity averaged over the latitude range indicated by dashed horizontal lines in (a) and (c) (and given positive values in this case, though in each case the flow is directed away from the radars). The indigo trace corresponds to the Finland average velocities, whilst the red trace corresponds to the Syowa East average velocities. Superimposed on each panel are the times of FTEs, boundary layer (BL), and magnetopause (MP) encounters identified in the Cluster observations. (From Wild et al., 2003.)

connected flux tubes observed in the southern ionosphere were not the same as the reconnected flux tubes seen simultaneously by the Finland radar and Cluster. However, the convection flow modulations seen simultaneously in the two hemispheres in both the pre- and post-noon sectors supported the idea that the reconnection occurred along a single reconnection line extending over at least $4 \mathrm{~h}$ MLT. The groundbased data in the Southern Hemisphere were thus necessary to infer the large-scale geometry of the magnetopause reconnection in this case.

Several authors have exploited Cluster and ground-based observations of the cusp region in order to investigate the reconnection process during intervals of southward directed IMF. For example, on 17 March 2001, between 05:05 and 06:50 UT, the Cluster spacecraft crossed the high-altitude northern cusp while the SuperDARN radars measured lineof-sight velocities typical of cusp echoes in the conjugate ionosphere (Marchaudon et al., 2004b). This allowed for an investigation of the relationship between spacecraft observations reminiscent of flux transfer events (FTE) (Russell 
Cluster \& SuperDARN convection velocity
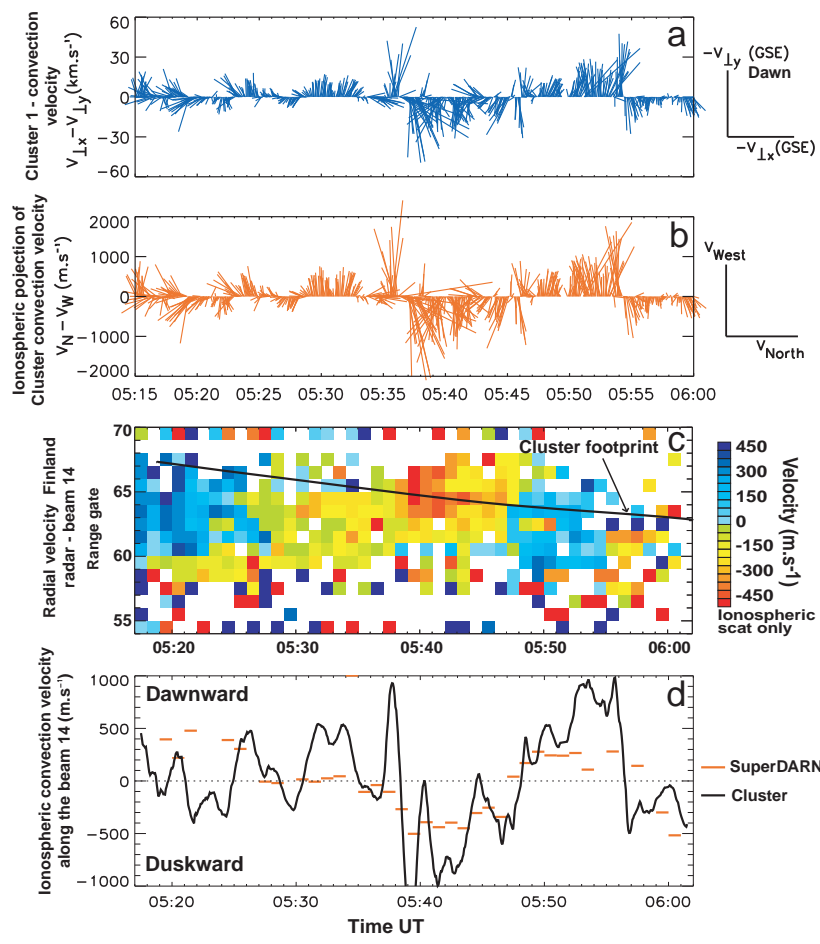

Fig. 4. Convection velocity measured by SuperDARN and Cluster. (a) Cluster 1 CIS ion perpendicular velocity vectors. Each vector represents the perpendicular-to-B component of the plasma velocity projected onto the XY GSE plane. Because the local magnetic field is close to the ZGSE direction, the YGSE component is mainly dawnward. (b) Projection into the ionosphere at $250 \mathrm{~km}$ altitude of the CIS velocity vectors, where $\mathrm{V}_{\text {west }}$ and $\mathrm{V}_{\text {north }}$ correspond to the velocity components in the magnetic west and north directions, respectively, in AACGM coordinates. (c) Range-time plot of LOS velocity for the SuperDARN Hankasalmi beam 14 with the Cluster footprint superimposed (black line). Positive (negative) Doppler velocities correspond to flow toward (away from) the radar. (d) Comparison of velocity measured by Cluster (solid black line) and SuperDARN (red segments). The Cluster CIS velocity has been averaged over $1 \mathrm{~min}$ and projected along the beam 14 of Hankasalmi. The SuperDARN velocity is the radial velocity measured at the Cluster footprint. (From Marchaudon et al., 2004a,b.)

and Elphic, 1978; 1979) and corresponding flow bursts in the ionosphere. The Cluster spacecraft were at a separation distance of $600 \mathrm{~km}$ and crossed the conjugate SuperDARN fields-of-view in the pre-noon sector at 11:30 MLT. Measurements of the local ion population indicated that the satellites were located in the high altitude cusp. Moreover, the location and energy-time dispersion of observed ion injection structures were characteristic of a northward IMF cusp, entirely consistent with the prevailing IMF conditions at the time. A transition of the IMF direction from north-duskward to south-dawnward and back to northward-duskward coincided with observations of a reversal of the convection flow at Cluster from dawnward to duskward and back to dawnward. This reconfiguration was consistent with the observa- tions and models of Northern Hemisphere westward flow for positive $\mathrm{B}_{Y}$ and eastward for negative $\mathrm{B}_{Y}$ (Reiff and Burch, 1985; Cowley et al., 1991). The ionospheric radars observed a simultaneous change in ionospheric convection from dawnward to duskward and back to dawnward again.

Marchaudon et al. (2004b) went on to conduct a detailed comparison of the convection velocities measured in the ionosphere and in the high-altitude cusp. As presented in Fig. 4, the Cluster CIS ion perpendicular velocities (Fig. 4a) were mapped down into the ionosphere (Fig. 4b) and the similarity with the radar-determined convection directions was found to be quite excellent (Figs. 4c and d). Furthermore, during the duskward convection interval, the phase velocity of plasma structures could be deduced from the Cluster 4-point measurements. Bipolar structures in the perpendicular magnetic field component identified these as plasma injections and FTEs (Russell and Elphic, 1978). In the conjugate ionosphere, embedded duskward moving flow bursts were simultaneously observed by one of the SuperDARN radars. The phase velocities determined at the Cluster altitude were mapped into the ionosphere, compared with the flow burst phase velocities measured by the radar, and an excellent agreement was demonstrated once again. The authors have therefore demonstrated that during a brief interval of southward-dawnward pointing IMF, the sporadic particle injections at Cluster and transient flow bursts in the ionosphere were both related signatures of pulsed reconnection at the dawn flank of the magnetopause.

Employing data from Cluster, Polar, and SuperDARN, Maynard et al. (2003) investigated the signatures of temporally varying magnetic reconnection at the high-latitude magnetopause. This study drew upon observations from multiple case studies, but showcased data recorded on 12 March 2001 , at which time the IMF clock angle was $140^{\circ}$. Field and particle measurements made by Polar whilst skimming the nose of the magnetosphere at 11:45 UT revealed accelerated ions and wave Poynting flux consistent with magnetic reconnection at a location northward of the spacecraft - displaced significantly from the subsolar magnetopause. A short time later (12:10 UT), the Cluster quartet was traversing the Northern Hemisphere cusp and revealed similar signatures of time-varying reconnection, although in the case of Cluster, the reconnection site was inferred to lie southward of the spacecraft.

Whilst the Polar spacecraft observed the field and plasma corresponding to the exhaust on the southward side of the reconnection site, the satellite's expected footprint in the Northern Hemisphere ionosphere was located within the diagnostic volume of the SuperDARN radar network. The SuperDARN "map-potential" technique (Sect. 2.2) revealed a series of flow bursts in the high-latitude $\left(75^{\circ}\right)$, post-noon sector (13:30 MLT) ionosphere. By examining the timing of peak velocities within these flow bursts in the vicinity of the footprint, and then comparing these with the reconnection signatures observed by Polar in the vicinity of the subsolar magnetopause, Maynard and co-workers demonstrated the ability to monitor both exhaust regions of high-latitude 
reconnection. Furthermore, the SuperDARN observations indicated that temporal fluctuations in the reconnection rate continued for over one hour, an inference to which the in-situ Polar observations were unable to contribute due to the increasing separation of the spacecraft from the magnetopause. The signatures of reconnection observed later in the interval by Cluster, whilst not contemporaneous with those from Polar, were in excellent correspondence with the continuing SuperDARN observations. As indicated in Fig. 5, they reveal variations within the peak ionospheric flow velocity in the vicinity of the spacecraft footprints. This summary of the SuperDARN measurements clearly demonstrates the correspondence between enhancements of reconnection observed by Polar and Cluster (indicated by red and blue dots, respectively) and enhancements in the ionospheric convection in the conjugate ionosphere.

The multi-spacecraft measurements were furthermore able to reveal the temporal nature of the reconnection signatures, which comprised enhanced fluxes of ions and wave Poynting flux originating southward of the Cluster spacecraft and cusp. An estimate of the current density over the Cluster tetrahedron using the Curlometer technique (Dunlop et al., 2002a,b) indicated that the structures were generally associated with tailward and northward directed current. Drawing upon observations from a catalogue of 14 reconnection events (including those observed during the 12 March 2001 inter$\mathrm{val}$ ), the authors examined the occurrence of high-latitude reconnection using the simultaneous detection of field-aligned wave Poynting flux and accelerated ions as the primary remote indicators of reconnection. The in-situ data were compared with SuperDARN and MHD simulations, which led to the suggestion that reconnection frequently occurs preferentially at high latitudes, especially when the IMF clock angle is $<150^{\circ}$.

In another investigation of high latitude reconnection during southward IMF, Farrugia et al. (2004) exploited Cluster's unusual trajectory through the exterior cusp on 21 January 2001, in order to examine the characteristic signatures of transient reconnection in the region tailward of the cusp. During the interval of interest (15:30-16:00 UT), Cluster was moving on an outbound trajectory through the cusp poleward boundary region at an altitude of $11 R_{E}$ in the midafternoon sector (15:20 MLT). Cluster 1 CIS observations indicated fast tailward and northward flow bursts of the order of $220 \mathrm{~km} \mathrm{~s}^{-1}$ (a substantial fraction of the solar wind velocity) recurring every $2-5 \mathrm{~min}$. A comparison of the magnetic field and plasma measurements indicated that the flow bursts were Alfvénic waves carrying field-aligned current into the ionosphere, thus mediating momentum transfer along recently reconnected magnetic field lines. At much lower altitudes $(1000 \mathrm{~km})$, the FAST spacecraft (Carlson et al., 1998) was traversing from south to north the region of the topside ionosphere magnetically conjugate to Cluster. The observed stepped cusp ion precipitation was interpreted as further evidence of the temporal changes in the reconnection rate that also gave rise to the pulsed flows observed at Cluster.

The Northern Hemisphere magnetic footprint of the Clus-

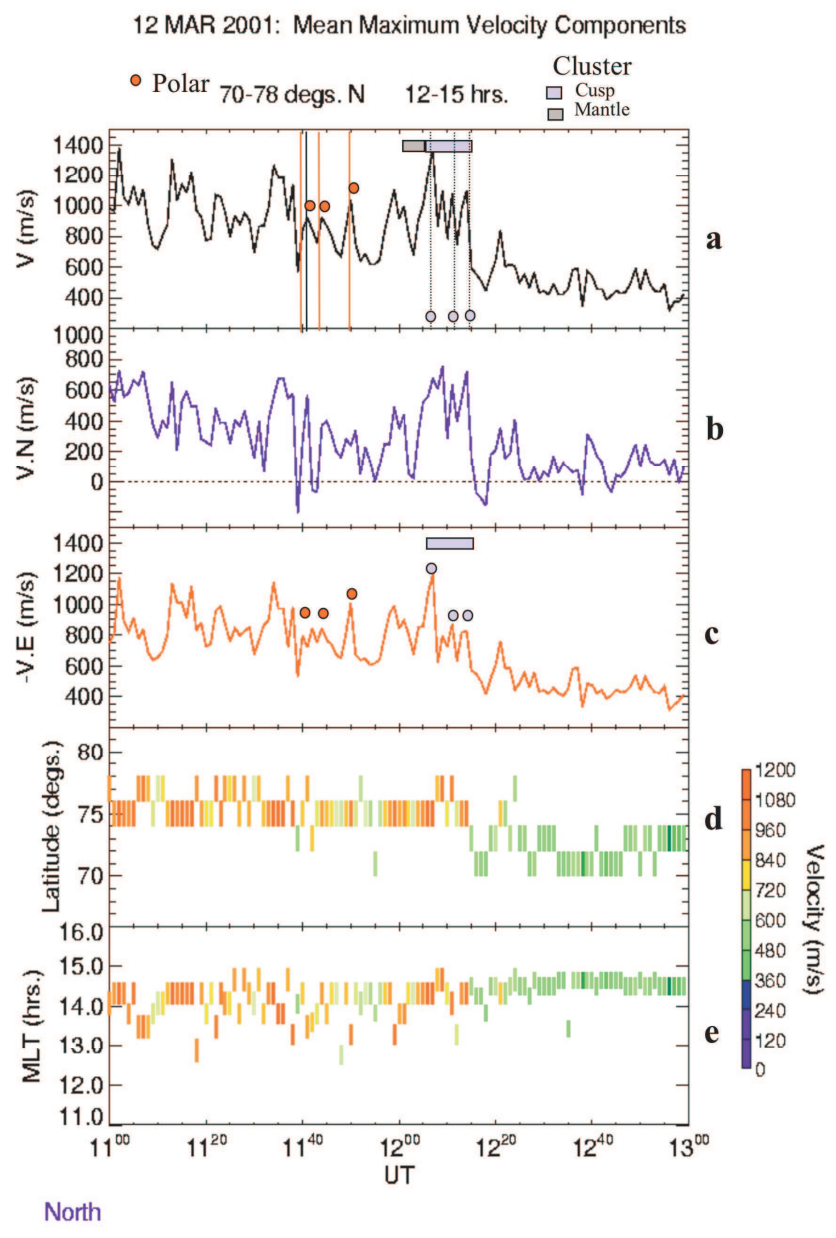

East

Fig. 5. Variations in the peak ionospheric flow velocity in the region 70-78 Mlat between 12:00-15:00 MLT and 11:00-13:00 UT on 12 March 2001. This region contained the estimated footprints of Cluster and Polar. The black trace indicates the overall peak ionospheric velocity while the blue and red traces present the northward and westward components, respectively. The lower panels indicated the latitudinal and MLT location of the peak flow velocity, colour-coded according to the scale. (From Maynard et al., 2003.)

ter 1 and FAST spacecraft during this time was located in the mid-afternoon sector, in close proximity to the Sondre Stromfjord incoherent scatter radar and within the fieldsof-view of the Iceland West and Kapuskasing SuperDARN radars. Using data from eight of the Northern Hemisphere radars, the SuperDARN "map-potential” technique indicated that the Cluster footprint was located slightly westward of the dayside ionospheric convection throat in a region of high speed $\left(1000 \mathrm{~m}^{-1}\right)$ anti-sunward flow. Detailed examination of the SuperDARN line-of-sight velocity measurements in the vicinity of Cluster's footprint revealed a pulsing of the ionospheric flow into the polar cap, typical of the classic poleward-moving radar auroral forms/pulsed ionospheric flows (PMRAFs/PIFs) generally accepted as the ionospheric signatures of flux transfer events. As in previous studies (e.g. Wild et al., 2001), a one-to-one correlation between 
the PMRAFs/PIFs observed in the SuperDARN data and the pulsed flows observed by Cluster (during the interval between the outermost pair of vertical lines) was not observed, supporting the notion that a magnetospheric flow burst with a repetition rate of less than a few minutes exerts a more general "stirring" effect on the magnetospheric plasma at the foot of the open field line. However, comparison of the FAST and SuperDARN data demonstrated, for the first time, an excellent correspondence between two individual cusp ion steps and two ionospheric convection events (PMRAFs), lending weight to the interpretation of cusp ion steps as evidence of temporal (e.g. Cowley et al., 1991), rather than spatial (e.g. Trattner et al., 1999) structuring of the cusp. Comparison of the FAST and Sondrestrom observations also clearly indicated that the open/closed magnetic field line boundary was located $1-2^{\circ}$ equatorward of the dayside convection reversal boundary. Farrugia et al. (2004) re-emphasise the importance of the high latitude boundary region located poleward of the cusps as an active site of momentum transfer, even during intervals of southward IMF a concept championed by Haerendel et al. (1978) in one of the earliest studies of magnetosphere-ionosphere coupling, but often overlooked in intervening years.

Finally, in a study showcasing the full-spectrum of ground-based instrumentation and techniques, Lockwood et al. (2001a) reported a series of observations made during the interval 08:00 to 09:30 UT on 14 January 2001. Observations from the EISCAT Svalbard Radar (ESR) and DMSPF12 satellite were compared, during an interval of predominantly southward IMF. The Cluster spacecraft were moving from the tail lobe through the dusk sector mantle, their footprints displaced from the location of the ESR by $\sim 4 \mathrm{~h}$ of MLT. However, both Cluster and ESR observed strikingly similar signatures, corresponding to enhancements of electron concentration (in the case of the ESR) and changes in electron flux, ion flux and spacecraft potential (in the case of Cluster). Data from the 32-m antenna of the ESR, which was pointed towards magnetic north at low elevation, shows that these events were poleward-moving regions of high density plasma, often classed as "polar cap patches", with an apparent repetition period of the order of $10 \mathrm{~min}$.

An overpass of DMSP-F12 showed dispersed energy signatures in both the ion and electron populations, suggesting the presence of pulsed reconnection (e.g. Newell and Meng, 1991), a conclusion supported by measurements of ionospheric flow by the SuperDARN radars. The derived convection patterns indicated that these events observed by the ESR should also pass over the predicted footprint of the Cluster satellites. The Cluster spacecraft observed enhancements in electron and ion flux, and variations in spacecraft potential, which were not only essentially identical at all satellites (separation $600 \mathrm{~km}$ ) but also very similar to the events observed by the ESR (as shown in Fig. 6). The similarity was particularly marked in variations of the high-altitude electron density observed at the ESR and the low energy magnetosheath electrons measured by the PEACE instruments on Cluster.

The correlation between the ESR and Cluster observations

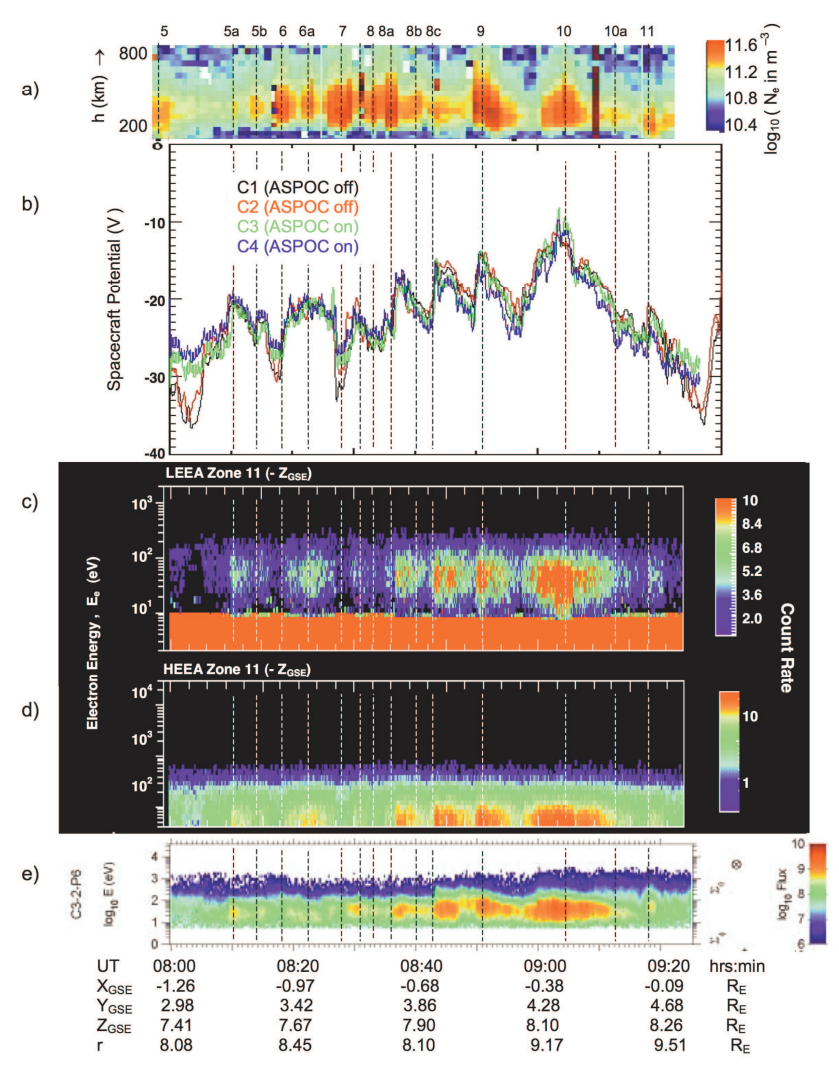

Fig. 6. From top to bottom: (a) electron density measurements made using the ESR field-aligned antenna, (b) spacecraft potential measurements from the EFW instrument on all four Cluster spacecraft, (c) electron measurements from the HEEA detector of the PEACE instrument on Cluster 3, (d) electron measurements from the LEEA detector of the same instrument and (e) ion measurements from the CIS instrument on Cluster 3. The ESR measurements have been time-shifted to give the best agreement with the Cluster observations at events 5 and 11. (From Lockwood et al., 2001a.)

suggested that the patches were related to changes in flux in the softest electrons and hence arose due to modulations in the precipitation of magnetosheath electrons (Watermann et al., 1994). One possibility is that such modulations could be caused by density variations in the source magnetosheath plasma, in which case they would be present whether the reconnection was steady or pulsed, although the dispersed ion and electron signatures measured by DMSP strongly suggest the influence of pulsed reconnection, with some of the events seen in the DMSP data clearly corresponding to the ESR observations. However, modulations of low-energy magnetosheath plasma might be expected during pulsed reconnection, since the location at which reconnected field lines thread the magnetopause evolves with time elapsed since reconnection, and the characteristics of the magnetosheath population might be very different near the sub-solar point (corresponding to newly-reconnected field lines) from that at high latitudes (corresponding to field lines reconnected for a longer period). The correspondence between the ESR and Cluster observations therefore suggests that the mechanism 
governing the soft particle flux is more complex than a simple dependence on the elapsed time since reconnection.

\subsection{Dayside reconnection under northward IMF}

In comparison to the southward IMF scenario, the configuration and dynamics of the magnetosphere during periods of northward IMF is less well understood. It is generally accepted that the reconnection process does not cease entirely, although the reconnection rate is almost certainly reduced. However, it seems likely that the reconnection site is displaced from the low- to high-latitude magnetopause, where large magnetic shears develop between the IMF and the field lines, within the magnetospheric lobes. Whilst "lobe reconnection" does not increase the amount of open flux in the system (indeed it may close pairs of already open field lines, leading to an overall decrease of open flux), the rapid reconfiguration of newly-reconnected field lines results in magnetospheric and ionospheric convection patterns in contrast to those expected for southward IMF.

On 14 January 2001, the same day studied by Lockwood et al. (2001a) as reported in the previous section, the IMF $\mathrm{B}_{Z}$ observed by ACE turned northward at around 09:45 UT, corresponding to a time of 11:00 UT at which the northward turning impinged on the high-latitude magnetosphere. Thereafter, $B_{Z}$ remained northward for at least four hours, though with occasional intervals of intermediate clock angle. During this period, a superb collection of Cluster and ground-based data were obtained, due to the large number of observing systems in operation, making this one of the most important intervals for Cluster studies of the cusp and magnetopause under northward IMF conditions.

Lockwood et al. (2001b) reported observations made in the interval 11:00 to 13:00 UT, a time when Cluster spacecraft were moving toward the dayside magnetopause, passing through the interior boundary of the magnetic cusp, and moving toward the exterior cusp boundary. Their study focused on a number of intervals in which data from the CIS and PEACE instruments suggested that Cluster made brief excursions into the low-latitude boundary layer (LLBL). These LLBL events were marked by the appearance of low-energy magnetosheath ions and electrons, and the complete or partial disappearance of energetic magnetospheric electrons, though not of the magnetospheric ions. The Cluster data and the corresponding ESR observations are shown in Fig. 7. Appropriately lagged measurements by ACE show that these periods coincided with transient swings in the IMF clock angle from northward pointing to values near $90^{\circ}$. This suggested that the LLBL incursions could be explained as the effect of reconnection pulses. Further evidence to support this hypothesis was provided by ground-based auroral measurements, which showed an erosion of the cusp aurora to lower latitudes during these events, and by data from the EISCAT Svalbard Radar, which showed poleward-moving transients at the same times.

Although the Cluster data during these periods showed some of the characteristics expected of Flux Transfer Events,

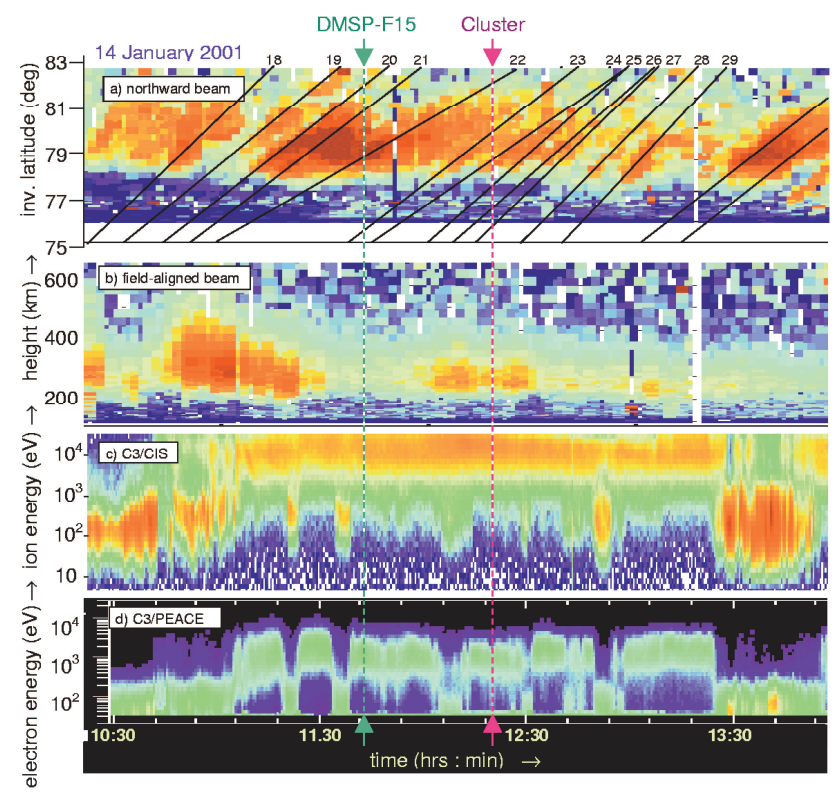

Fig. 7. The transient events seen by Cluster and the EISCAT Svalbard Radar on 14 January 2001. From the top: (a) electron density observed along the northward-looking beam of the ESR, with black lines marking poleward moving events, (b) electron density observed along the field-aligned ESR beam, (c) energy-time spectrogram of ion differential flux as observed by the CIS instrument on Cluster 3 and (d) energy-time spectrogram of electron count rate observed by the HEEA detector of the PEACE instrument on Cluster 3 . The numbering scheme for events in the top panel corresponds to that in Fig. 6. The mauve and green arrows represent the times of closest conjunction of the ESR with Cluster and DMSP-F15, respectively. (From Lockwood et al., 2001b.)

they did not exhibit classical FTE signatures. Notably lacking, at least in the earliest events, was the bipolar magnetic signature which is a well-known attribute of FTE events (e.g. Russell and Elphic, 1978, 1979) and arises from an excess of magnetic pressure at their core. Lockwood et al. (2001b) suggested that the observed signatures nonetheless corresponded to FTEs, using the Cluster field and particle data to show that the plasma was close to being in pressure equilibrium, such that no bipolar signature would be expected. The lack of the bipolar signature was suggested to be due to the location of these LLBL events, which occurred on the interior edge of the cusp. The latest LLBL events in the series were observed as Cluster neared the exterior cusp boundary, and for these events it seemed that the bipolar magnetic signature had begun to appear. The earliest observations in the series (i.e. those in the interior cusp) were therefore interpreted as being the first observations of FTEs at middle altitudes. Furthermore, the observations were interpreted as being strongly supportive of the theory that the LLBL lies on open magnetic field lines, as suggested by a number of previous studies (e.g. (Onsager, 1994; Fuselier et al., 1991, 1992). Only an open magnetic topology could explain all aspects of the reported observations.

A study by Moen et al. (2001) addressed the same 
sequence of events during the outbound pass of Cluster through the high-latitude lobe, cusp, magnetosheath and magnetopause between 12:30 and 15:30 UT on 14 January 2001. In their study, the key data set (in addition to the Cluster data) was a series of auroral images at $630.0 \mathrm{~nm}$, obtained using an all-sky imager at Ny Ålesund, Svalbard, concentrating in particular on two events. The two events spanned the intervals from 12:52-12:56 UT, and 13:27-13:57 UT, during which Cluster had brief encounters with regions characterised by low-energy electrons and where the high energy electron component was almost entirely absent. Analysis of the spacecraft potential data confirmed that these intervals corresponded to boundary crossings. The first interval was interpreted as an encounter with the closed LLBL, caused by an inward bulge of the boundary layer, due to a boundary layer wave propagating tailward over the satellites. This was the same event which Lockwood et al. (2001b) had interpreted as being due to a Flux Transfer Event observed in the interior cusp. Moen et al. (2001) interpreted the second event as a crossing of the outer cusp.

In both events, the ground-based imager data showed an intensification of the 630.0-nm emission, with red-line aurora expanding eastwards towards Svalbard (as illustrated in Fig. 8). The entry and exit times of Cluster into the boundary layer population corresponded well to the times that the red-line aurora expanded over the magnetic footprint of the spacecraft. In the second event (the cusp crossing), this eastward expansion was consistent with the transient reconfiguration of the cusp and convection pattern, following a change in IMF clock angle from strongly northward to westward, a situation which would favour reconnection on the dusk flank. The auroral emission at this time showed poleward-moving forms, characteristic of FTEs. The first event, however, occurred when the cusp was in the pre-noon sector, and Moen et al. (2001) ascribed it to an encounter with closed LLBL field lines on a sunward-convecting flow. When discussed in terms of the categories defined by Sandholt et al. (1998), the auroral signatures in the second event were identified as similar to "Type 7", believed to originate from the dusk sector Boundary Plasma Sheet. The data, however, supported the interpretation that these emissions corresponded to cusp auroral activity at a surprisingly late local time, with accelerated electron beams and discrete aurora occurring on open field lines.

Opgenoorth et al. (2001) focused on the interval between 13:00 and 14:00 UT on 14 January 2001, and thus includes the second event studied by Moen et al. (2001). Opgenoorth et al. (2001) demonstrated that a dramatic re-organisation of the high-latitude convection pattern and current systems occurred, due to a change in the direction of the IMF. A flow channel, directed eastward and poleward, appeared over Canada and expanded (also eastward and poleward) toward Svalbard. At the same time, the four Cluster spacecraft and their magnetic footprint, in the viewing area of the Sondre Stromfjord radar, were engulfed by cusp-like precipitation with transient magnetic and electric field signatures. The ESR observed poleward-moving transients and fast flow

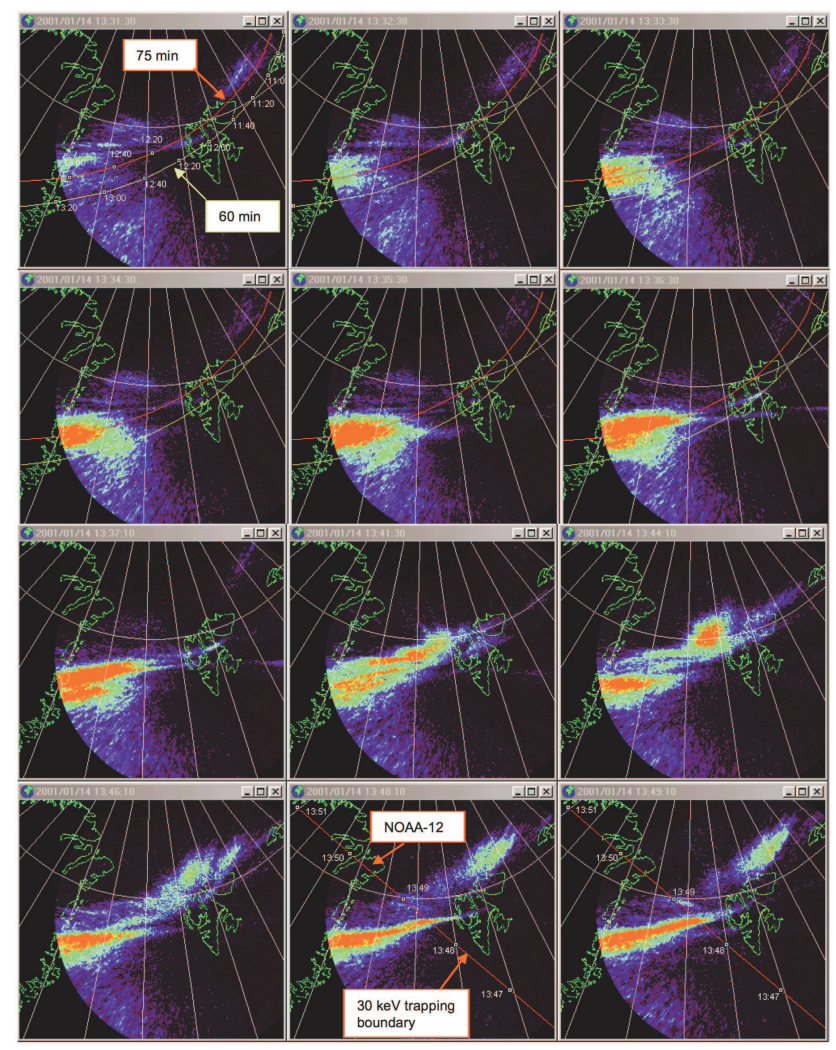

Fig. 8. A sequence of all-sky images of an 630.0-nm emission taken from Ny Ålesund, displayed on a geographical frame of reference, assuming an emission altitude of $250 \mathrm{~km}$. Emission intensity is colour-coded on a linear scale from blue to red. The red and yellow curves in the upper images represent the nominal ground-track of Cluster calculated for two different lags ( 75 and $60 \mathrm{~min}$ ) of the IMF observations. The straight red line west of Svalbard in the lower images represents the flight path of NOAA-12. The images show a progressive eastward expansion of the red line aurora toward Svalbard, consistent with the reconfiguration of the convection pattern reported by Opgenoorth et al. (2001). (From Moen et al., 2001.)

channels associated with auroral structures which formed to the west and north of the radar. The ground-based data showed that the cusp region had moved from its normal prenoon location to extend far into the dusk sector, allowing for the first, quite unexpected, encounter of the Cluster spacecraft with the cusp. This confirmed the interpretation of Moen et al. (2001) that the observations corresponded to a crossing of the cusp.

SuperDARN, magnetometer, EISCAT and satellite results, synthesised together using the AMIE technique (see Sect. 2.2), showed that a pre-existing two-cell convection pattern, with no evidence of lobe reconnection, evolved into a very distorted pattern following the appearance of a strong channel of northeast directed flow, which formed a narrow extension of the dusk cell. This distorted pattern persisted for some $15 \mathrm{~min}$, during the time that Cluster observed the cusplike features, before returning to its previous orientation. Examination of the data from individual radars, magnetometer 
networks and optical instruments strikingly confirmed the details of this overall picture.

The Cluster data showed a remarkable correspondence with the features observed by the ground-based instruments, suggesting that Cluster encountered the same structures of precipitation and convection as were observed at the latitude of Svalbard. The drop-out of the energetic particles in the Cluster data occurred at the time when the eastward flow channel arrived at the Cluster footprint (as indicated in Fig. 9). Consideration of the data from all four Cluster spacecraft revealed that the encounter with the low energy plasma was characterised by features in electric field, magnetic field and plasma density, all of which passed over the spacecraft in the same order, allowing a vector velocity to be determined for the propagation of the transient which was consistent with the ground-based observations. The Cluster particle data were all explicable in terms of an encounter with the exterior cusp, and this was confirmed by DMSP data from around the same time. The only feature inconsistent with a cusp passage was an increase in the magnetic field strength.

The observations were interpreted as being caused by the onset of sub-solar reconnection around 13:20 UT. This was during a period of $\mathrm{B}_{Z}$ north, but with a clock angle greater than $45^{\circ}$, conditions under which Lockwood et al. (2000) and McCrea at al. (2000) have shown that sub-solar and lobe reconnection can exist simultaneously. The flow channels could thus be understood as arising due to the tension force on newly-reconnected field lines, and would be consistent with the global magnetometer results. The precursor electric field events seen in connection to the main flow channel could have been due to the ionospheric return flows associated with FTEs, and the fact that corresponding magnetic signatures were not observed might be due to the propensity for field-aligned current sheets to form closed magnetic structures. The overall situation, in which the dayside magnetosphere was deformed by strong field-aligned currents associated with a flow channel, is probably unusual, though the current understanding of cusp dynamics is not good enough to make this claim too strongly. The extent of the flow channel (5 h in MLT) certainly appeared surprising when compared to previous observations, particularly for such moderate conditions.

In a very fortunate coincidence on 18 March 2002, the Cluster spacecraft crossed the magnetopause at the same time as the IMAGE-FUV instrument observed a bright proton aurora spot in the ionosphere (Phan et al., 2003). Previous investigations have confirmed that such a proton aurora spot occurs during northward IMF conditions (Frey et al., 2002 Fuselier et al., 2002). The strong relationship between the location in local time and the IMF $B_{Y}$ component has suggested that the proton aurora spot is the manifestation of magnetopause reconnection, and the direct entry and precipitation of solar wind particles. On this day, the Cluster spacecraft crossed the magnetopause between 14:54:5215:03:52 UT. The crossing occurred tailward of the cusp and was recognized by the $175^{\circ}$ rotation of the magnetic field from the lobe to the magnetosheath orientation. Plasma jets

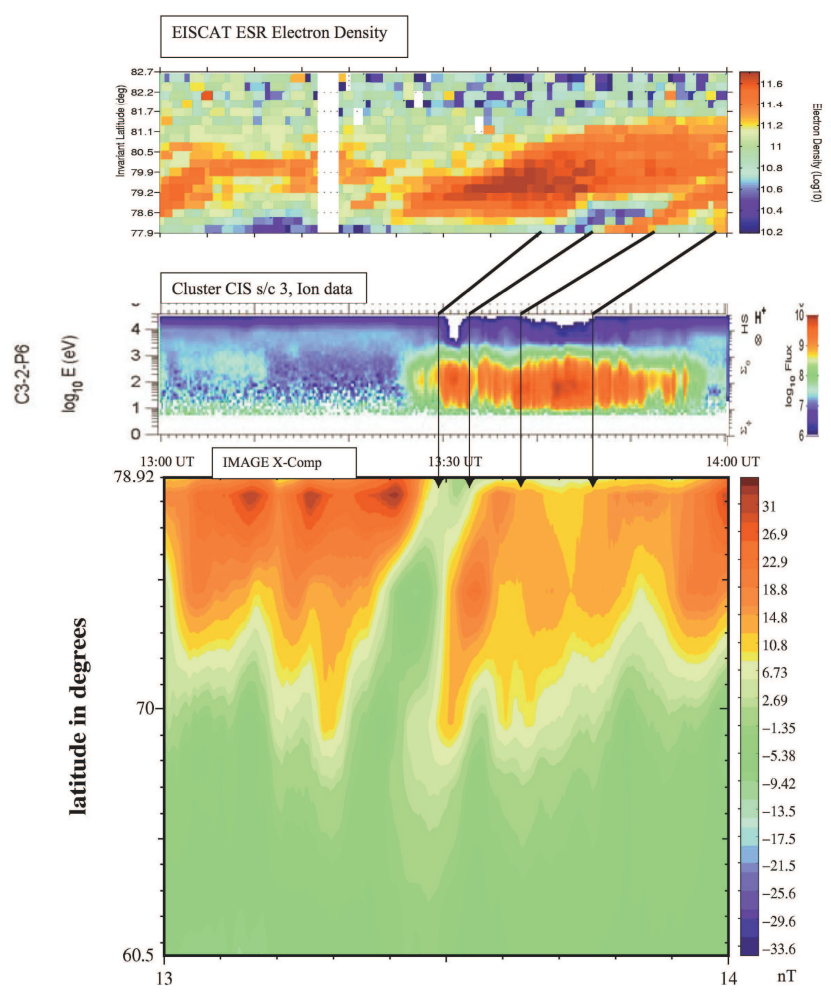

Fig. 9. Stacked plot showing the electron density observed along the northward-looking beam of the ESR (top panel), total ion flux from the CIS instrument on the Cluster 3 spacecraft (middle panel) and magnetic X-disturbance along the central meridian of the Scandinavian IMAGE magnetometer network (lower panel). The thin arrows show the relationship of features in the CIS data to regions of eastward (red) and westward (green) current flow as observed by the magnetometer network. The heavier black bars illustrate the possible continued polar propagation of these features towards the southernmost latitudes observed by the ESR. (From Opgenoorth et al., 2001.)

with flow enhancements were observed, first anti-sunward and then sunward, indicating the passage of a reconnection $\mathrm{X}$-line across the spacecraft. A Walén test was performed (Sonnerup et al., 1987), resulting in the determination of a good deHoffman-Teller frame and a flow velocity of $90 \%$ of the Alfvén velocity, confirming the occurrence of reconnection close to the spacecraft. With a small spacecraft separation of only $100 \mathrm{~km}$ the magnetopause structures appeared almost identically in the spin resolution data of all spacecraft. Following a strong increase in solar wind dynamic pressure at around 13:22 UT, the FUV instrument observed a strong proton aurora spot in the dayside ionosphere for more than $4 \mathrm{~h}$ (Frey et al., 2003b). As the Cluster spacecraft passed overhead, their position could be mapped down into the ionosphere (as presented in Fig. 10), confirming the direct connection between the reconnection signatures in the magnetopause and the occurrence of the bright proton aurora spot at the geomagnetic footprint. Furthermore, estimates of the auroral brightness based upon the energy and flux of protons in the jets encountered by Cluster, matched the IMAGE 

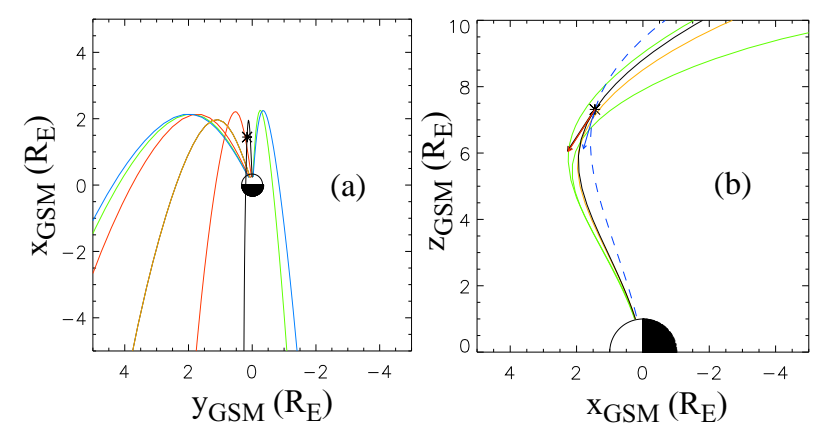

Fig. 10. Mapping of magnetic field lines from the ionospheric proton spot into the magnetosphere. Different colours start at different brightness levels around the centre of the proton spot. Arrows represent magnetic field vectors at the Cluster location from actual measurements (red) and the Tsyganenko-01 model with exaggerated solar wind dynamic pressure. (From Phan et al., 2003.)

observations. Having demonstrated the connection between the high-altitude and the ionospheric observations, Phan and co-workers attempted to map the proton spot out into the magnetosphere. First, the measured and modelled magnetic field magnitudes and strengths were brought into correspondence (Phan et al., 2003). The extent of the reconnection $\mathrm{X}$-line could then be estimated from the ionospheric size of the proton spot to be at least 3.6 $R_{E}$. As such, the combination of the Cluster measurements with remotely-sensed observations allowed the confirmation of a direct relationship between magnetopause reconnection and the occurrence of the proton aurora spot, and an estimate of the reconnection site size which would have been impossible from only the in-situ measurements.

Finally, a study by Pitout et al. (2001) used data from the EISCAT Svalbard Radar, DMSP-F13 and the Cluster satellites, on 2 February 2001, to study the dynamics of the cusp region during an interval in which $\mathrm{B}_{Z}$ was generally northward, and signatures of lobe reconnection predominated. Some of the interval also corresponded to conditions of southward IMF, when poleward flows and strong polewardmoving transients were observed by the northward-looking beam of the ESR. During the interval of $\mathrm{B}_{Z}$ north, which corresponded to the closest conjunction of Cluster with the cusp, the ESR showed low densities and temperatures, and a sunward flow at low velocity. The Cluster and DMSP data supported the interpretation that Cluster passed through the northernmost boundary of the cusp region, observing highly structured plasma characterised by reversed dispersion, due to ion injections caused by pulsed lobe reconnection. However, it did not appear that the events observed by the ESR were the same as those seen by Cluster. This could be explained by the inference that the height at which the northward-looking beam of the ESR intersected the cusp ionosphere $(\sim 300 \mathrm{~km})$ was too high to observe the signatures of the precipitating ions detected by Cluster. Furthermore, a very close correspondence was noted between the IMF $B_{Z}$ measured by ACE and the meridional plasma flow measured by the ESR, with an anti-sunward flow for southward IMF and a sunward flow for northward IMF. An interesting feature was that lobe reconnection seemed to be effective here in the winter magnetosphere at relatively small values of northward IMF, although some previous studies (e.g. Crooker and Rich, 1993) had asserted it to be primarily a summer phenomenon.

\subsection{Reconnection signatures in the cusp}

All too often, simple descriptions of the cusp fail to highlight the truly dynamic nature of this hugely important region. However, the organisation of fields and plasma within the cusp remains uncertain. Satellites crossing the polar cusp often record energetically-dispersed features in ion energy spectra. These are a consequence of the motion of newlyopened magnetic field lines, produced by magnetopause reconnection, convecting with the anti-sunward flowing solar wind. In general, the cusp structure is complex and variations in the observed ion energy dispersion signatures are often step-like in appearance (so-called "cusp ion steps"). The question of whether these cusp structures are predominantly temporally or spatially organised, and the associated debate regarding the quasi-steady or transient nature of reconnection, remains the focus of research worldwide.

The most common explanation of these cusp ion steps is that they correspond to a temporal effect. The cusp is pulsating under the action of a burst of enhanced magnetopause reconnection, with neighbouring reconnected flux tubes generated by successive reconnection pulses. Open flux tubes have different time histories since reconnection (Cowley and Lockwood, 1992; Lockwood and Smith, 1994) and the jumps between steps correspond to the satellite encountering successive flux tubes (from successive reconnection pulses). The flux tubes are convected with the open magnetic field under the joint action of magnetic tension and solar wind flow. This explanation is supported by ground-based observations of successive PMAFs/PMRAFs in conjunction with satellite observations of these cusp ion steps (Lockwood et al., 1995; McWilliams et al., 2001a).

However, studies using combinations of two satellites suggest spatial rather than temporal structures in the cusp ion structures. Examples include an investigation where Interball and Polar observed the same complicated structures $1.5 \mathrm{~h}$ after each other (Trattner et al., 1999), or when Polar and FAST observed similar structures while crossing the same MLT region during stable solar wind conditions (Trattner et al., 2002). The interpretation proposed to explain such observations is that reconnection at the magnetopause can be a rather constant process with only very minor changes in the reconnection rate. During stable IMF conditions, a steady, opened flux tube can be created that is spatially limited by the size of the magnetopause X-line. The existence of multiple X-lines may generate several coexisting, newly-opened flux tubes. The cusp ion steps observed by satellites are then due to the crossing of different flux tubes in which the distance between the open-closed field line boundary and the 
satellite position is different, as indicated in Fig. 11. The closer the satellite is from the open-closed field line boundary, the higher the ion energy observed by the satellite due to time-of-flight effects. Moreover, if IMF conditions are variable, temporal modifications of the convection pattern can occur and change the location of the open-closed field line boundary relative to the spacecraft, and hence change the distance travelled by an opened flux tube to the spacecraft. The variations of the distance between the open-closed field line boundary and the satellite position can therefore result in the smooth reversal of previous ion energy dispersion or to a sudden step within the ion energy spectrum observed at the satellite.

Spacecraft separated in altitude are generally considered advantageous for cusp studies, as the different velocities of the satellites would indicate whether similar observed structures were in fact spatially or temporally organised (Trattner et al., 2004). Since the Cluster satellites cross the cusp at similar altitudes, this advantage is lost. However, the identical instrumentation and the time delay of up to $45 \mathrm{~min}$ between consecutive cusp crossings compensated for this disadvantage in the study by Trattner et al. (2003) and allowed for detailed investigation of the cusp during changing solar wind conditions. During the studied period on 25 July 2001, the SuperDARN network was operating in a special Cluster support mode and determined the global convection pattern. Two of the Cluster spacecraft crossed the cusp within $6 \mathrm{~min}$ of one another, during southward IMF conditions, and observed very similar ion fluxes (as presented in the top and bottom panels of Fig. 12). Several sudden steps in the ion energy-time spectra were explained by two scenarios. In one case the temporal changes in the location of the convection pattern shortens or lengthens the convection length of magnetic field lines from the open-closed field line boundary to the position where they are intercepted by the satellites. The other is the result of a reorganization of the convection pattern. This reorganization moved the boundary between the convection cells over the location of the observing Cluster satellites. The entry into a different spatially separated convection cell, where the location of the ion open-closed field line boundary was significantly closer to the observing satellites, then resulted in the sudden step-up of the ion dispersion. The results were therefore consistent with a spatial interpretation of cusp structures (Trattner et al., 2003).

A related study investigated observations on 23 September 2001 when the IMF conditions were very variable, with changes mostly in the IMF $\mathrm{B}_{Z}$ direction (Trattner et al., 2004). Such varying conditions are likely to introduce temporal changes in the reconnection location, and most probably, temporal changes in the reconnection rate. Two of the Cluster spacecraft observed very similar ion dispersion structures while entering the cusp within one minute of each other. The projection of the satellite observations, together with the ground-based (SuperDARN) convection observations, revealed that these structures were probably of a temporal nature. The second spacecraft observed the same step feature about 1 higher in latitude and 1 min later than the

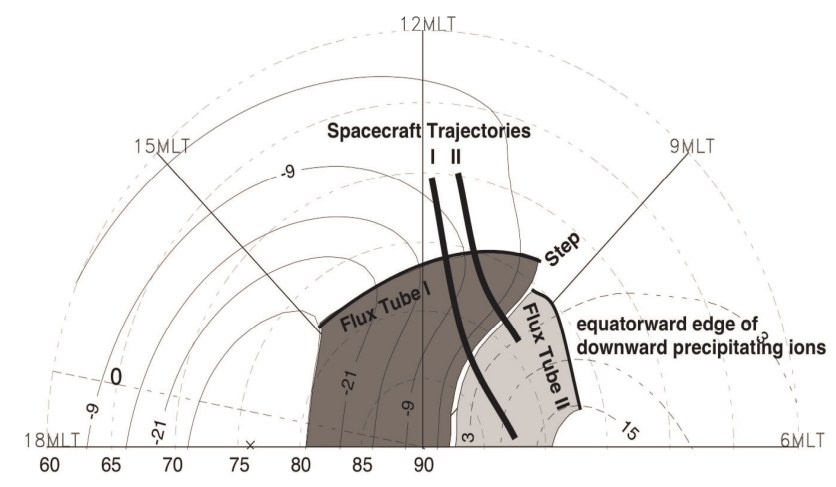

Fig. 11. Ionospheric convection cells derived from the statistical element of the SuperDARN "map potential" model for $-\mathrm{B}_{Z}$ and $-\mathrm{B}_{Y}$ IMF input, in order to illustrate how major cusp structures could be spatial instead of temporal. Two flux tubes and two satellite trajectories have been superimposed on the convection cells. (From Trattner et al., 2004.)

low-latitude spacecraft, which is consistent with a temporally varying structure as predicted by the pulsed reconnection scenario with a varying reconnection rate. The estimated convection speed of the structure at the spacecraft altitude were also consistent with the convection speed measured by the radar. Clearly, in this study, ground-based observations made it possible to observe the ionospheric convection pattern over an extended period of time. These observations made it possible to distinguish between the temporal and spatial interpretations of the in-situ measurements (even though they were recorded at reduced temporal resolution). The projection of the satellite footprints onto the ionospheric convection map ultimately revealed that changes in the ion dispersions coincided with the motion of the spacecraft into different structures of the convection pattern, in this case, different convection cells.

Another perspective on the temporal variability of magnetic reconnection in the cusp is provided by Bosqued et al. (2005). A combination of $90 \mathrm{~min}$ of Cluster multi-point data at $\sim 5 R_{E}$ altitude and global dayside imaging data provided by the IMAGE-SI-12 instrument was used to analyze the northern cusp crossing on 14 July 2001. The IMF was pointing southward/strongly duskward and, for more than $30 \mathrm{~min}$, the solar wind pressure $\mathrm{p}_{s w}$ was highly variable and reached $13 \mathrm{nPa}$. Simultaneous observations in the northern 13:00-14:50 MLT sector, at 71-75 latitude, revealed intense cusp activity, characterized by multiple, impulsive energydispersed ion injections, with a recurrence time of $8-10 \mathrm{~min}$, that were perfectly correlated in space and time with an intense Ly- $\alpha$ brightening. These two coupled transient signatures were one-to-one related to repeated $\mathrm{p}_{s w}$ enhancements which also led to an equatorward shift of the brightest UV aurora and its spreading in MLT and latitude. The Ly- $\alpha$ brightness was positively related to $\mathrm{p}_{s w}$ but not to the IMF clock angle (Frey et al., 2002), and is remarkably similar (within a factor of 2) to the expected count rate deduced from the total ion energy flux measured by Cluster on the same field line. 


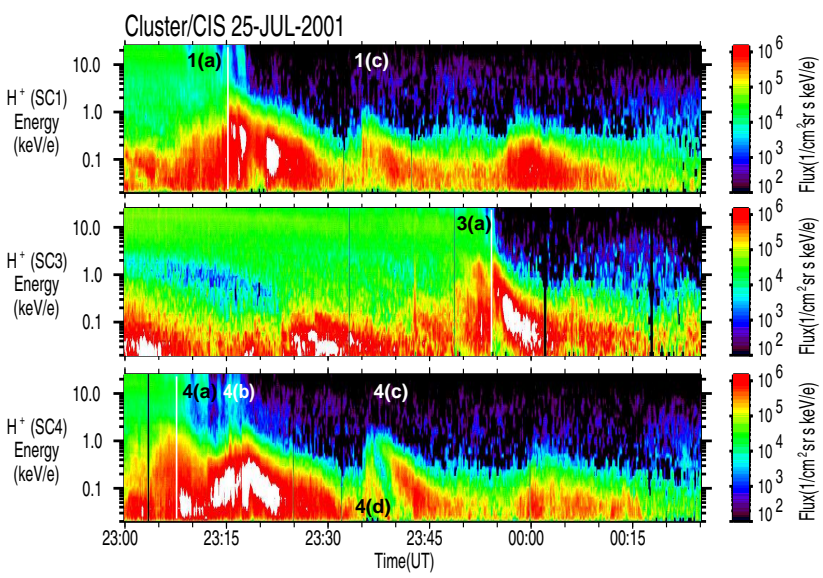

Fig. 12. Cluster CIS observations for the cusp crossings on 25 July 2001. Plotted are $\mathrm{H}^{+}$omni-directional flux measurements $\left(1 / \mathrm{cm}^{2} \mathrm{~s}\right.$ sr keV/e) for Cluster 1,3 , and 4 . All spacecraft encounter distinctive structures with sudden jumps in the ion energy dispersion that are similar on Cluster 1 and 4 , but different on the later arriving Cluster 3. (From Trattner et al., 2003.)

The authors inferred a rather steady reconnection site located at $10-12 R_{E}$ from Cluster, i.e. on the dusk flank of the compressed magnetosphere, at around 17:00-18:00 MLT. They interpreted these very dynamic and transient features as clear signatures of pulsed magnetic reconnection operating in a localized region of the magnetopause, centred on the preferential anti-parallel merging site. The results unambiguously reveal that the reconnection rate at this reconnection site is not spontaneously self-varying but, more evidently, directly modulated by upstream dynamic pressure $\mathrm{p}_{s w}$ and/or Alfvén Mach number perturbations. Their results show that the reconnection process even during southward IMF appears to be steady, with modulations caused by changes in the solar wind conditions.

\subsection{Summary}

Cluster's multi-point measurement capability has revealed new insights into the location and size of the dayside reconnection region, as well as re-confirming the intrinsic link between the coupling of the interplanetary and terrestrial magnetic fields at the magnetopause and plasma dynamics in the high-latitude ionosphere (as observed by groundbased instruments). The high-altitude trajectory of the spacecraft through the cusp and high-latitude magnetopause has resulted in measurements that have re-invigorated the discussion of dayside reconnection at a range of latitudes and under various IMF configurations. The multipoint observations of previously-identified and new phenomena have greatly improved our understanding of the highly dynamic dayside magnetosphere and ionosphere scrutinized by spaceand ground-based techniques.

Flux transfer events observed by Cluster during intervals of southward-oriented IMF have revealed the basic elements of the dayside solar wind-magnetosphere-ionosphere cou- pling process. Magnetospheric flux tubes opened to interplanetary space by magnetic reconnection with the IMF at the dayside magnetopause (i.e. FTEs) have been conclusively linked to transient signatures observed in the ionospheric footprints of the cusps. In particular, the flux tube motion and inter-FTE period has been demonstrated to be the same when observed in the magnetosphere by Cluster or in the ionosphere by ground-based instruments. Inter-hemispheric, ground-based measurements have also revealed that magnetic reconnection can occur over an azimuthally extended reconnection X-line spanning several hours of MLT.

During intervals when the IMF is oriented southward, but with a significant dawn-dusk component, coordinated Cluster/ground-based investigations have provided compelling evidence that the coupling between the interplanetary and magnetospheric magnetic fields can take place far from the low-latitude subsolar region. Several studies have demonstrated that dayside magnetic reconnection can be sustained in the high-latitude region tailward of the cusp.

Remotely-sensed measurements during intervals of northward IMF have proven invaluable to the interpretation of the complex multi-spacecraft Cluster data. Space-based observations of the proton aurora during a sustained interval of northward IMF indicated that a reconnection line $\left(3.6 R_{E}\right.$ in length) located tailward of the cusp and traversed by Cluster remained active over several hours. In another case, clear evidence of pulsed dayside reconnection observed in the ionospheric footprint of the cusp suggested that the in-situ signatures of FTEs observed by Cluster in the mid-altitude cusp differ from those often observed at higher altitudes in the vicinity of the magnetopause. Evidence has also been presented contradicting the view that under northward IMF conditions, magnetospheric and ionospheric dynamics are generally weaker than during intervals of southward IMF. Indeed, the first ever encounter of the Cluster spacecraft with the magnetospheric cusp occurred during an interval of northward IMF. Ground-based data clearly indicated a dramatic and unexpected reconfiguration of the high-latitude convection pattern as the cusp extended far into the dusk sector.

Finally, Cluster and ground-based observations have contributed to the active debate regarding the temporal/spatial nature of dayside reconnection signatures in cusp. The multipoint nature of the Cluster measurements might have resolved this discussion conclusively. However, based upon the Cluster data reviewed in this paper, there is compelling evidence (supported by ground-based data) for both the spatial and temporal interpretations of reconnection signatures in the cusp.

Therefore, while numerous new results have emerged from the first few years of the Cluster mission, several key areas are still not fully understood. Indeed, many new questions have arisen. These include:

- Is magnetic reconnection at the dayside magnetopause predominantly steady or bursty, or is this a function of some external influence (i.e. IMF configuration)? 
- With the tetrahedron configuration of Cluster, is it possible to measure the electrodynamics of an FTE, especially the distribution of the field-aligned currents (with the Cluster curlometer) and the ionospheric closure of the currents (with ground-based observations)?

- How significant is dayside reconnection tailward of the cusp in terms of the creation/destruction of open magnetic flux, as inferred from ground-based techniques based on observations of the changing polar cap size? (i.e. does magnetic reconnection under northward IMF actually create open magnetic flux tubes)?

- Is there in-situ evidence of sunward-moving open flux tubes during intervals of northward IMF, corresponding to sunward ionospheric convection within the polar cap?

- Can multi-point, in-situ measurements reveal the size of the dayside reconnection X-line line? Furthermore, how does this compare to the "merging gap" in the ionospheric convection pattern derived from ground-based measurements?

It is anticipated that the increased use of significantly larger spacecraft separations in the future, the provision of additional data from the Double Star pair of spacecraft, and the continuing expansion in coverage of ground-based instruments (in both hemispheres) will contribute to the resolution of many such issues.

\section{Nightside processes}

\subsection{Introduction}

The nightside processes can be ascribed to the interaction between the solar wind and the magnetosphere-ionosphere system, like the dayside processes. Unlike the dayside, however, the magnetospheric field is not compressed due to the solar wind, but rather stretched out into a long magnetotail. There are mainly two processes governing the global dynamics of the nightside magnetosphere and the ionosphere: convection and substorms. The strongest driving mechanism of the convection is the reconnection of the field lines between the solar wind and the magnetosphere. When the IMF is southward, the reconnected field lines at the dayside are transported toward the nighside, reconnected at the distant tail, and then transported back toward the dayside, creating inward and an earthward flow in the plasma sheet and causing the twocell flow-current pattern in the ionosphere. When the flux merging rate at the dayside is larger than at the nightside, the magnetic field energy becomes stored in the magnetotail and is released in an explosive way during a substorm. A variety of signatures involving both the ionosphere and magnetosphere take place: particle acceleration and precipitation, fast plasma flows, enhanced field-aligned currents and ionospheric electrojets. Furthermore, disturbances take place on different spatial scales. For example, convection in the magnetosphere actually consists of transient, localized high speed flows, called bursty bulk flow (BBF), and slow background flows. Reconnection involves processes from MHD scales ( 1 to $10 R_{E}$ ) down to the electron kinetic scales $(0.5$ to $5 \mathrm{~km}$ ). The widths of auroral arcs can range from $100 \mathrm{~km}$ to $100 \mathrm{~m}$. The multi-scale properties and the interaction between the ionosphere and the magnetosphere make nightside processes very complicated. In the following sections we review recent studies which have combined the results of Cluster multi-point observations and the ground-based observations to study: (1) Large-scale convection and boundaries, (2) Substorms, (3) Fast flows, and (4) Auroral arcs.

\subsection{Large-scale convection and nightside boundaries}

The global magnetic convection typically forms a two-cell convection pattern in the ionosphere. On the dusk (dawn) side, the ionospheric flow is eastward (westward) at the highlatitude portion and westward (eastward) in the lower latitude. The border between these two flow directions is called the "convection reversal boundary (CRB)" or "shear flow region". As will be discussed below new results have been obtained concerning the temporal/spatial characteristics on the shear flow region and the open/closed boundary by combining Cluster and ground-based data.

Amm et al. (2003) analysed the mesoscale structure of the early morning side ionospheric shear flow region using combined data from Cluster and the MIRACLE network of ground-based instruments in Fennoscandia. During the event on 6 February 2002, between 23:00 and 00:00 UT, the Cluster satellites were located close to their perigee at $4 R_{E}$, and their magnetic footprints moved poleward, closely aligned with the central chain of magnetometers of the ground network. Because the footprints were almost linearly aligned along the direction of their motion through the ionosphere, in this study Cluster's multi-satellite abilities were mainly used to distinguish between spatial and temporal changes along the close-to-meridional profile covered by the combined data sets.

Using the ground-based magnetic and ionospheric electric field data, Amm et al. (2003) computed meridional profiles of the true ionospheric currents, conductances, and fieldaligned currents using the JEQ-based method of characteristics (see Sect. 2.2). Since all the ionospheric parameters obtained from the ground-based measurements were varying only in the meridional direction, a 1-D version of the method of characteristics was used. From Cluster, the FACs were determined from each satellite separately, assuming that they were crossing zonally oriented current sheets.

Figure 13 illustrates the main result of Amm et al. (2003). The figure shows the FAC measured by Cluster 2 in the lower panel and the magnetic field immediately below the ionosphere along meridional profiles at the central meridian of MIRACLE, as derived from the ground magnetometers. Here, positive magnetic fields correspond to eastward currents and negative ones to westward currents. The location of the change of sign is marked by a green line and called the magnetic convection reversal boundary (MCRB), in contrast 
to the CRB which is determined by ionospheric electric field or convection measurements. Typically, the MCRB is located $0.5-1.5^{\circ}$ of latitude poleward of the CRB in the morning sector (e.g. Amm et al., 2000). The pink line marks the location of the magnetic footprint of Cluster 2 in space and time, and the blue dashed line denotes the latitude at which the satellite crosses the CRB. While a single sheet of upward FAC is observed at the equatorward flank of the westward electrojet (region A), two sheets of downward FAC are present. One is caused by the equatorward gradient of conductances at the poleward flank of the westward electrojet (region B), and the other by the positive divergence of the electric field in the vicinity of the CRB (region C). The two downward FAC regions are separated by $0.5-2^{\circ}$ in latitude. This double FAC feature is independently confirmed by the FAC derived from all four Cluster satellites and from the method of characteristics which show an excellent agreement when compared along the Cluster magnetic footprint line. While the observations of the four Cluster satellites showed some differences according to the temporal variation of the current system, as shown in Fig. 13, the basic spatial structure of the FAC system remains unchanged in the results of all four satellites. The open-closed field line boundary, as determined from the ion spectrogramms of the CIS instrument, was located 3$4^{\circ}$ poleward of the CRB. Therefore, the use of the CRB as a proxy for the open-closed field-line boundary can lead to significant errors.

The open-closed boundary in the dawn sector was studied by Wild et al. (2004) by comparing space-born particle observations including Cluster and ground-based observations using several different techniques. The polar cap (PC) boundary detection techniques utilizing space-based observations of UV aurora (Brittnacher et al., 1999) have an advantage of obtaining the boundary at all MLT with a high temporal resolution. However, studies comparing particle data from low-altitude satellites have revealed that such techniques may have problems especially in the dawn sector (Kauristie et al., 1999; Baker et al., 2000), which partly can be overcome with some statistical corrections (Carbary et al., 2003). SuperDARN spectral width boundaries can also be used as a proxy for the PC-boundary, as demonstrated by Chisham et al. (2004), although this technique also has some uncertainty in the dawn sector. Wild et al. (2004) investigated these different PC-boundaries determined from the IMAGE WIC and SI-13 cameras with passbands of 140-180 nm and $130-140 \mathrm{~nm}$, respectively, and from the SuperDARN data, and compared them with precipitation data from Cluster, FAST and one of the DMSP satellites, when the satellites flew across the dawn sector auroral oval during 15:0916:04 UT on 8 December 2001. Figure 14 summarises the PC-boundary locations as determined from the particle precipitation data and UV data. At 04:00-05:00 MLT the poleward boundary in the IMAGE WIC image is several degrees equatorward from the corresponding boundary deduced from the Cluster CIS and PEACE data. The PC-boundary in the SI-13 image is more consistent with the particle data. The PC-boundary proxy from SuperDARN spectral widths was

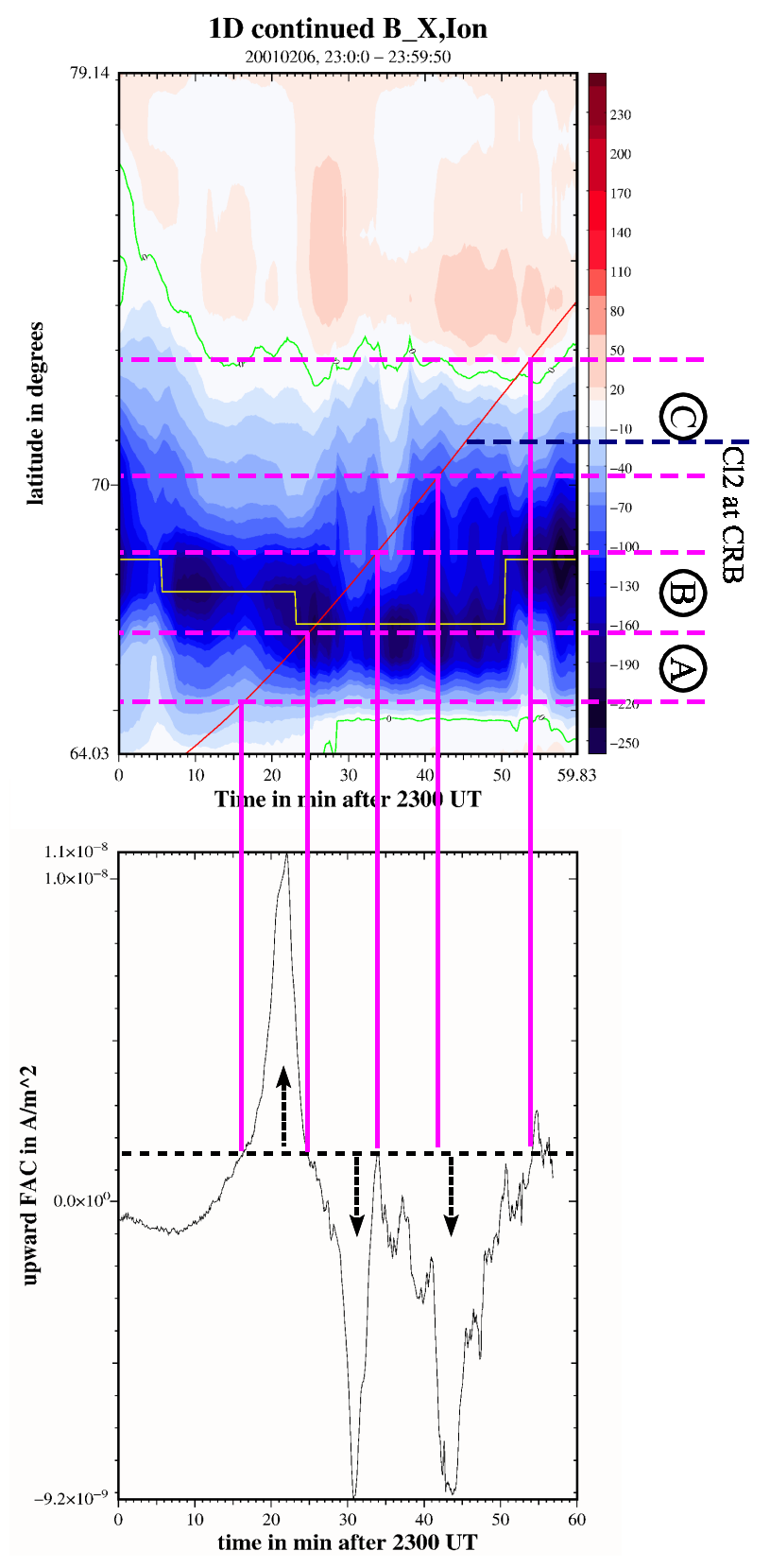

Fig. 13. (Upper panel) Magnetic field immediately below the ionosphere along meridional profiles at the central meridian of MIRACLE, as derived from the ground magnetometers. Positive magnetic fields correspond to eastward currents and negative ones to westward currents. The location of the change in sign is marked by a green line and called magnetic convection reversal boundary (MCRB). (lower panel) FAC measured by Cluster 2 with upward FAC being positive. The pink line marks the location of the magnetic footprint of Cluster 2 in space and time, and the blue dashed line denotes the latitude at which the satellite crosses the CRB. (From Amm et al., 2003.)

located poleward of the most intense WIC emission. PEACE data showed that the region poleward of the WIC emission but still within SI-13 emission was occupied by very soft $(<5 \mathrm{keV})$ electron precipitation. The WIC poleward 
boundary corresponded roughly to the location where the energy flux of the hard precipitation, which dominated at lower latitudes, dropped below the flux of the soft precipitation.

The study of Wild et al. (2004) demonstrated that at least in some cases, the difficulty of estimating reliably the PC-location in the dawn sector can be overcome by crosschecking the UV wideband (mainly LBH) observations with the UV emission at shorter wavelengths (OI emission at $<140 \mathrm{~nm}$ ). An interesting topic for future studies is to check whether the temporal variations in the particle-based and UVbased PC-boundary locations are consistent with each other. This issue can be studied, for example, using data from Cluster near-perigee oval crossings with one satellite lagging the others (or the string of pearls configuration) and simultaneous IMAGE WIC and SI-13 images.

\subsection{Substorm studies}

The concept of an auroral substorm was introduced about 40 years ago by Akasofu (1964). The original Akasofu scenario includes only the expansion and recovery phase but a few years later McPherron (1970) expanded this picture to also include the growth phase. Today the auroral morphology and dynamics of the substorm are well known, but there are several issues, especially in the magnetospheric processes, that are still under discussion. Below we review recent substorm studies which utilise the multi-point observations of Cluster and various GB measurements.

The initial triggering mechanism of the substorm expansion phase onset has been and continues to be a controversial issue in magnetospheric research. The Near-Earth Neutral Line model (NENL) and the Current Disruption model (CD) are the most widely discussed scenarios in this context (e.g. Baker et al., 1996; Lui, 1996). In the NENL model, the primary cause for the substorm expansion is reconnection which takes place in the mid-tail. Reconnection causes formation of a tailward moving plasmoid and earthward-directed high speed flows, which transport flux, mass and energy into the near-Earth region. As a consequence, there is a disruption of the near-Earth cross tail current and a build-up of the substorm current wedge (SCW). In the CD model the initial causes of the expansion are plasma instabilities developing in the near-Earth region at downtail distances of 6-10 $R_{E}$, which lead to the current disruption and SCW formation. The disruption front propagates tailwards and launches reconnection in the mid-tail. Several Geotail statistical studies have shown that mid-tail flows are preceed by $2-3 \mathrm{~min}$ substorm-related Pi2 onset signatures (before Nagai et al., 1998; Machida et al., 1999) or UV auroral onsets (Miyashita et al., 2003). Such observations have been interpreted as supporting the NENL model. Lyons (2000), however, argued that in the NENL scenario that the mid-tail reconnection signatures should appear at least $5 \mathrm{~min}$ before the Pi2 onset due to the finite propagation speeds. The difficulty in estimating the transit times properly still leaves some space for discussion. Four-point observations by Cluster were proven to be useful to identify X-lines and follow their motion (Runov et
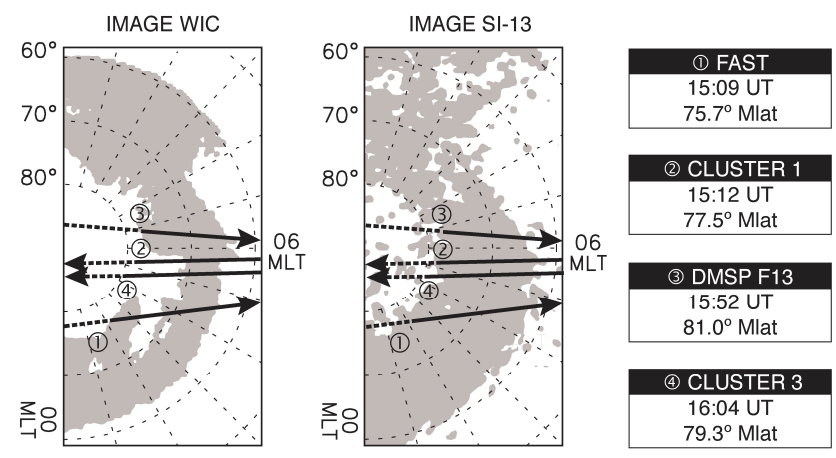

Fig. 14. A schematic summary of the distribution of UV auroras and FAST, DMSP F13, Cluster 1 and 3 overflights on 8 December 2001. In the satellite paths the transition from dashed to solid line indicates the transition from open to closed field lines (PC-boundary). The gray silhouette shows the UV aurora distribution at 15:19:49 UT the times and the PC-locations of the satellite overflights are given in the numbered boxes. (From Wild et al., 2004.)

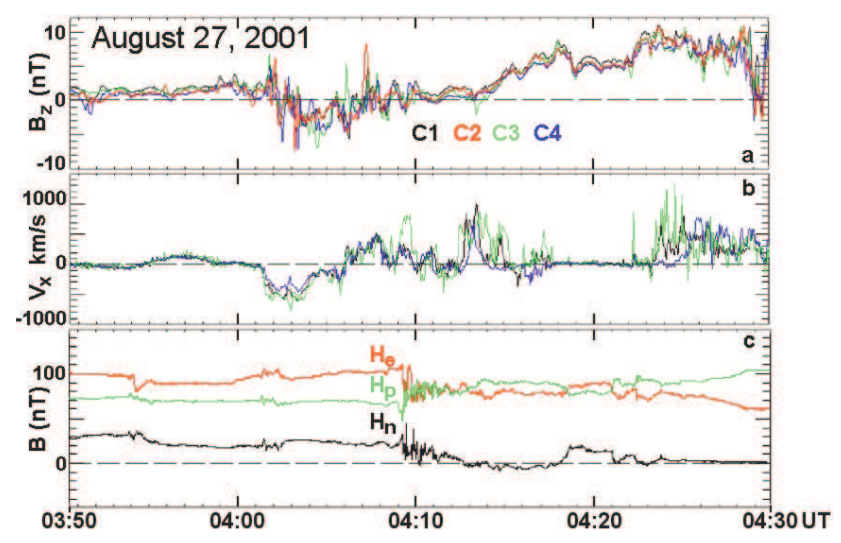

Fig. 15. (Upper and middle panel) Cluster FGM and CIS observations of the $\mathrm{B}_{Z}$, GSM and ion earthward and tailward flows, (Lower panel) GOES magnetic field data for the parallel ( $H p$ green), earthward $(\mathrm{He}$, red) and normal ( $\mathrm{Hn}$, black) components recorded during a substorm on 27 August 2001. (From Baker et al. 2002.)

al., 2003) and to probe in detail the injection front (Baker et al., 2002a). Therefore, Cluster can provide additional information in such substorm studies, i.e. the propagation direction of the disturbance.

Baker et al. (2002b) studied an isolated substorm on 27 August 2001 and demonstrated, at least in this well-observed case, that simultaneous satellite observations from the midtail and near-Earth regions were consistent with the NENL model. Data from Geotail (solar wind), GOES-8 (geostationary, at 23:00 LT), Polar (downtail at $9 R_{E}$, at 02:00 LT), and Cluster (downtail at $19 R_{E}$, at 00:30 LT) were used. IMAGE WIC images were used for substorm onset timing. These images show several local brightenings from 02:00 UT to the onset of the global scale activity at 04:08 UT. Figure 15 shows magnetic field data from Cluster and GOES8. The dipolarization observed by GOES-8 took place at 


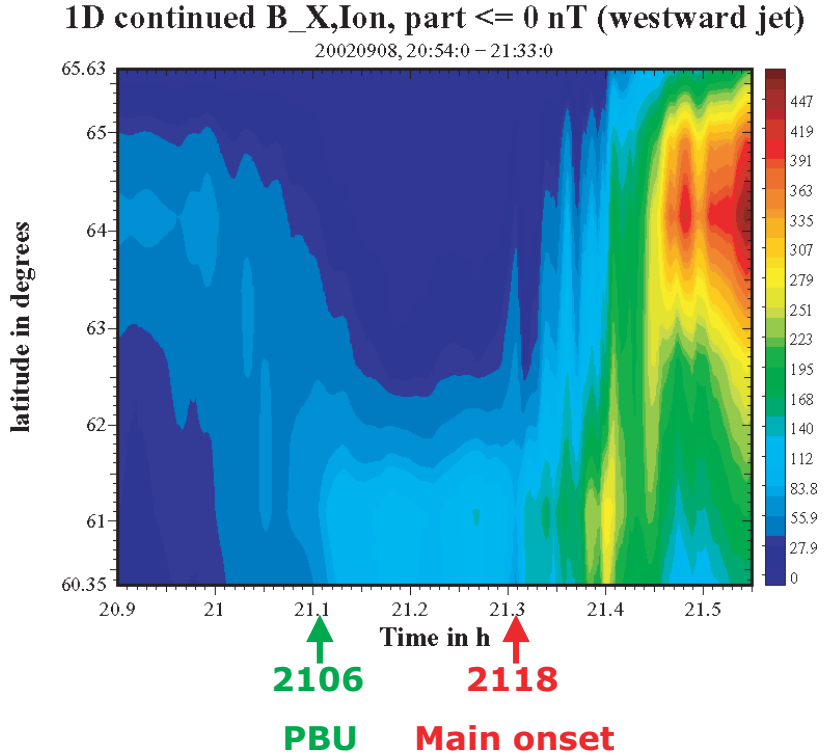

Fig. 16. The time-latitude distribution of the westward equivalent ionospheric currents as deduced from the MIRACLE magnetometer data recorded during a substorm on 8 September 2002 (From Sergeev et al., 2005).

04:09 UT, i.e. essentially simultaneously with the auroral onset, while the plasmoid signatures (IMF $\mathrm{B}_{z}>0$ values followed by $\mathrm{B}_{z}<0$ values and tailward flow) started at Cluster already at 04:01 UT. Thus, the mid-tail reconnection signatures were observed in this case $7 \mathrm{~min}$ prior to the near-Earth and auroral onsets.

Sergeev et al. (2005) also used a radial configuration of ISTP, Cluster and LANL spacecraft to study the relationship of substorm growth and expansion phase phenomena in the near- and mid-tail during a substorm on 8 September 2002. The westward electrojet activity in the midnight sector, as deduced from ground magnetometer data, is shown in Fig. 16. During the growth phase the electrojet drifted southward to exceptionally low latitudes, where the pseudo-breakup was recorded as a minor intensification at 21:06 UT and the main onset as a sequence of pulsations followed by a poleward expansion of the activity starting at 21:18 UT. With the particle and magnetic field data of the fortunate satellite constellation, Sergeev et al. (2005) were able to show that at the main onset the activity propagated from a midtail reconnection region $\left(\mathrm{XGSM}<-16 R_{E}\right.$ ) earthwards and thus was favorable to the NENL scenario. However, about 12 min prior to the onset a local pseudo-breakup took place that was most prominent in the geostationary observations and thus likely triggered by inner magnetospheric instabilities, as suggested by the CD-scenario. Another interesting observation for this substorm was that the energy storage in the lobe magnetic field became exceptionally large during the growth phase but the subsequent expansion was only moderate (AE $\sim 400 \mathrm{nT}$ ). This contrast between the massive energy loading during the growth phase and the subsequent moderate dissipation during the expansion was explained as due to the cold and dense

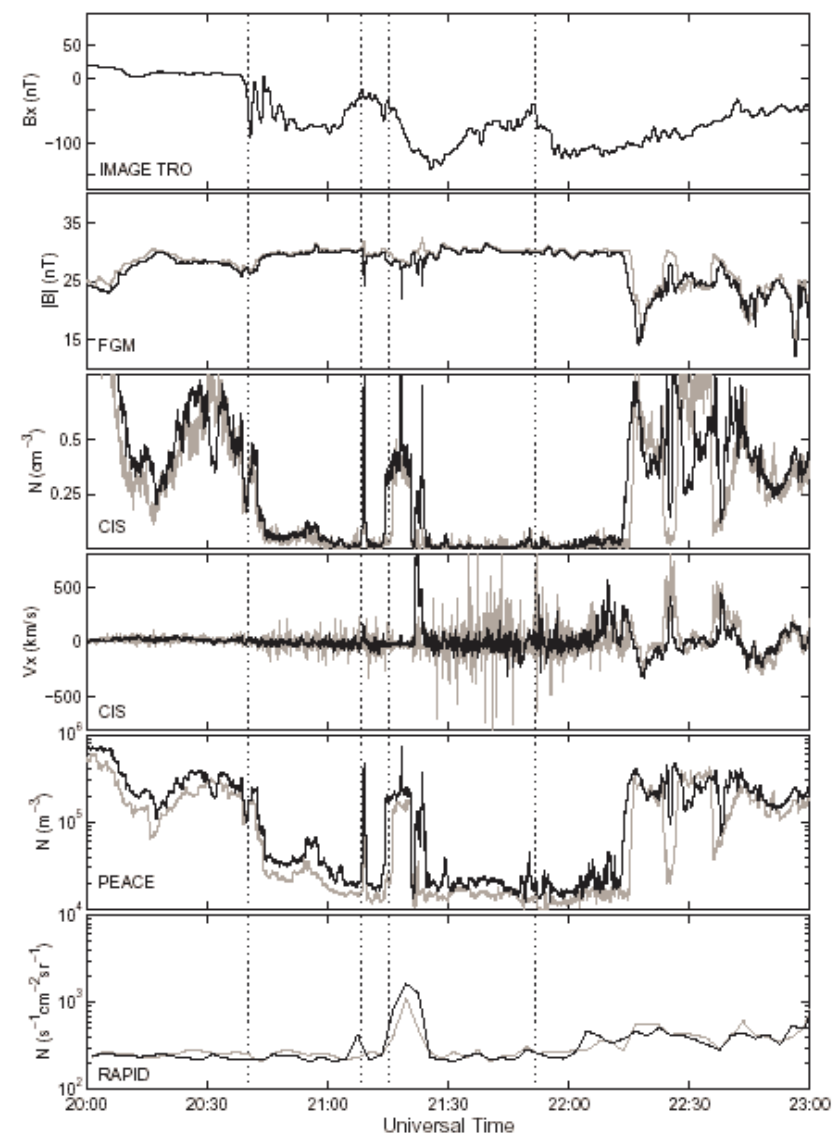

Fig. 17. North component magnetogram from the MIRACLE magnetometer station Troms $\varnothing$ (TRO) and data from Cluster 3 (gray) and 4 (black). The substorm onset and intensifications have been marked by dashed vertical lines. (From Borälv et al., 2002.)

plasma sheet before the substorm.

A detailed comparison between the ionosphere and magnetosphere for a small substorm with several intensifications was performed by Borälv et al. (2002) based on groundbased observations from the Northern Hemisphere and Cluster observations from the southern plasma sheet (at a downtail distance of $18.5 R_{E}$ ). The substorm (maximum AE only about $100 \mathrm{nT}$ ) took place in the Scandinavian sector on 19 September 2001 at 20:00-23:00 UT. Solar wind data from WIND (at XGSM=83 $R_{E}$ ) shows that IMF $\mathrm{B}_{Z}$ turned to negative values around 20:11 UT (at the satellite, time delay to the magnetopause $16 \mathrm{~min}$ ), and stayed barely below zero during the following $1.5 \mathrm{~h}$. According to the MIRACLE magnetometer data the substorm onset took place at 20:40 UT and had three further intensifications at 21:09, 21:15, and 21:51 UT. Recovery started at 22:15 UT. ASC images show a breakup at 20:39 UT followed by continuous activity until 22:04 UT. EISCAT data showed ionospheric electron temperature enhancements roughly at the times of the onset and intensifications (for ASC and EISCAT data, see Borälv et al., 2005).

Ground-based magnetic field observations, together with data from Cluster s/c 3 and 4, are shown in Fig. 17 from 
Borälv et al. (2002). The plotted quantitites are, from top to bottom, the ground magnetic field north component at MIRACLE station Troms $\varnothing$ (TRO, CGM lat $66.6^{\circ}$, MLT $=\mathrm{UT}+2.5 \mathrm{~h}$ ), the FGM magnetic field strength, the CIS $\mathrm{H}^{+}$density and velocity, a PEACE proxy for the electron density (energy range from $34 \mathrm{eV}$ to $26.46 \mathrm{keV}$ ), and finally the RAPID high-energy electron (energy range 20$400 \mathrm{keV}$ ) flux. The westward ionospheric current intensifications observed as negative deviations in the ground-based $\mathrm{B}_{X}$ (marked with the vertical dotted lines) are associated with distinct variations in the plasma sheet magnetic field and enhancements in the particle densities. The correlation in CIS velocity data is not that obvious (the high velocities observed by s/c 3, for example, during 21:30-22:00 UT were recorded in the lobe conditions of low count rates and thus may not be reliable).

The variations in the CIS and PEACE densities in Fig. 17 can be interpreted as s/c motion between the high density plasma in the plasma sheet or plasma sheet boundary layer (PSBL) and low density plasma in the southern lobe. At the onset, Cluster moved from the plasma sheet to the southern lobe where they stayed until the substorm recovery except during the short plasma sheet or PSBL encounters around the substorm intensification times. The correlation between the ground-based activations and the s/c plasma sheet encounters is remarkably good when remembering that the observations were made on the different sides of the current sheet. By performing the multi-point timing analysis, the directions of the PSBL/lobe boundary motions were detemined for these cases. The plasma sheet encounters at 21:09 and 21:15 UT were associated with travelling compression regions (TCRs), possibly caused by moving bulges in the plasma sheet-lobe interface, as demonstrated by a detailed analysis of the Cluster observation (Slavin et al., 2003). Results from the timing analysis of the plasma sheet-lobe interface observations from Cluster for the substorm onset, as well as for the subsequent intensifications, implied that plasma sheet motions in the Ydirection were as significant as in the Z-direction. For example, the PSBL moved dawnward when Cluster exited into the lobe at the substorm onset (for a more detailed analysis, see Borälv et al., 2005). This is difficult to understand in the traditional picture where the entire plasma sheet drops out when associated with the plasma sheet thinning. These observations suggest either that a localized plasma sheet thinning took place locally centered at the onset region or that flapping of the entire current sheet occurred as in another event observed by Cluster, reported by Sergeev et al. (2003). The event of Borälv et al. (2002) demonstrates nicely how a tiny substorm, at least in terms of ground-based activity (AE-index), can cause significant variations in the magnetotail. Furthermore, the study showed how the propagation direction of the disturbance, which is new information obtained by Cluster multipoint analysis, can contribute to the understanding of plasma sheet dynamics during substorms.

Draper et al. (2004) present Cluster observations in the tail during two substorms in conjunction with ionospheric flow measurements with SuperDARN. The flows stimulated

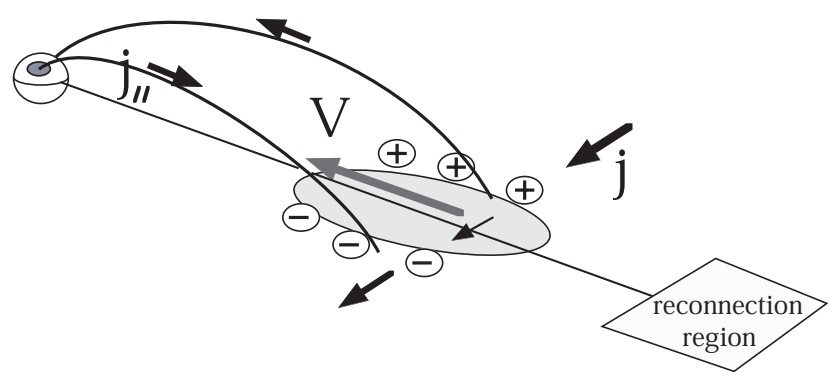

Fig. 18. Illustration of the plasma bubble model (Chen and Wolf, 1993) and associated field aligned currents (Adapted from Nakamura et al., 2001).

by the second expansion phase onset occur of the order of 1 min after the simultaneous signatures of expansion phase onset at Cluster in the lobe, at geosynchronous orbit and in ground magnetometer data. This demonstrates that the expansion phase is responsible for the onset of enhanced flows, although the nature of the observations does not allow the authors to determine whether this is stimulated by reconnection. During the recovery phase of the first substorm, the Cluster spacecraft observed the earthward passage of a diamagnetic cavity of near-zero magnetic field, which is a new and interesting phenomenon. Its possible ionospheric signature has yet to be confirmed.

\subsection{Fast flows}

One of the most important topics in BBF studies is its relationship to the ionospheric processes. The observed equivalent current pattern during flow bursts suggests that the plasma sheet flows are connected to the ionospheric current via a small field-aligned current wedge (Kauristie et al., 2000). Chen and Wolf $(1993 ; 1999)$ proposed that BBFs can be considered as underpopulated flux tubes that are electrically polarized and thereby launch Alfvén waves in a sense where upward FAC is flowing at the duskward edge (see Fig. 18). Birn and Hesse (1996) and Birn et al. (1999; 2004) showed that earthward reconnection flows are diverted dawnward and duskward in association with the dipolarization of the magnetic field and consequently FACs of the current wedge are generated by the flow shear in the closed field line region.

A review of the various ionospheric phenomena related to the fast flows is given by Amm and Kauristie (2002). One major question they pose concerns the difference between substorm and non-substorm events. They also point out that many of the observed ionospheric effects can be shielded or greatly obscured during substorm expansions, by the inherent large-scale electrodynamics. As will be reviewed in the following section, Cluster observations of BBFs, combined with conjugate ionospheric observations, allow us to discuss the spatial structure of the disturbances and relevant electrodynamics both at the ionosphere and the magnetosphere. Cluster-GB observations are also crucial for 
quantitative determination of the role of the fast flows in the global magnetospheric energy conversion processes.

Grocott et al. (2004) studied the ionospheric counterpart of a BBF which occurred during a pseudo-breakup in the course of a substorm growth phase, some $10 \mathrm{~min}$ after a southward turning of the IMF and some 50-60 min before a major expansion phase onset, thus largely circumventing any effects from the substorm expansion phase in the ionosphere. This is the first study showing both the ionospheric flow pattern and the auroral activation associated with a simultaneous observation of a flow burst in the magnetosphere. Cluster observed earthward flow with a perpendicular component reaching $400 \mathrm{~km} \mathrm{~s}^{-1}$ between 22:28 and 22:35 UT on 7 September 2001 when the spacecraft was near midnight, $(X, Y, Z) \mathrm{GSE}=(-19,1.3,0.7) R_{E}$ (not shown). Ionospheric observations during the flow event observed by the CUTLASS radars, the MIRACLE and SAMNET magnetometers and the FUV auroral imager on the IMAGE spacecraft are shown in Fig. 19, adapted from Grocott et al. (2004). A small, negative excursion in the $X$ component of the magnetic field with an amplitude of $10 \mathrm{nT}$ and some Pi2 activity, were observed at the ground stations close to the footpoint of Cluster during the BBF (Fig. 19a). Clear signatures associated with the BBF are observed in the ionospheric flow obtained by CUTLASS, as well as in the auroral precipitation pattern in the IMAGE UV data (Figs. 19b and c). During the interval shown in Figs. $19 \mathrm{~b}$ and c, the auroral activity was at its maximum, with a developed "blob" of auroral emission centered at around $67^{\circ} \mathrm{N}$ where the Cluster footpoint was located (shown as an open circle). Figures $19 \mathrm{~b}$ and $\mathrm{c}$ also show the flow vectors and equipotential contours derived using the Map Potential technique (see Sect. 2.3). This localized auroral activation and the enhanced ionospheric flows $\left(1000 \mathrm{~m} \mathrm{~s}^{-1}\right)$ were first observed between 22:28-22:30 UT (not shown), which was within 2 min of the plasma sheet flow onset, near the Cluster footpoint. The aurora further developed at 22:32-22:34 UT (Fig. 19b) and the pre-midnight flows developed into an " $\mathrm{S}$ " shape with the aurora located in the velocity shear between east and west flows. The fieldaligned current pattern in Fig. 19c is inferred from the curl of the velocity field (derived from the electric potential) using the technique described by McWilliams et al. (2001b), interpreting the obtained vorticity to be due to the ionospheric Hall currents' vortices associated with field-aligned currents. The region of high intensity emission in the pre-midnight auroral zone, including the Cluster footpoint, corresponds to an upward field-aligned current. A region of downward fieldaligned current exists poleward of this and slightly later in magnetic local time. This field aligned current pattern is similar to a substorm current wedge. However, the weak magnetic field perturbation indicates the absence of the westward electroject, expected to close the field aligned currents, and suggests a low Hall current as well as a low Pedersen conductivity. This is in contrast to the active intervals, such as during substorms, when the enhanced conductivity significantly affects the ionospheric current and electric field, as was shown in the example of a N-S aurora (Amm et al., 1999). Although these N-S aurora or auroral streamers have been considered to be conjugate to the magnetospheric fast flows (Sergeev et al., 1999), no significant enhancement in the equatorward ionospheric flow was detected in the vicinity of this N-S aurora, but significant conductivity enhancement in the auroral region was observed (Amm et al., 1999).

Nakamura et al. (2005) used multi-point observations both in space and on the ground to study an isolated flow burst event on 1 September 2002 at 22:02 UT, when the Cluster footpoint was located within the MIRACLE area. Similar to Grocott et al. (2004), the event was associated with a clear but weak ionospheric disturbance, which took place during a prolonged, almost $1.5 \mathrm{~h}$, southward IMF interval preceding a major substorm onset (Draper et al., 2004). Results from the magnetospheric and ionospheric observations of the flow burst event are summarized in Fig. 20. Cluster magnetic field and ion observations in Figs. 20a-e show that earthward flow with the speed exceeding $700 \mathrm{~km} \mathrm{~s}^{-1}$ was observed in association with a sharp enhancement in $\mathrm{B}_{Z}$, indicating dipolarization. The flow was accompanied by a decrease in density and an increase in magnetic field pressure (not shown), which is a signature for an underpopulated flux tube (Sergeev et al., 1996).

The structure of the fast flows was determined by examining the orientation of the dipolarization front, by performing the minimum variance analysis of the magnetic field in the same way as in Sergeev et al. (1996) and Nakamura et al. (2002). The obtained direction of the dipolarization front is shown in Fig. 20f. The shape of the dipolarization front is expected to reflect the spatial structure of the fast flowing plasma. If we simply assume a dipolarization front with a circular shape in the $X-Y$ plane, as illustrated by the grey curve in Fig. 20f, the dimension of the front, and therefore the spatial scale of a flow channel, is estimated to have a width of about $1.5-2.2 R_{E}$. This is consistent with a typical scale of a flow burst obtained from a Cluster multi-point statistical study (Nakamura et al., 2004). The pink arrows, illustrating the direction of the flow shear, indicate that there is a clockwise flow rotation in the vicinity of the dipolarization front. The corresponding magnetic shear will produce a field-aligned current out of the ionosphere, as expected at the dusk part of a current wedge-like field-aligned current pattern.

Figure 20g shows the equivalent current pattern near the footpoint of Cluster, using the 2-D upward continuation technique described in Sect. 2.2. Although the amplitude of the disturbance in the equivalent current associated with the flow did not exceed several tens of nT, a clear, localized pattern developed, consisting of a south-westward directed current in the region, including the Cluster footpoint and northwestward directed current at the northeast side of the former. Such an equivalent current pattern was also obtained for an N-S aurora during an active substorm time (Amm et al., 1999), except for the larger amplitude and wider area of the current compared to the event in Fig. 20. The observed equivalent current pattern in Fig. 20g suggested that there was an upward field-aligned current in the vicinity of 

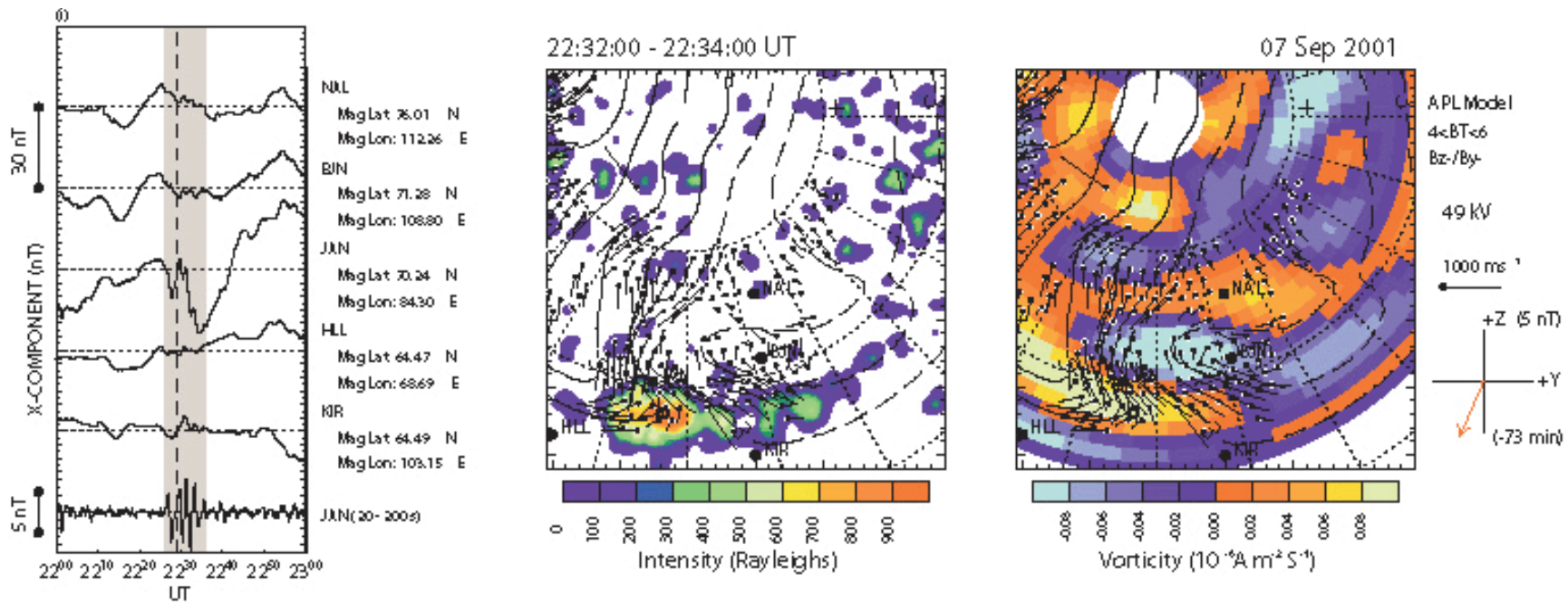

Fig. 19. (a) X-component magnetometer data and Pi2-filtered (20-200s) data. The vertical dashed line at 22:29 UT indicates the time of a BBF event observed by Cluster and the grey-shaded portion represents the interval 22:26-22:36 UT. (b) IMAGE UV auroral data and (c) patterns of field-aligned currents derived from the vorticities of the ionospheric flows for the interval 22:32-22:34 UT. Positive vorticities (red/yellow) indicate an upward field-aligned current, and negative vorticities (blue) a downward field-aligned current. Also shown are flow vectors and equipotential contours derived using the Map Potential model, the locations of the five magnetometers used, and the Cluster footprint location, indicated by the hollow black circle. At the right side of the figure the transpolar voltage, Applied Physics Laboratory (APL) statistical model, vector scale and IMF vector are shown. (From Grocott et al., 2004.)
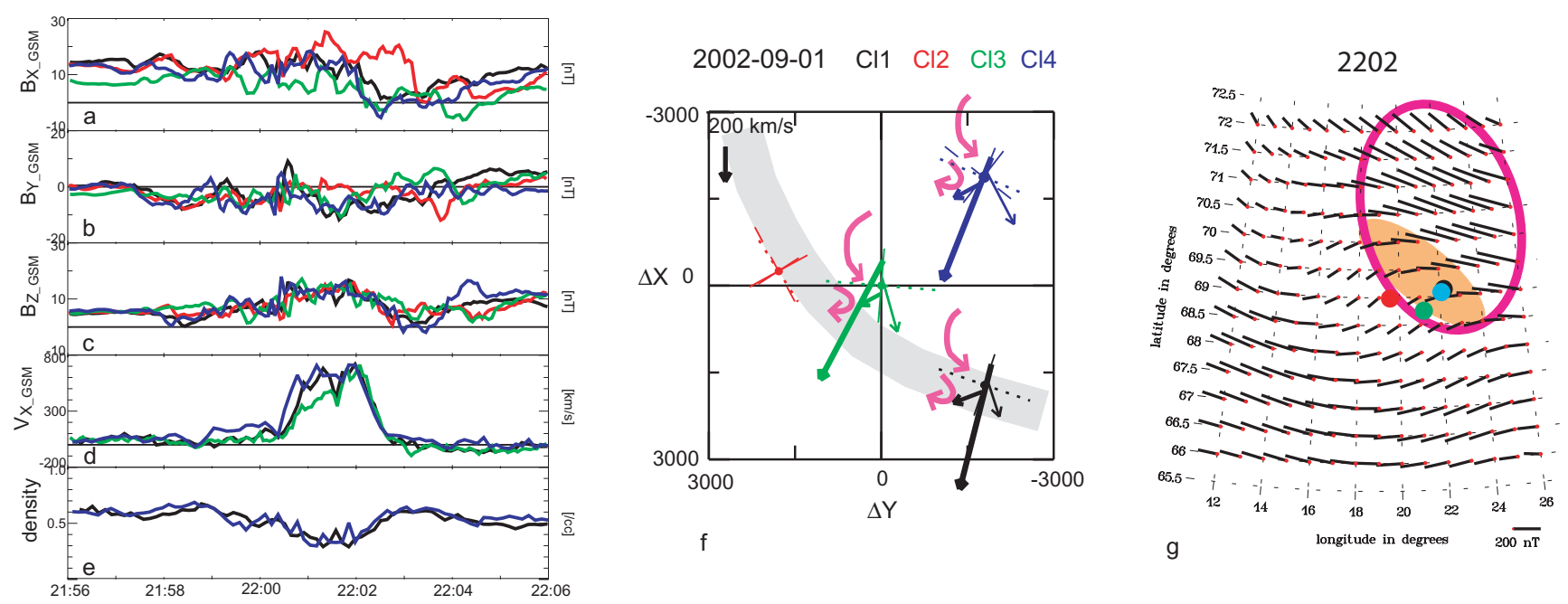

Fig. 20. Cluster observation of (a) X, (b) Y, and (c) Z components of the magnetic field (in GSM coordinates), (d) X component of the ion flow, (e) proton density, between 21:56 and 22:06 UT. For the ion plots, proton data from the CODIF instrument are used for Cluster 1 and 4, while ion data from the HIA instrument are shown for Cluster 3. (f) Location of the four Cluster spacecraft relative to the reference spacecraft (Cluster 3) in GSM X-Y plane. The dotted lines show the projection of the dipolarization front described in the text. The thick arrows are the plasma flows at the interval of maximum flow speed while the thin, short arrows correspond to the flow vector just before and after dipolarization front. The possible shape of the dipolarization front is illustrated with a gray curve. The flow shear direction is shown with pink arrows. (g) Equivalent current pattern at 22:02 UT together with the magnetic footpoints of Cluster. The most likely location of the conjugate region of the flow channel (area surrounded by pink line) and the center of the precipitation (orange) as inferred from the magnetosphere-ionosphere observation are illustrated. (Adapted from Nakamura et al., 2004.)

the Cluster footpoint, which was consistent with the Cluster flow shear observation. The expected area conjugate to the flow channel and the upward field aligned current region are also illustrated in Fig. 20g. Similar to Grocott et al. (2004), SuperDARN observed an enhanced equatorward flow in the ionosphere (not shown). Again, this observations suggested that, due to the low (or very localized) conductivity enhancement, the flow pattern associated with the BBF was reflected directly in the ionosphere electric field pattern without modification from the enhancement in the conductance. While 


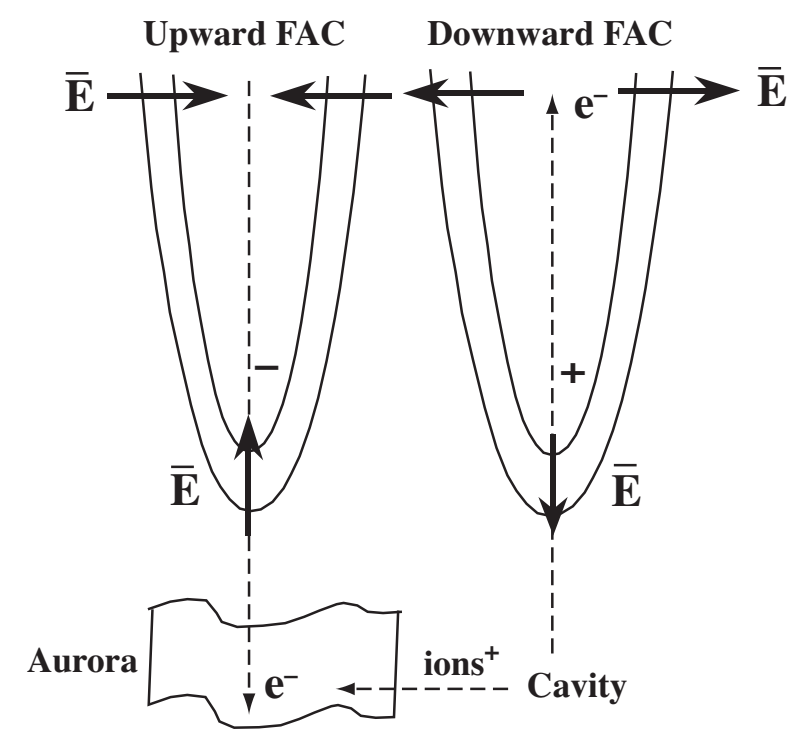

Fig. 21. Schematic figure of the quasi-electrostatic model of auroral arcs. Negative and positive potential structures in the magnetosphere and the acceleration of electrons by these structures are shown. In the ionosphere, the field-aligned currents (FACs) are closed by a perpendicular current carried by ions. Formation of visible aurora and a density cavity are also shown, as discussed in Sect. 4.5 (Figure provided by A. Aikio.)

the BBFs studied by Grocott et al. (2004) and Nakamura et al. (2005) were from intervals of low geomagnetic activity, McPherron et al. (2002) reported fast flows during an active period when Cluster passed through the plasma sheet during three consecutive substorms. During the third substorm, Cluster measured a prolonged earthward flow while the GSM $\mathrm{Z}$ component of the magnetic field increased. This earthward flow was bursty, and reached a peak of $900 \mathrm{~km} \mathrm{~s}^{-1}$. During this substorm interval (about $60 \mathrm{~min}$ ), the tail lobe field, as well as IMF, was almost unchanged, implying that the dayside and nightside reconnection rates were balanced. This, in turn, suggested that the electric field in the tail lobe and the plasma sheet were equal. Since the lobe electric field can be considered to map into the polar cap, the plasma sheet potential can be equated to the cross polar cap potential, which was measured during this interval by SuperDARN and was found to be steady at $50 \mathrm{kV}$. This value and the flux transported during this interval, due to the fast flows, were used to obtain the width of flow channel. The total flux transported for a channel of width $1 R_{E}$ during $60 \mathrm{~min}$, was $20 \mathrm{MWb} / R_{E}$. From these values the width of an equivalent flow channel was estimated to be $7.8 R_{E}$. It should be noted that such an equivalent flow channel might be made up of several smaller, real channels.

The study concluded that $100 \%$ of the flux entering the lobe during this time interval could have been returned by the observed flow. On the other hand, Angelopoulos et al. (1994) concluded that a single BBF transports only about $2 \%$ of the total flux necessary to create a substorm that is driven by a polar cap potential of $150 \mathrm{kV}$. This estimate was based on numbers obtained from their statistics: duration time of $550 \mathrm{~s}$ and transported flux of $2.5 \mathrm{MWb} / R_{E}$ for each $\mathrm{BBF}$; in addition, it was assumed that a flow channel is $3 R_{E}$ wide. The difference in the two estimates of the transport rate comes from the longer duration and therefore larger flux transport, and a wider flow channel, but smaller polar cap potential for the former study (McPherron et al., 2002). It is an interesting open question as to whether these different magnetospheric transport rates are due to different states of the magnetosphere. Further study is needed to explain how the substorm BBFs studied by McPherron et al. (2002) are related to the single BBFs during weak geomagnetic activity, discussed in Grocott et al. (2004) and Nakamura et al. (2005).

\subsection{Auroral arcs}

Auroral arcs are the result of magnetosphere-ionosphere coupling. In particular, visible arcs are a manifestation of energy input from the magnetosphere to the ionosphere. The visible arc corresponds to an upward FAC sheet region. The current continuity requires a downward FAC sheet region, which for an isolated stable arc is typically located on the equatorward (poleward) side of the evening (morning) sector arc (Opgenoorth et al., 1990; Aikio et al., 1993) or sometimes on both sides (e.g. Aikio et al., 2002).

Many properties of auroral arcs can be described by a quasi-electrostatic model, where the upward FAC region corresponds to precipitating magnetospheric electrons which have been accelerated downward by a field-aligned potential drop. A satellite moving across the arc, within and above the acceleration altitudes, measures a converging bipolar electric field (see Fig. 21). The upward electric field of the negative potential structure accelerates ambient ions upward, producing upward ion beams and a high-altitude density cavity (Mozer et al., 1980). The downward FAC region has a reversed (positive) potential structure, which accelerates ionospheric electrons upward to carry the return current of aurora (e.g. Carlson et al., 1998). The cold, upward moving electron beams are accompanied by transversely heated ions and ion conics. The dominant ion heating seems to be from broadband, extremely low frequency (BBELF) wave emissions below the ion plasma frequency (e.g. André et al., 1998).

Alfvén waves play a crucial role in setting up the auroral electrodynamics. Poynting flux from Alfvén waves often dominates the energy transport from the tail reconnection region (Wygant et al., 2000). As the large-scale Alfvén waves propagate toward the auroral acceleration region, small-scale Alfvénic structures can be generated through various plasma physical processes. These dispersive Alfvén waves carry a parallel electric field, which can accelerate electrons to the ionosphere (Stasiewicz et al., 2000).

In the following, new results of the auroral arc dynamics obtained by the Cluster-GB coordination will be presented. The four-satellite constellation of Cluster has provided the opportunity to study the temporal evolution of quasi-static fields, as was shown by Marklund et al. (2001) in their study on downward FAC evolution. Yet, the typical configuration 

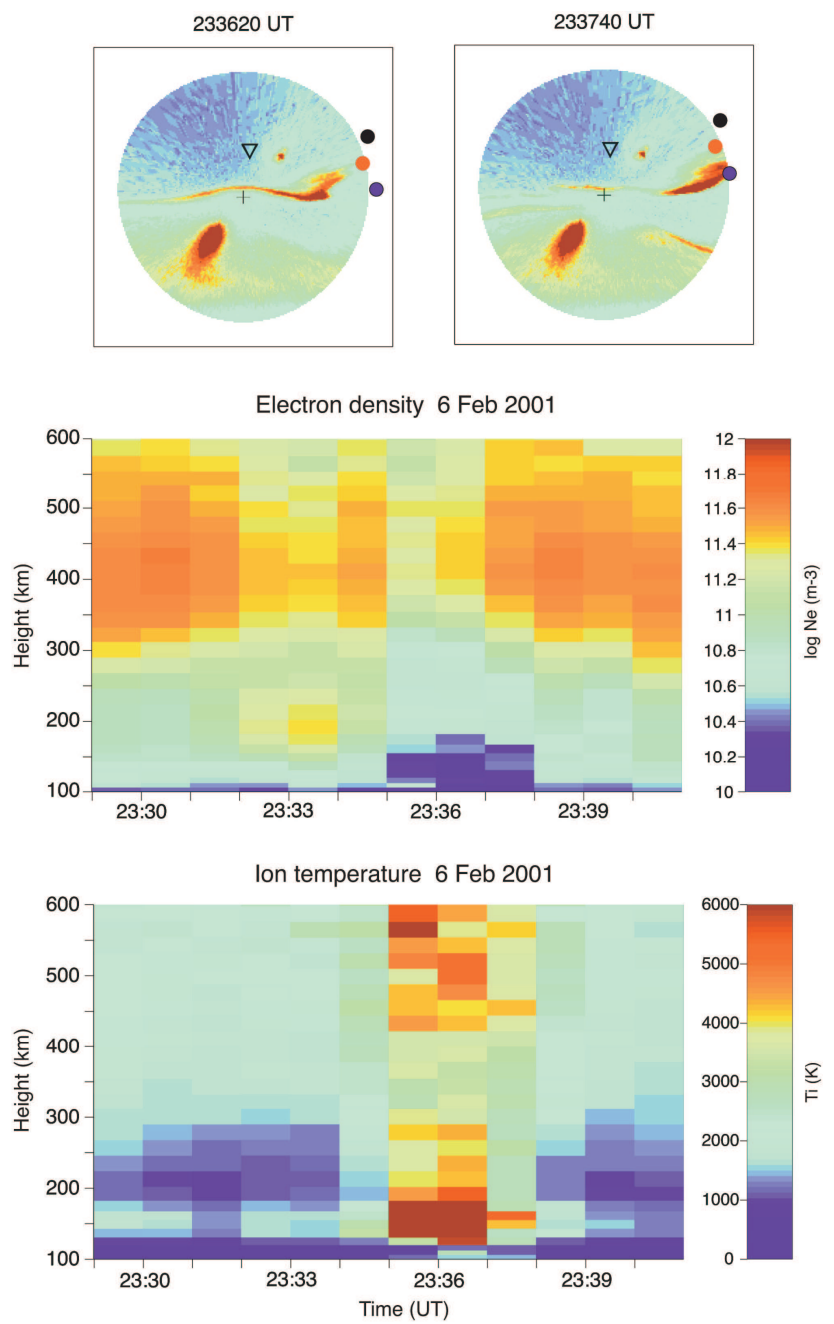

Fig. 22. (top) Abisko all-sky camera pictures from two time intervals of cavity formation with Cluster (1=black, $2=$ red and $4=$ blue) locations mapped. The triangle indicates the location of EISCAT. Moon is visible in the lower left part and an artificial light spot poleward of the arc. (bottom) EISCAT radar measurements of electron density and ion temperature. (From Aikio et al., 2004.)

of Cluster satellites in the nighttime auroral oval crossings, which is a string of pearls, can leave ambiguity in determining whether some changes are temporal or a manifestation of the east-west motion of spatial structures. Ground-based observations allow the distinction to be made and can also provide a longer timeline of observations and wider spatial coverage.

Aikio et al. (2004) studied the temporal evolution of two auroral arcs by the Cluster s/c, all-sky cameras and magnetometers of the MIRACLE network, as well as the EISCAT UHF radar. The four Cluster s/c passed over Northern Scandinavia in the poleward direction on 6 February 2001 at a distance of about $4.4 R_{E}$ in the post-midnight sector. The $\mathrm{s} / \mathrm{c}$ followed two closely spaced strings of pearls, allowing the study of the temporal evolution of arcs with a time scale of one to a few minutes. The first arc that Cluster s/c 1-

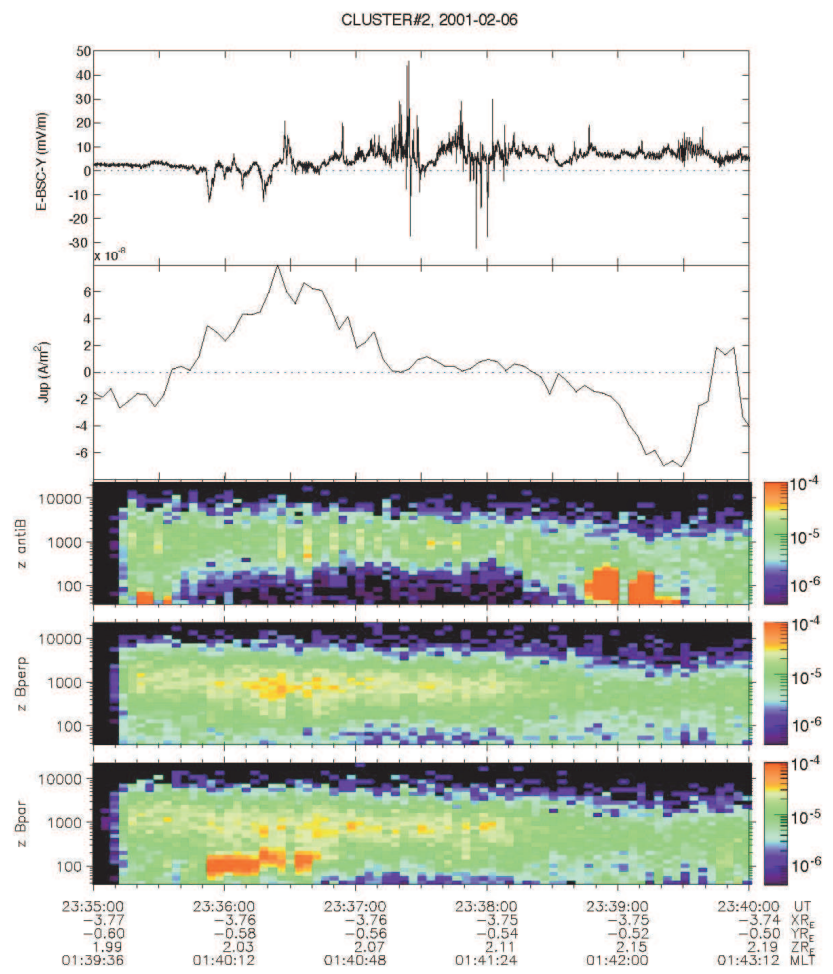

Fig. 23. Cluster 2 measurements above an auroral arc. From top to bottom: high-resolution electric field from the EFW, FAC (positive values correspond to current away from the ionosphere) from the FGM, and electron fluxes in the anti-parallel (upward), perpendicular and parallel (downward) to B directions from the PEACE HEEA instrument in units of $\mathrm{erg} \mathrm{cm}^{-2} \mathrm{str}^{-1} \mathrm{~s}^{-1} \mathrm{eV}^{-1}$. (From Aikio et al., 2004.)

4 crossed, drifted slowly equatorward, as was measured by the Sodankylä ASC $\left(63.9^{\circ} \mathrm{N}, 107^{\circ} \mathrm{E}\right.$, in CGM coordinates). The arc was associated with a current system consisting of an upward FAC from the visible arc and a downward FAC poleward of it, obviously connected by an equatorward Pedersen current in the ionosphere, typical of morning sector arcs. The GB observations showed a pseudo-breakup onset while the Cluster s/c were passing the arc and as a result, the total FAC doubled between the s/c 1 and 2 crossings of the arc, separated by about $80 \mathrm{~s}$. The increase was due to a widening of the FAC sheets, not due to an increase in current densities. It took 1-2 min for the current systems to evolve after the onset of sub-auroral $\mathrm{Pi} 2$ pulsations, which may indicate that it took several bounces of Alfvén waves between the magnetosphere and the ionosphere to set up the new current system after changes in the magnetosphere.

About $8 \mathrm{~min}$ after the pseudobreakup onset, a new arc started to form poleward of the existing arc, close to the zenith of the Abisko ASC $\left(65.3^{\circ} \mathrm{N}, 102^{\circ} \mathrm{E}\right)$. Two Cluster s/c (2 and 4) crossed a fold in the arc (Fig. 22, top panel). Again, the visible arc was associated with an upward FAC (Fig. 23, second panel). The upward FAC region showed intense, low frequency fluctuations in the electric field, which retained their structuring during at least $70 \mathrm{~s}$, which was the 


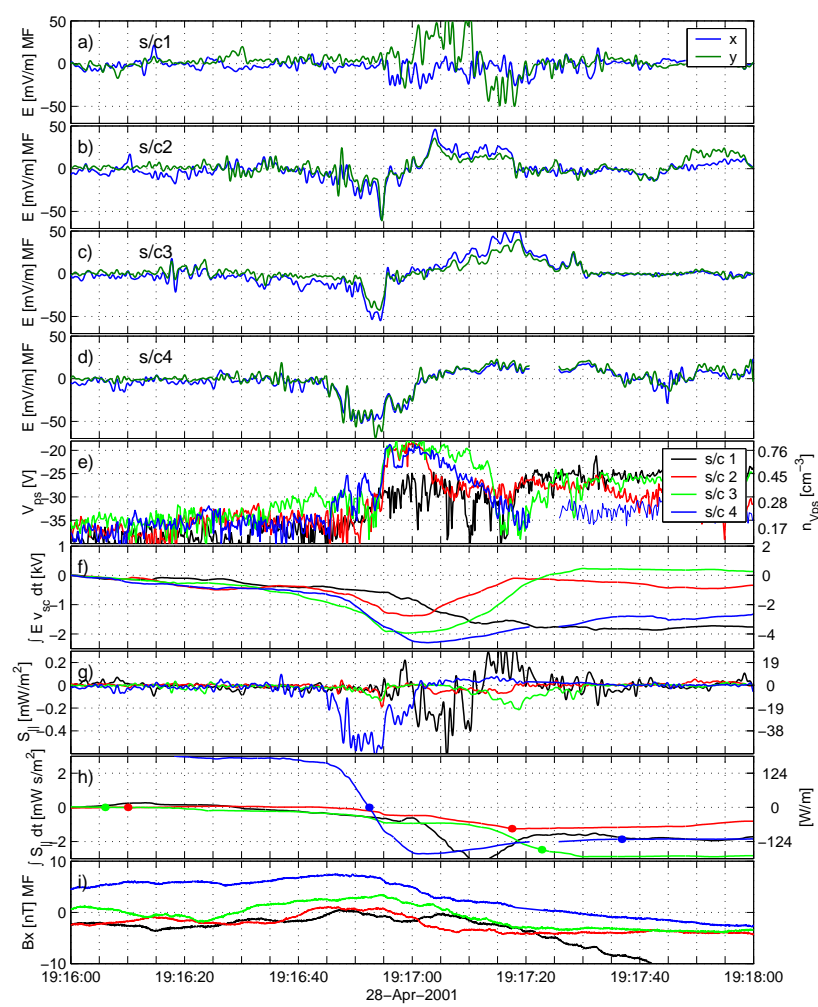

Fig. 24. Cluster overview plot from all four s/c from auroral arc crossing. (a-d) Electric field in mean field coordinates; $x$ is poleward and y is eastward. (e) Probe to spacecraft potential and derived density estimate. (f) Integrated potential, the labels on the right show values if the arc motion is taken into account. (g) Fieldaligned Poynting flux calculated from total $\mathrm{E}$ and $\mathrm{dB}$. (h) Integrated Poynting flux; it is set to zero at the beginning of the interval, marked by dots, used to estimate the total integrated energy flux. For $(\mathrm{g})$ and $(\mathrm{h})$ labels on the right show values at the ionosphere. (i) Poleward component of $\mathrm{dB}$ in field-aligned coordinates. (From Vaivads et al., 2003.)

time difference between s/c 2 and 4 crossings of the arc (Fig. 23, top panel). Within the same region, downgoing, locally accelerated, suprathermal electron beams were observed (Fig. 23, bottom panel). It was suggested that electrons were accelerated by dispersive Alfvén waves. However, since the suprathermal electrons were of low energy $(200 \mathrm{eV})$, it was concluded that they were not able to produce the visible auroral arc observed at the wavelength of $557.7 \mathrm{~nm}$ (and only weakly at $630 \mathrm{~nm}$ ), but the electrons had to be further energised below the s/c. The return current (downward FAC) regions were located on both sides of the arc, but the poleward return current was wider and more intense, as shown for s/c 2 in Fig. 23, second panel. PEACE electron measurements showed that the arc was embedded in the central plasma sheet (Fig. 23, three bottom panels). The downward FACs were associated with cold upward beams of electrons of ionospheric origin, which had been accelerated below the s/c (Fig. 23, third panel). The energy of the electrons in the poleward downward FAC increased from $200 \mathrm{eV}$ at $\mathrm{s} / \mathrm{c} 2$ to $1000 \mathrm{eV}$ at $\mathrm{s} / \mathrm{c} 4$ in $70 \mathrm{~s}$. At the same time, there was a small increase in the width of the current from 50 to $70 \mathrm{~km}$ from s/c 2 to 4 , while the total FAC remained constant.

The EISCAT radar, which was located within the poleward downward FAC region, showed the formation of an electron density cavity in the ionospheric $\mathrm{E}$ and lower $\mathrm{F}$ regions (Fig. 22, middle panel) during the time when the arc was bright at the meridian of EISCAT (the fold and the arc were propagating eastward). A strong ion temperature increase indicated the presence of an intense horizontal electric field (Fig. 22, bottom panel). The observations were interpreted as follows: As the density cavity due to the downward FAC in the ionosphere forms, the ionospheric Pedersen conductance decreases and the return current region forms a growing load for the current circuit. In order to maintain the horizontal part of the current system, the horizontal electric field has to increase, as happened according to the EISCAT radar observations. The evacuation of ionospheric electrons carrying the field-aligned return current implies that, in order to maintain a sufficient return current, either the energy of the electrons must be increased or the current region must be widened. Cluster observations indicated that both processes occurred. The basic physical reason for the formation of the cavity is that the downward FAC is carried by upward moving ionospheric electrons, whereas the horizontal Pedersen current is carried by ions in the $\mathrm{E}$ and lower $\mathrm{F}$ region, and in order to maintain plasma neutrality, a net outflow of charge carriers occurs in the current closure region (see Fig. 21). Simulations of cavity formation by Doe et al. (1995) and Karlsson and Marklund (1998) have shown that a cavity can form in a time scale of some tens of seconds to a few seconds.

Investigations using the Polar satellite have shown that at high altitudes (4-6 $R_{E}$ ) the downward Poynting flux carried by Alfvén waves may dominate over the energy of precipitating particles at the outer edge of the plasma sheet (Wygant et al., 2000). It was suggested that a large part of the Poynting flux is converted to parallel particle acceleration in the auroral acceleration region.Vaivads et al. (2003) compared the energy flux carried by the Poynting flux at Cluster s/c to the electron energy flux measured by the low-altitude DMSP F14 satellite. The conjunction (geomagnetic longitude of Cluster differed by $40-80 \mathrm{~km}$ from F14) took place in the Southern Hemisphere at 20:00 MLT on 28 April 2001. Cluster crossed a quiet time auroral arc at a geocentric distance of $4.7 R_{E}$, well above the main acceleration region, whereas DMSP F14 was at an altitude of $850 \mathrm{~km}$, well below the acceleration region.

The auroral arc studied in Vaivads et al. (2003) appeared at a density gradient corresponding to the outer edge of the plasma sheet ion population. The speed and planarity of the arc were estimated from the four Cluster $\mathrm{s} / \mathrm{c}$. The estimated potential drops of 3-4kV (Fig. 24, panel f) and the energies of upgoing ions observed at Cluster altitudes gave values of the parallel acceleration potential in good agreement with those derived from auroral electrons by DMSP ( $3 \mathrm{keV})$, supporting the quasi-static U-potential model. The Poynting flux (Fig. 24, panel h) calculated for the bipolar electric field 
structure (Fig. 24, panels a-d) and the accompanying magnetic field signature at Cluster yielded values of 70-150 W/m (projected to the ionosphere and with uncertainty of 50\%), which were comparable to the value of $180 \mathrm{~W} / \mathrm{m}$ from precipitating electrons at DMSP. The energy carried by electrons and ions at Cluster altitudes was small. Thus, it was suggested that the Poynting flux feeds the auroral electron acceleration.

In a companion paper, Wahlund et al. (2003) studied the broad-band ELF emissions, which spanned a broader region around the auroral arc studied by Vaivads et al. (2003). It was suggested that BBELF emissions are dispersed, linear, polarised Alfvén waves (DAW) transporting energy downward to the ionosphere and leading to particle acceleration when dissipating part or all of their energy along the propagation path by wave-particle coupling, causing ion heating, suprathermal electron bursts and higher frequency ion-mode waves, and possibly also electric potential structures. Indeed, significant $\mathrm{H}^{+}$and $\mathrm{O}^{+}$outflows with energies around $1 \mathrm{keV}$ were observed simultaneously with the broad-band emissions. In the study by Aikio et al. (2004), BBELF emissions were observed both in up- and downward FAC regions, but they were highly localised in space and time, and could appear/disappear between two Cluster s/c passages of the same arc, which were separated by $60-90 \mathrm{~s}$. Hence, auroral arcs are not all the time associated with intense BBELF fluctuations at high altitudes, though commonly observed by satellites.

Ion outflow from the auroral regions is a significant source of plasma in the magnetosphere, particularly during storm times. A number of statistical studies have shown how the outflow depends on location and geomagnetic activity. However, Peterson et al. (2002) showed that the actual ion outflow structures are filamentary in nature, and highly variable in space and time. Kistler et al. (2002) studied ion outflows from Cluster and IMAGE satellite data. The idea was that if the outflow is correlated with arcs, the outflow regions would be moving with the arcs. The Cluster pass was through the northern auroral oval, close to magnetic midnight at an altitude of 4.4-4.9 $R_{E}$ during the 23 February 2001 substorm. Simultaneous observations of global aurora were available from the FUV instrument on the IMAGE satellite. Significant outflow of both $\mathrm{H}^{+}$and $\mathrm{O}^{+}$was observed by the CIS experiment and the outflow was highly structured. A reasonable correspondence between the observed auroral structures and the energy of the ion outflow was found: the more intense auroral structures corresponded to higher energy ion outflow. Because of the high altitude of the Cluster spacecraft, it was not possible to determine whether the emissions corresponded to ion beams or conics at lower altitude.

The multiple Cluster s/c were used in Kistler et al. (2002) to determine the horizontal velocity of the outflow structures. The ion outflow structures were moving mainly equatorward at about $0.7 \mathrm{~km} \mathrm{~s}^{-1}$ (value mapped to the ionosphere), with one exception, which moved rapidly poleward at $1.5 \mathrm{~km} \mathrm{~s}^{-1}$ (Fig. 25). In general, the motion of the ion outflow regions was found to be consistent with the convective motion of

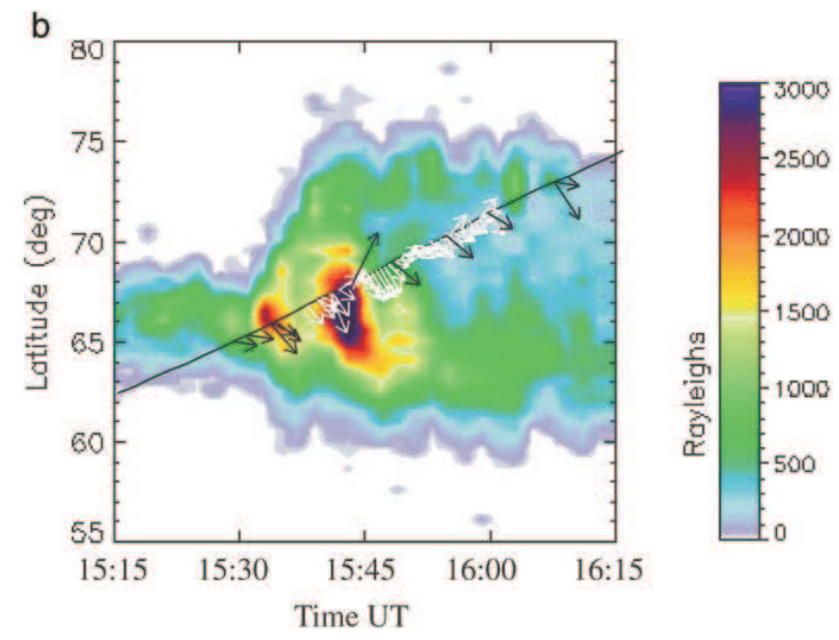

Fig. 25. A keogram showing the auroral emissions as a function of time in the midnight MLT sector from the FUV camera on IMAGE. The track of the Cluster 3 is given by the solid black line. The slopes of the black arrows give the horizontal velocities of the ion outflow structures and the slopes of the white arrows give the convection velocities determined from the EDI instrument on Cluster. (From Kistler et al., 2002.)

plasma observed by the EDI instrument (the slopes of black and white vectors coincide in Fig. 25). Although the overall auroras expanded poleward during this event, only one poleward moving ion outflow region was observed. That time period did correspond to a time when the Cluster s/c mapped to the poleward edge of an expanding aurora (see the isocontours of auroral emission intensity in Fig. 25). Thus, the question of whether the motion of the ion outflow region follows the fast poleward motion of auroras, or the plasma convection, was left somewhat ambiguous.

\subsection{Summary}

As shown in the previous sections, ground-based observations have been effectively combined with both the Cluster perigee observations, where the orbit has a "string of pearl" configuration and the satellites cross over the oval precipitation and upwelling structures at an altitude of $4 R_{E}$; and the Cluster apogee observations at $19 R_{E}$, which provide in-situ measurement of plasma and fields in the magnetotail. Here we briefly summarize the results.

The temporal evolution of structures both across and along the field lines of large-scale convection boundaries was obtained from Cluster perigee observations over GB networks. It was found that the region 1 current sheet may split into two parts: one is produced by the conductivity gradient and the other by the positive divergence of the electric field. In another study, the polar cap boundary was determined by using high and low altitude satellites and radar measurements, and the results were compared.

By combining ground-based observations with in-situ measurements of Cluster and also with other ISTP 
spacecraft, different aspects of substorms have been studied, such as onset mechanisms, global tail dynamics and ionosphere-magnetosphere couplings. By using GB observations for the accurate timing and localization of the disturbance, and Cluster for monitoring the reconnection region, it was found that reconnection was the primary mechanism for the onset in several studies. In cases where the initial disturbance region in the magnetosphere was not covered by Cluster, multi-point observations with other spacecraft were used to determine the propagation direction of the disturbances. In one event, the GB activations were associated with plasma sheet motions in the magnetotail, which were as significant in the $\mathrm{Y}$ as in the $\mathrm{Z}$ direction. Studies of this kind require that a substorm onset occurs when the spacecraft constellation is in the correct position, and therefore only a limited number of events have been studied with Cluster so far.

Global and dense coverage of the ground-based network data enabled the identification of the detailed ionospheric response for localized structures in the magnetosphere, such as BBFs. These isolated flows took place during relatively quiet periods with weak precipitation and hence, the magnetospheric electric field feature was clearly identified in the ionosphere because of the negligible effect of the conductivity enhancements. The enhanced flows were associated with a localized auroral activation. The Cluster separation of $4000 \mathrm{~km}$ during 2002 was ideal to determine further the spatial structure of these flows, in comparison with ionospheric disturbance in space and time. The scale size of the flow channel was also identified in two studies, under quite different conditions of magnetic activity, and values of about 2 and $8 R_{E}$ were obtained, where the latter one refers to an equivalent flow channel width.

By utilizing Cluster measurements at an altitude of about $4.5 R_{E}$ and conjugate observations from the ground and lowaltitude spacraft, interesting, new features of the auroral arc dynamics have been identified. It was shown that the highaltitude, downward Poynting flux is converted at the acceleration region to a large extent by the precipitating electron energy. Above aurora, upward accelerated ions are often measured; it was found that the highest energy ion outflows corresponded to the brighest aurora. In one event, the temporal evolution of the return (downward) FAC region was studied. Cluster observed electron beams, which were of ionospheric origin and, in addition, accelerated between the ionosphere and the s/c, with an increase in acceleration potential from 200 to $1000 \mathrm{kV}$ in $70 \mathrm{~s}$. The EISCAT radar observed formation of a density cavity in the return current region, which lasted for a few minutes. Thus, obviously the evacuated part of the ionosphere formed a growing load for the magnetosphere, which reacted by increasing the voltage between the ionosphere and the magnetosphere. This is an indication of the active role that the ionosphere can play in the magnetosphere-ionosphere coupling.

Many new results have been obtained from combined Cluster and ground-based studies of the nightside processes. Yet, there are still many questions to be answered by the combination of ground-based observations with Cluster observa- tions, and also with other ISTP and future missions. In the following we list some of the important questions:

- What is the consequence of the ion outflow in the magnetosphere?

- What are the ionospheric signatures of flux ropes and $\mathrm{X}$-line?

- What are the magnetospheric signatures of auroral arcs?

- How do localized processes such as BBF relate to larger scale magnetotail dynamics or a global substorm disturbance in the ionosphere?

- How do mid-tail and near-Earth disturbances interact during substorm onsets?

The Cluster/Double Star conjunction and the larger spatial separation of Cluster, and the future project of global multipoint spacecraft missions such as THEMIS, are expected to give us some clues to these problems.

\section{Conclusions and outlook}

This review illustrates how much coordinated ground-based observations have, over the first four years of the Cluster mission, become an essential complement and a valuable source of information for the scientific interpretation of insitu spacecraft measurements. In more than 30 selected examples it has been demonstrated that knowledge on the state of the surrounding plasma, and on the location or the dynamics of boundaries during the encountered events is of utmost importance when judging the physical relevance of in-situ observations. Often equally important, information concerning the recent past of encountered events gave crucial clues on the pre-conditioning or stability of the plasma regimes probed by the spacecraft. Sometimes, even the information on the further development of certain events, as provided by continued observations of the event, long after the satellites have passed the interesting region, allowed scientists to identify events as, for example, pseudo-breakups or major onsets of energy release. Such additional knowledge after the fact will help to identify proxies or representative indicators for future statistical studies, based on either data-set on its own.

For many of the described cases one would have been able to neither reach a conclusion on the large-scale impact of observed micro-physical effects, nor on the scale of a disturbance, nor on the temporal persistence of a feature, were it not for the global or meso-scale and long-term simultaneous coverage by ground-based data for these events. In a way, planet Earth, with its network of advanced coordinated instrumentation, has indeed and very much, as originally planned, become the "fifth Cluster satellite", right at the center of the global coupled system, constituted by the solar wind, the magnetosphere and the ionosphere.

Out of an enormous suite of standard, ground-based instruments, networked magnetometers, ionospheric radars, and 
optical instruments provided the most important additional input on large-scale or even sometimes global, spatial and temporal context, while more local interaction and coupling processes have been addressed by localized, but highly specialized ground-based facilities, such as incoherent scatter radars. ISRs can measure a number of ionospheric parameters at the same time and over a large a range of altitudes, but only at a few selected locations or scan directions (see Opgenoorth and Lockwood, 1997). Together, with the use of appropriate models and being well embedded in other supporting network data, they have made major contributions to the overall understanding of the observed processes.

It has also been tantalizing to see how the ground-based space science community, together with its closest collaborators - modelers and principal investigators at low Earth orbiting or imaging missions - have teamed up in their efforts to make the best out of the unique opportunity provided by the Cluster mission. On the hardware side networks have been established, maintained and globally interconnected, facilities renovated or developed and new instrumentation, for example, the EISCAT Svalbard Radar, has been put into place. On the software side the provision of combined and often value-added data products, advanced data browsing, reduction procedures and assimilative modeling, have allowed a larger number of scientists, both from the space and groundbased communities, to use multi-instrument data much more efficiently than previously. Cluster, even though coming into orbit only at a late stage of the ISTP, has through this activity become the catalyst of an entirely new type of collaborative, multi-instrument space physics.

Looking more at the physical problems and phenomena addressed by the studies reviewed here in more detail, it comes as no surprise that most deal either with localized features, such as arcs, fast flows, boundary dynamics and reconnection regions, or with short-lived transients, like onsets of dayside reconnection, substorm energy release, and flow or energy bursts in entire or partial plasma populations. Undoubtedly, much progress has been made in the understanding of individual events and many elusive features, such as auroral arcs, plasma flow channels, localized particle acceleration have been studied in greater detail. However, these studies have also revealed that nature still mocks us (scientists) with an ever-changing behaviour and with ever-variable features. Even if one finds a multitude of cases supporting one particular theory, it is still always possible to find a small, but significant number of counter-examples, supporting an opposing theory, or leaving doubts about the general validity of the prime theory. For example, it has definitively become clear that reconnection does occur at the expected locations (and often in transient form) for the appropriate directions of the IMF, but reconnection also seems to occur at strange locations and under strange or variable conditions. We have furthermore seen and verified examples of surprisingly steady reconnection signatures. Likewise in the nightside tail the spacing of the satellites and the intrinsic timing problems between various magnetospheric regions have not yet allowed us to draw final conclusions about the nature of substorm triggering. An important unresolved issue is whether there is always one and only one initial trigger mechanism and consequent instability leading to a substorm, or whether several processes in the near-Earth tail and at the inner edge of the plasma sheet can trigger each other in a variety of causal relations and temporal sequences. So it remains for future studies to leave the event-by-event state of analysis behind and to determine in a more refined or even statistical way which processes are in fact the dominant or governing ones, meaning "occurring most of the time, being the most likely to occur, and also being most efficient in terms of energy transport from one plasma regime to another".

We feel that we have identified, described, analysed and, to some degree, even understood the majority of the phenomena occurring in the coupled solar wind magnetosphere ionosphere system. However, we have not been able to put our finger on exactly which ones of all of these observed processes are the dominant ones in the cross-scale coupling mechanisms. Most of the features described in this review deal in one way or another with the in-situ observation of micro-physical processes which are observed to affect macro-physical states and global distributions of plasma. We can consequently identify two basic drawbacks with the data presently at our disposal. Even though we have basically visited all regions of the solar wind and magnetosphere at least once, we have not yet had an opportunity to monitor in-situ the relevant key space regions simultaneously, for example, the near-Earth and mid-tail (plus, of course, the support from the global GB set of observations), or the sub-solar magnetopause and the high and low altitude cusps (again supported with GB observations). Also, we have, so far, not been able to resolve the scale-size of one important plasma regime, the electron scale, which may still hold the key to some of the ever increasing collection of candidate wave-particle and wave-wave interaction mechanisms of importance for energy coupling and trigger of larger scale instabilities.

What then are the future opportunities provided by Cluster, future contemporary and successor missions? It has already been mentioned that the advent of the complementary Double Star mission will open new opportunities to study the mid-tail with Cluster and the near-Earth tail in the equatorial plane with DSP-1, while DSP-2 will probe the polar auroral field lines. Similarly, the Cluster/Double Star constellation will allow the monitoring of sub-solar magnetopause, exterior and interior cusp at the same time, providing ample near-term science opportunities to improve on the findings of studies presented here. In the longer term the THEMIS mission, with its radially spaced spacecraft, will add on to such opportunities, hopefully still meeting parts of the Cluster/Double Star constellation in orbit.

The extension of the Cluster mission towards late 2009 will give even more exciting opportunities to address the identified outstanding questions. In the first year even larger inter-spacecraft separations up to several $R_{E}$ will allow us to probe larger regions of space simultaneously, hopefully shedding more light on the temporal and causal event chains in the dayside and nightside magnetosphere. Larger s/c 
separation will also allow for the coverage of longer time intervals with consecutive passes of individual s/c close to perigee. At about mid term of the intended extension the lack of fuel will force the Cluster project team to sacrifice the 3$\mathrm{D}$ tetrahedron configuration of the Cluster s/c, a drawback that can be turned into a virtue. By moving only one satellite, the one with the maximum remaining fuel, closer and closer to one partner s/c, while holding the remaining $3 \mathrm{~s} / \mathrm{c}$ in a stable, two-dimensional, planar configuration, parallel to boundaries to be crossed, one can obtain a first glimpse at local cross-scale coupling mechanisms, by monitoring the presence or absence of certain small-scale (100 km or less) phenomena during large scale events. Even later in the Cluster mission an ever increasing deterioration of the baseline orbit, that is "sinking" of perigee and apogee (towards lower altitudes and southern latitudes, respectively) will allow the mission to shortly visit previously excluded regions, such as the near-Earth auroral field lines, the sub-solar point and the inner magnetosphere from $15 R_{E}$ down to as low as 6 or $5 R_{E}$, passing regions never visited by multi-spacecraft before. In summary, future missions in the magnetospheric realm can provide many answers to the remaining questions, mostly on the chain of causality for local processes in a larger framework. However, so far actually no mission, which is presently in the plan of any larger space agency, addresses the electron plasma scale, together with a simultaneous investigation of ion and MHD scale phenomena, in the key regions of the magnetosphere. In the present brainstorming and future planning activities carried out by some of the larger space agencies such needs have recently been formulated, and it remains to see whether these ideas, and most of all the continuous flow of ground breaking results from the Cluster missions like the ones presented here, can lead our community to design the ultimate multi-spacecraft, multi-scale mission for future magnetospheric research, which - almost no need to mention it here - will, of course, never be complete without an ever improving, in terms of efficiency and coverage, ground-based network of instruments.

Acknowledgements. The authors would like to thank the International Space Science Institute (ISSI, Bern) that made this review possible by funding two meetings of the international team of scientist that have composed this paper. We are grateful to the ISSI staff for their excellent support during the team meetings. We would like to thank the Cluster PIs (see Table 1) and the Cluster instrument teams for providing the Cluster data for the studies reviewed here, and the international ground-based community for providing the ground-based data for these studies. We are indebted to the funding agencies all over the world that have made it possible to run the instruments of which data are presented in this paper. A. Marchaudon is sponsored by the Particle Physics and Astronomy Research Council (PPARC) Rolling Grant, in the UK. During the course of this research, J. A. Wild was supported by UK Particle Physics and Astronomy Research Council (PPARC) grant numbers PPA/G/O/2001/0014 and PPA/G/O/2003/0013. During part of the preparation of this manuscript Mark Lester was funded by the Institute for Advanced Study, La Trobe University, Melbourne. Ian McCrea's participation was supported by PPARC rolling grant number PPA/G/O/2003/00025.

The Editor in chief thanks A. Masson, V. Sergeev and $\mathrm{Ph}$. Louarn for their help in evaluating this paper.
Table 2. List of used acronyms and their explanations.

\begin{tabular}{|c|c|}
\hline Acronym & Expanded meaning \\
\hline AACGM & Altitude Adjusted Corrected GeoMagnetic (coordinates) \\
\hline ACE & Advanced Composition Explorer (satellite) \\
\hline $\mathrm{AE}$ & Auroral Electrojet (index) \\
\hline AMIE & $\begin{array}{l}\text { Assimilative Mapping of Ionospheric Electrodynamics procedure } \\
\text { (Richmond et al., 1988) }\end{array}$ \\
\hline ASC & All-Sky Camera \\
\hline ASI & All-Sky Imager \\
\hline ASPOC & Active Spacecraft POtential Control (Cluster) \\
\hline BAT-R-US & A global MHD-simulation code by Powell et al. (1999) \\
\hline BBELF & BroadBand Extremely Low Frequency (waves) \\
\hline $\mathrm{BBF}$ & Bursty Bulk Flow \\
\hline $\mathrm{CD}$ & Current Disruption model (Lui, 1996) \\
\hline CGM & Corrected GeoMagnetic (coordinates) \\
\hline CHANDRA & $\begin{array}{l}\text { Space-based X-ray Observatory nameed after the Indian-American } \\
\text { Nobel laureate, Subrahmanyan Chandrasekhar }\end{array}$ \\
\hline CIS & Cluster Ion Spectrometry instrument (Cluster) \\
\hline Cluster-GB & Cluster-Ground-Based \\
\hline CPS & Central Plasma Sheet \\
\hline CUTLASS & Co-operative UK Twin Located Auroral Sounding System \\
\hline DAW & linear polarised Alfvén waves \\
\hline $\mathrm{DC}$ & Direct Current \\
\hline DMSP & Defense Meteorological Satellite Program \\
\hline DWP & Digital Wave Processing experiment (Cluster) \\
\hline ECM & Elementary Current Method (Amm, 2001) \\
\hline EDI & Electron Drift Instrument (Cluster) \\
\hline EFW & Electric Field and Wave instrument (Cluster) \\
\hline EISCAT & European Incoherent SCATer (association/radar) \\
\hline ESA & European Space Agency \\
\hline ESR & EISCAT Svalbard Radar \\
\hline FAC & Field-Aligned Current \\
\hline FAST & Fast Auroral Snapshot Explorer (satellite) \\
\hline FGM & FluxGate Magnetometer (Cluster) \\
\hline FOV & Field-Of-View \\
\hline FTE(s) & Flux Transfer Event(s) \\
\hline FUV & Far UltraViolet $(120-250 \mathrm{~nm})$ \\
\hline GGCM & Geospace General Circulation Model (Raeder et al., 1998) \\
\hline GSE & Geocentric Solar Ecliptic \\
\hline GSM & Geocentric Solar Magnetic \\
\hline GUMICS-4 & $\begin{array}{l}\text { Grand Unified Magnetosphere Ionosphere Coupling Simulation } \\
\text { (Janhunen, 1996) }\end{array}$ \\
\hline HEEA & High Energy Electron Analyser (part of PEACE instrument) \\
\hline $\mathrm{HF}$ & High Frequency (3-30 MHz) \\
\hline IMAGE & $\begin{array}{l}\text { Imager for Magnetopause-to-Aurora Global Exploration } \\
\text { spacecraft) }\end{array}$ \\
\hline IMAGE & $\begin{array}{l}\text { International Monitor for Auroral Geomagnetic Effects } \\
\text { (magnetometer network) }\end{array}$ \\
\hline IMF & Interplanetary Magnetic Field \\
\hline ISR & Incoherent Scatter Radar \\
\hline ISTP & International Solar-Terrestrial Program \\
\hline JEQ & EQuivalent current \\
\hline KRM & $\begin{array}{l}\text { Kamide-Richmond-Matsushita-Mishin technique } \\
\text { (Kamide et al., 1981) }\end{array}$ \\
\hline $\begin{array}{l}\text { LBH } \\
\text { LBHI }\end{array}$ & $\begin{array}{l}\text { Lyman-Birge-Hopfield bands in the UV emission } \\
\text { LBH long wavelengths }\end{array}$ \\
\hline LBHs & LBH short wavelengths \\
\hline LEEA & Low Energy Electron Analyser (part of PEACE instrument) \\
\hline LFM & Lyon-Fedder-Mobarry (code) (Fedder et al., 1995) \\
\hline LLBL & Low Latitude Boundary Layer \\
\hline $\begin{array}{l}\text { LOS } \\
\text { MCRB }\end{array}$ & $\begin{array}{l}\text { Line-Of-Sight } \\
\text { Magnetic Convection Reversal Boundary }\end{array}$ \\
\hline
\end{tabular}


Table 2. Continued.

\begin{tabular}{|c|c|}
\hline Acronym & Expanded meaning \\
\hline MHD & MagnetoHydroDynamic \\
\hline MI & Magnetosphere-Ionosphere \\
\hline MIRACLE & $\begin{array}{l}\text { Magnetometers-Ionospheric Radars-Allsky Cameras } \\
\text { Large Experiment }\end{array}$ \\
\hline MLAT & Magnetic LATitude \\
\hline MLT & Magnetic Local Time \\
\hline MSP & Meridian Scanning Photometer \\
\hline NASA & National Aeronautics and Space Administration \\
\hline NENL & Near-Earth Neutral Line model (Baker et al., 1996) \\
\hline $\mathrm{PC}$ & Polar Cap \\
\hline PEACE & Plasma Electron And Current Experiment (Cluster) \\
\hline PI & Principal Investigator \\
\hline $\mathrm{PIF}(\mathrm{s})$ & Pulsed Ionospheric Flow(s) \\
\hline PMAF(s) & Poleward-Moving Auroral Form(s) \\
\hline $\operatorname{PMRAF}(\mathrm{s})$ & Poleward-Moving Radar Auroral Form(s) \\
\hline PSBL & Plasma Sheet Boundary Layer \\
\hline $\mathrm{RE}$ & Earth Radius \\
\hline RAPID & Research with Adaptive Particle Imaging Detectors (Cluster) \\
\hline SAMNET & UK Sub-Auroral Magnetometer Network \\
\hline SCW & Substorm Current Wedge \\
\hline SECS & Spherical Elementary Current Systems (Amm, 1997) \\
\hline SI & Spectroscopic Imager \\
\hline STAFF & $\begin{array}{l}\text { Spatio-Temporal Analysis of Field Fluctuation } \\
\text { experiment (Cluster) }\end{array}$ \\
\hline STARE & Scandinavian Twin Auroral Radar Experiment \\
\hline SuperDARN & Super Dual Auroral Radar Network \\
\hline SWT & Science Working Team \\
\hline T01 & Tsyganenko 2001 magnetic field model (Tsyganenko, 2002a,b) \\
\hline $\mathrm{T} 87$ & Tsyganenko 1987 magnetic field model (Tsyganenko, 1987) \\
\hline T89 & Tsyganenko 1989 magnetic field model (Tsyganenko, 1989) \\
\hline TCR & Travelling Compression Region \\
\hline THEMIS & $\begin{array}{l}\text { Time History of Events and Macroscale Interactions during } \\
\text { Substorms }\end{array}$ \\
\hline TRANSCAR & A numeric model of the ionosphere by Blelly et al. (1996) \\
\hline UHF & Ultra High Frequency (300-3000 MHz) \\
\hline UT & Universal Time \\
\hline $\mathrm{UV}(\mathrm{I})$ & Ultra Violet (Imager, on the Polar satellite) \\
\hline VHF & Very High Frequency $(30-300 \mathrm{MHz})$ \\
\hline VLF & Very Low Frequency (3-30 kHz) \\
\hline WBD & Wideband plasma wave instrument (Cluster) \\
\hline WHISPER & $\begin{array}{l}\text { Whisper of HIgh frequency and Sounder for Probing Electron } \\
\text { density by Relaxation (Cluster) }\end{array}$ \\
\hline WIC & Wideband Imaging Camera (on the IMAGE satellite) \\
\hline
\end{tabular}

\section{References}

Aikio A. T., Lakkala, T., Kozlovsky, A., and Williams, P. J. S:.Electric fields and currents of stable drifting auroral arcs in the evening sector, J. Geophys. Res., 107, 1424, doi:10.1029/2001JA009172, 2002.

Aikio, A. T., Mursula, K., Buchert, S., Forme, F., Amm, O., Marklund, G., Dunlop, M., Fontaine, D., Vaivads, A. and Fazakerley, A.: Temporal evolution of two auroral arcs as measured by the Cluster satellite and coordinated ground-based instruments, Ann. Geophys., 22, 4089-4101, 2004,

\section{SRef-ID: 1432-0576/ag/2004-22-4089.}

Aikio, A. T., Opgenoorth, H. J., Persson, M. A. L., and Kaila, K. U.: Ground-based measurements of an arc-associated electric field, J. Atmos. Terr. Phys., 55, 797-808, 1993.
Akasofu, S.-I.: The development of the auroral substorm, Planet Spac., 12, 273-282, 1964.

Amm, O., Janhunen, P., Opgenoorth, H. J., Pulkkinen, T. I., and Viljanen, A.: Ionospheric shear flow situations observed by the MIRACLE network, and the concept of Harang Discontinuity, AGU monograph on magnetospheric current systems, Geophysical Monograph 118, 227-236, 2000.

Amm, O., Pajunpää, A., and Brandström, U.: Spatial distribution of conductances and currents associated with a north-south auroral form during a multiple-substorm period, Ann. Geophys., 17, 1385-1396, 1999.

Amm, O.: Aikio, A., Bosqued, J.-M., Dunlop, M., Fazakerley, A., Janhunen P., Kauristie, K., Lester, M., Sillanpää, I., Taylor, M., Vontrat-Reberac, A., Mursula., K., and André, M.: Mesoscale structure of a morning sector ionospheric shear flow region determined by conjugate Cluster II and MIRACLE ground-based observations, Ann. Geophys., 21, 1737-1751, 2003, SRef-ID: 1432-0576/ag/2003-21-1737.

Amm, O. and Viljanen, A.: Ionospheric disturbance magnetic field continuation from the ground to the ionosphere using spherical elementary current systems, Earth, Pl. Sp., 51, 431-440, 1999.

Amm, O.: Direct determination of the local ionospheric Hall conductance distribution from two-dimensional electric and magnetic field data: application of the method using models of typical ionospheric electrodynamic situations, J. Geophys. Res., 100, $21473-21488,1995$.

Amm, O.: Ionospheric elementary current systems in spherical coordinates and their application, J. Geomagn. Geoelectr., 49, 947955, 1997.

Amm, O.: Method of characteristics in spherical geometry applied to a Harang discontinuity situation, Ann. Geophys., 16, 413-424, 1998,

SRef-ID: 1432-0576/ag/1998-16-413.

Amm, O.: The elementary current method for calculating ionospheric current systems from multi-satellite and ground magnetometer data, J. Geophys. Res., 106, 24 843-24 856, 2001.

Amm, O.: The method of characteristics for calculating ionospheric electrodynamics from multi-satellite and groundbased radar data, J. Geophys. Res., 107(A10), 1270, doi:10.1029/2001JA005077, 2002.

Amm, O. and Kauristie, K.: Ionospheric signatures of bursty bulk flows, Surveys in Geophys., 23, 1-32, 2002.

André, M., Norqvist, P., Andersson, L., Eliasson, L., Eriksson, A. I., Blomberg, L., Erlandson, R. E., and Waldemark, J.: Ion energization mechanisms at $1700 \mathrm{~km}$ in the auroral region, J. Geophys. Res. 103, 4199-4222, 1998.

Angelopoulos, V., Kennel, C. F., Coroniti, F. V., Pellat, R., Kivelson, M. G., Walker, R. J., Russell, C. T., Baumjohann, W., Feldman, W. C., and Gosling, J. T.: Statistical characteristics of bursty bulk flow events, J. Geophys. Res., 99, 21 257-21 280, 1994.

Baker, D. N., Ergun, R. E., Burch, J. L., Jahn, J.-M., Daly, P. W., Friedel, R., Reeves, G. D., Fritz, T. A., and Mitchell, D. G.: A telescopic and microscopic view of a magnetospheric substorm on 31 March 2001, Geophys. R. L., 29(18), 1862, doi: 10.1029/2001GL014491, 2002a.

Baker, D. N., Hones, E. W., Jr., Higbie, P. R., Belian, R. D., and Stauning, P.: Near equatorial, high-resolution measurements of electron precipitation at L 6.6, J. Geophys. Res., 86, 2295-2313, 1981.

Baker, D. N., Peterson, W. K., Eriksson, S., Li, X., Blake, J. B., Burch, J. L., Daly, P. W., Dunlop, M. W., Korth, A., Donovan, E., 
Friedel, R., Fritz, T. A., Frey, H. U., Mende, S. B., Roeder, J., and Singer, H. J.: Timing of magnetic reconnection initiation during a global magnetospheric substorm, Geophys. R. L., 29(24), 2190, doi:10.1029/2002GL015539, 2002b.

Baker, D. N., Pulkkinen, T. I., Angelopoulos, V., Baumjohann, W., and McPherron, R. L.: Neutral line model of substorms: Past results and present view, J. Geophys. Res., 101, 12 975-13010, 1996.

Baker, J., Greenwald, R., Ruohoniemi, J., Frster, M., Paschmann, G., Donovan, E., Tsyganenko, N., Quinn, J., and Balogh, A.: Conjugate comparison of SuperDARN and Cluster EDI measurements of ExB plasma drift, J. Geophys. Res., 109(A1), A01209, doi:10.1029/2003JA009912, 2003.

Baker, J. B., Clauer, C. R., Ridley, A. J., Papitashvili, V. O., Brittnacher, M. J., and Newell, P. T.: The nightside poleward boundary of the auroral oval as seen by DMSP and the Ultraviolet Imager, J. Geophys. Res., 105, 21 267-21 280, 2000.

Bale, S. D., Mozer, F. S., and Phan, T.: Observation of lower hybrid drift instability in the diffusion region at a reconnecting magnetopause, 29, 24, 2180, doi:10.1029/2002GL016113, 2002.

Balogh, A., Carr, C. M., Acuña, M. H., Dunlop, M. W., Beek, T. J., Brown, P., Fornaon, K. H., Georgescu, E., Glassmeier, K.H., Harris, J., Musmann, G., Oddy, T., and Schwingenschuh K.: The Cluster Magnetic Field Investigation: overview of in-flight performance and initial results, Ann. Geophys., 19, 1207-1217, 2001 ,

SRef-ID: 1432-0576/ag/2001-19-1207.

Bell, T. F., Inan, U. S., Platino, M., Pickett, J. S., Kossey, P. A., and Kennedy, E. J.: Cluster Observations of Lower Hybrid Waves Excited at High Altitudes by Electromagnetic Whistler Mode Signals from the HAARP facility, Geophys Res. Lett., 31(L06811), doi:10.1029/2003TGL018855, 2004.

Berchem, J. and Russell, C. T.: Flux transfer events on the magnetopause: spatial distribution and controlling factors, J. Geophys. Res., 89, 6689-6703, 1984.

Birn, J. and Hesse, M.: Details of current disruption and diversion in simulations of magnetotail dynamics, J. Geophys. Res., 101, $15345-15358,1996$.

Birn, J., Hesse, M., Haerendel, G., Baumjohann, W., and Shiokawa, K.: Flow braking and the substorm current wedge, J. Geophys. Res., 104, 19 895-19904, 1999.

Birn, J., Raeder, J., Wang, Y. L., Wolf, R. A., and Hesse, M.: On the propagation of bubbles in the geomagnetic tail, Ann. Geophys., 22, 1773-1786, 2004,

\section{SRef-ID: 1432-0576/ag/2004-22-1773.}

Blelly, P.-L., Robineau, A., Lilensten J., and Lummerzheim, D.: Eight-moment fluid models of the terrestrial high-latitude ionosphere between 100 and $3000 \mathrm{~km}$, in Solar Terrestrial Energy Program (STEP): handbook of Ionospheric Models, (Ed.) Schunk, R. W., 53-72, 1996.

Borälv, E., Opgenoorth, H. J., Bosqued, J.-M., Dewhurst, J. P., Fazakerley, A., Owen, C. J., Dunlop, M., and Carter, M.: Substorm observations combining ground-based instruments and Cluster, Proceedings of the 6th International Conference on Substorms (Ed.) Winglee, R. M., 25-29 March, 399-403, Seattle, USA 2002.

Borälv, E., Opgenoorth, H. J., Kauristie, K., Lester, M., Bosqued, J.-M., Dewhurst, J. P., Owen, C. J., Dunlop, M., Slavin, J. A., Fazakerley, A., and Perry, C.: Correlation between ground-based observations of substorm signatures and magnetotail dynamics, Ann. Geophys., 23, 907-1011, 2005.

Bosqued, J. M., Phan, T. D., Dandouras, I., Escoubet, C. P.,
Rème, H., Balogh, A., Dunlop, M. W., Alcaydé, D., Amata, E., Bavassano-Cattaneo, M.-B., Bruno, R., Carlson, C. A., DiLellis, M., Eliasson, L., Formisano, V., Kistler, L. M., Klecker, B., Korth, A., Kucharek, H., Lundin, R., McCarthy, M., McFadden, J. P., Möbius, E., Parks, G. K., and Sauvaud, J.-A.: Cluster observations of the high-latitude magnetopause and cusp: initial results from the CIS ion instruments, Ann. Geophys. 19, 1545-1566, 2001.

Bosqued, J. M., Escoubet, C. P., Frey, H. U., Dunlop, M., Berchem, J., Marchaudon, A., Cerisier, J. C., Fazerkerley, A., Lavraud, B., Rème, H., Laakso, H., and Balogh, A.: Multipoint observations of transient reconnection signatures in the dayside cusp precipitation: A CLUSTER-IMAGE detailed case study, J. Geophys. Res., 110(A3), A03219, doi:10.1029/2004JA010621, 2005.

Boström, R.: Auroral electric fields, in Aurora and Airglow, (Ed.) McCormac, B. M., 293-303, Renhold, New York, 1967.

Brittnacher, M., Fillingim, M., Parks, G., Germany, G., and Spann, J.: Polar cap area and boundary motion during substorms, J. Geophys. Res, 104, 12 251-12 262, 1999.

Carbary, J. F., Sotirelis, T., Newell, P. T., and Meng, C.-I.: Auroral boundary correlations between UVI and DMSP, J. Geophys. Res., 108, 1018, doi:10.1029/2002JA009378, 2003.

Carlson, C. W., Pfaff, R. F., and Watzin, J. G.: The Fast Auroral Snapshot mission, Geophys. R. L., 25, 2013-2016, 1998.

Chen, C. X. and Wolf, R. A.: Interpretation of high-speed flows in the plasma sheet, J. Geophys. Res., 98, 21 409-21 419, 1993.

Chen, C. X. and Wolf, R. A.: Theory of thin-filament motion in Earth's magnetotail and its application to bursty bulk flows, J. Geophys. Res., 104, 14 613-14 626, 1999.

Chisham, G., Freeman, M. P., and Sotirelis, T.: A statistical comparison of SuperDARN spectral width boundaries and DMSP particle precipitation boundaries in the nightside ionosphere, Geophys. R. L., 31(2), L02804, doi:10.1029/2003GL019074, 2004.

Cornilleau-Wehrlin, N., Chanteur, G., Perraut, S., Rezeau, L., Robert, P., Roux, A., de Villedary, C., Canu, P., Maksimovic, M., de Conchy, Y., Hubert D., Lacombe, C., Lefeuvre, F., Parrot, M., Pinon, J. L., Décréau, P. M. E., Harvey, C. C., Louarn, Ph., Santolik, O., Alleyne, H. St. C., Roth, M., Chust, T., Le Contel, O., and STAFF team: First results obtained by the Cluster STAFF experiment, Ann. Geophys., 21, 437-456, 2003, SRef-ID: 1432-0576/ag/2003-21-437.

Cowley, S. W. H., Morelli, J. P., and Lockwood, M.: Dependence of convective flows and particle precipitation in the high-latitude dayside ionosphere on the $\mathrm{X}$ and $\mathrm{Y}$ components of the interplanetary magnetic field, J. Geophys. Res., 96, 5557-5564, 1991.

Cowley, S. W. H and Lockwood, M.: Excitation and decay of solar driven flows in the magnetosphere-ionosphere system, Ann. Geophys., 10, 103-115, 1992.

Crooker, N. U. and Rich, F. J.: Lobe cell convection as a summer phenomenon, J. Geophys. Res., 98, 13 403-13 407, 1993.

Décréau, P. M. E., Fergeau, P., Krasnoselskikh, V., Le Guirriec, E., Lévêque, M., Martin, Ph., Randriamboarison, O., Rauch, J. L., Sené, F.X., Séran, H. C., Trotignon, J. G., Canu, P., Cornilleau, N., de Féraudy, H., Alleyne, H., Yearby, K., Mögensen, P. B., Gustafsson, G., André, M., Gurnett, D. C., Darrouzet, F., Lemaire, J., Harvey, C. C., Travnicek, P., and Whisper experimenters: Early results from the Whisper instrument on Cluster: an overview, Ann. Geophys., 19, 1241-1258, 2001,

\section{SRef-ID: 1432-0576/ag/2001-19-1241.}

Deehr, C. and Lummerzheim, D.: Ground-based optical observations of hydrogen emission in the auroral substorm, J. Geophys. Res., 106, 33-44, 2001. 
Doe, R. A., Vickrey, J. F., and Mendillo, M.: Electrodynamic model for the formation of auroral ionospheric cavities, J. Geophys. Res., 100, 9683-9696, 1995.

Donovan, E. F. and Rostoker, G.: Internal consistency of the Tsyganenko magnetic field model and the Heppner-Maynard empirical model of the ionospheric electric field distribution, Geophys. R. L., 18, 1043-1046 1991.

Draper, N. C., Lester, M., Wild, J. A., Milan, S. E., Provan, G., Grocott, A., Cowley, S. W. H., Bogdanova, Y., Dewhurst, J. P., Fazakerley, A. N., Davies, J. A., and Bosqued, J.-M.: A joint Cluster and ground-based instruments study of two magnetospheric substorm events on 1st September 2002, Ann. Geophys., 22, 42174228, 2004,

SRef-ID: 1432-0576/ag/2004-22-4217.

Dungey, J. W.: Interplanetary field and the auroral zones, Phys. Res. Lett., 6, 47-48, 1961.

Dunlop, M. W., Balogh, A., and Glassmeier, K.-H.: Fourpoint Cluster application of magnetic field analysis tools: The discontinuity analyzer, J. Geophys. Res., 107(A11), 1385, doi:10.1029/2001JA005089, 2002b.

Dunlop, M. W., Balogh, A., Glassmeier, K.-H., and Robert, P.: Four-point Cluster application of magnetic field analysis tools: The Curlometer, J. Geophys. Res., 107(A11), 1384, doi:10.1029/2001JA005088, 2002a.

Engebretson, M. J., Hughes, W. J., Alford, J. L., Zesta, E., Cahill, Jr., L. J., Arnoldy, R. L., and Reeves, G. D.: Magnetometer Array for Cusp and Cleft Studies Observations of the Spacial Extent of Broadband ULF Magnetic Pulsations at Cusp/Cleft Latitudes, J. Geophys. Res., 100, 19371-19386, 1995.

Escoubet, C. P., Fehringer, M., and Goldstein, M.: The Cluster mission, Ann. Geophys., 19, 1197-1200, 2001,

SRef-ID: 1432-0576/ag/2001-19-1197.

Escoubet, C. P., Schmidt, R., and Goldstein, M. I.: Cluster - Science and mission overview, Space Sci. R., 79, 11-32, 1997.

Farrugia, C. J., Lund, E. J., Sandholt, P. E., Wild, J. A., Cowley, S. W. H., Balogh, A., Mouikis, C., Mobius, E., Dunlop, M. W., Bosqued, J.-M., Carlson, C. W., Parks, G. K., Cerisier, J.C., Kelly, J. D., Sauvaud, J.-A., Réme, H., and Evans, D. S.: Pulsed flows at the high-altitude cusp poleward boundary, and associated ionospheric convection and particle signatures, during a Cluster - FAST - SuperDARN - Sondrestrom conjunction under a southwest IMF, Ann. Geophys., 22, 2891-2905, 2004, SRef-ID: 1432-0576/ag/2004-22-2891.

Fedder, J. A., Slinker, S. P., Lyon, J. G., and Elphinstone, R. D.: Global numerical simulation of the growth phase and the expansion onset for a substorm observed by Viking, J. (Ed.) Geophys. Res., 100, 19 083-19093, 1995.

Foster, J. C., Holt, J. M., Musgrove, R. G., and Evans D. S.: Ionospheric convection associated with discrete levels of particle precipitation, Geophys. R. L., 13, 656-659, 1986.

Frey, H. U., Mende, S. B., Immel, T. J., Fuselier, S. A., Claflin, E. S., Gérard, J.-C., and Hubert, B.: Proton aurora in the cusp, J. Geophys. Res., 107(A7), 1091, doi:10.1029/2001JA900161, 2002.

Frey, H. U., Mende, S. B., Carlson, C. W., Gérard, J.-C., Hubert, B., Spann, J., Gladstone, R., and Immel, T.: The electron and proton aurora as seen by IMAGE-FUV and FAST, Geophys. R. L., 28, 1135-1138, 2001.

Frey, H. U., Mende, S. B., Immel, T. J., Gérard, J.-C., Hubert, B., Habraken, S., Spann, J., Gladstone, G. R., Bisikalo, D. V., and Shematovich, V. I.: Summary of quantitative interpretation of IMAGE far ultraviolet auroral data, Space Sci. R., 109, 255-283, 2003a.

Frey, H. U., Phan, T. D., Fuselier, S. A., and Mende, S. B.: Continuous magnetic reconnection at Earth's magnetopause, Nature, 426, 533-537, doi:10.1038/nature02084, 2003b.

Fuller-Rowell, T. J. and Evans, D. S.: Height-integrated Pedersen and Hall conductivity patterns inferred from the TIROS-NOAA satellite data, J. Geophys. Res., 92, 7606-7618, 1987.

Fuselier S. A., Klumpar, D. M., and Shelley, E. G.: Counterstreaming magnetosheath ions in the dayside low-latitude boundary layer, Geophys. R. L., 19, 425-428, 1992.

Fuselier S. A., Klumpar, D. M., and Shelley, E. G.: Ion reflection and transmission during reconnection at Earth's subsolar magnetopause, Geophys. R. L., 18, 139-142, 1991.

Fuselier, S. A., Frey, H. U., Trattner, K. J., Mende, S. B., and Burch, J. L.: Cusp aurora dependence on IMF $B_{Z}$, J. Geophys. Res., 107(A7), 1111, doi:10.1029/2001JA900165, 2002.

Germany, G. A., Parks, G. K., Brittnacher, M., Cumnock, J., Lummerzheim, D., Spann, J. F., Chen, L., Richards, P. G., and Rich, F. J.: Remote determination of auroral energy characteristics during substorm activity, Geophys. R. L., 24, 995-998, 1997.

Germany, G. A., Torr, D. G., Richards, P. G., Torr, M. R., and John, S.: Determination of ionospheric conductivities from FUV auroral emissions, J. Geophys. Res., 99, 23 297-23 305, 1994.

Greenwald, R. A., Baker, K. B., Dudeney, J. R., Pinnock, M., Jones, T. B., Thomas, E. C., Villain, J.-P., Cerisier, J.-C., Senior, C., Hanuise, C., Hunsucker, R. D., Sofko, G., Koehler, J., Nielsen, E., Pellinen, R., Walker, A. D. M., Sato, N., and Yamagishi, H.: DARN/SuperDARN: A Global View of the Dynamics of the high-Latitude Convection, Space Sci. Rev., 71, 761, 1995.

Greenwald, R. A., Weiss, W., Nielsen, E., and Thomson, N. R.: STARE: a new radar auroral backscatter experiment in northern Scandinavia, Radio Sci., 13, 1021-1039, 1978.

Grocott, A., Yeoman, T. K., Nakamura, R., Cowley, S. W. H., Frey, H. U., Rème, H., and Klecker, B.: Multi-instrument observations of the ionospheric counterpart of a bursty bulk flow in the nearEarth plasma sheet, Ann. Geophys., 22, 1061-1075, 2004.

Gurnett, D. A., Huff, R. L., Pickett, J. S., Persoon, A. M., Mutel, R. L., Christopher, I. W., Kletzing, C. A., Inan, U. S., Martin, W. L., Bougeret, J.-L., Alleyne, H. St. C., and Yearby, K. H.: First results from the Cluster wideband plasma wave investigation, Ann. Geophys., 19, 1259-1272, 2001,

SRef-ID: 1432-0576/ag/2001-19-1259.

Gustafsson, G., André, M., Carozzi, T., Eriksson, A. I., Fälthammar, C.-G., Grard, R., Holmgren, G., Holtet, J. A., Ivchenko, N., Karlsson, T., Khotyaintsev, Y., Klimov, S., Laakso, H., Lindqvist, P.-A., Lybekk, B., Marklund, G., Mozer, F., Mursula, K., Pedersen, A., Popielawska, B., Savin, S., Stasiewicz, K., Tanskanen, P., Vaivads, A., and Wahlund, J.-E.: First results of electric field and density observations by Cluster EFW based on initial months of operation, Ann. Geophys., 19, 1219-1240, 2001,

SRef-ID: 1432-0576/ag/2001-19-1219.

Haerendel, G., Paschmann, G., Sckopke, N., Rosenbauer, H., and Hedgecock, P. C.: The frontside boundary layer of the magnetopause and the problem of reconnection, J. Geophys. Res., 83, 3195-3216, 1978.

Hapgood, M. A.: Uses and abuses of field-line tracing, in Satellite Ground Based Coordination Sourcebook, (Eds.) Lockwood, M., Wild, M., and Opgenoorth, H., ESA SP-1198, 35-346, 1998.

Hasegawa, H., Fujimoto, M., Phan, T.-D., Rème, H., Balogh, A., Dunlop, M. W., Hashimoto, C., and Tandokoro, R.: Transport of solar wind into Earth's magnetosphere through rolled-up Kelvin- 
Helmholtz vortices, Nature, 430, 755-758, 2004.

Hesse, M., Birn, J., and Hoffman, R. A.: On the mapping of ionospheric convection into the magnetosphere, J. Geophys. Res. 102, 9543-9552, 1997.

Inhester, B., Untiedt, J., Segatz, M., and Kürschner, M.: Direct determination of the local ionospheric Hall conductance distribution from two-dimensional electric and magnetic field data, J. Geophys. Res., 97, 4073-4083, 1992.

Janhunen, P.: GUMICS-3: a global ionosphere-magnetosphere coupling simulation with high ionospheric resolution, in: Proceedings of Environmental Modelling for Space-Based Applications, 18-20 September 1996, Eur. Space Agency Spec. Publ. ESA SP392, 1996.

Janhunen, P.: Reconstruction of electron precipitation characteristics from a set of multiwavelength digital all-sky auroral images, J. Geophys. Res., 106, 18 505-18 516, 2001.

Johnstone, A. D., Alsop, C., Burge, S., Carter, P. J., Coates, A. J., Coker, A. J., Fazakerley, A. N., Grande, M., Gowen, R. A., Gurgiolo, C., Hancock, B. K., Narheim, B., Preece, A., Sheather, P. H., Winningham, J. D., and Woodliffe, R. D.: PEACE: A plasma electron and current experiment, Space Sci. Rev., 79, 351-398, 1997.

Kaila, K. U.: Determination of the energy of auroral electrons by the measurement of the emission ratio and altitude of aurorae, Planet. Space Sci., 37, 341-349, 1989.

Kamide, Y., Richmond, A. D., and Matsushita, S.: Estimation of ionospheric electric fields, ionospheric currents and field-aligned currents from ground magnetic records, J. Geophys. Res., 86, 801-813, 1981 .

Karlsson, T. and Marklund, G.: Simulations of effects of smallscale auroral current closure in the return current region, Phys. Space Plasmas 15, 401-407, 1998.

Kauristie, K., Sergeev, V. A., Kubyshkina, M., Pulkkinen, T. I., Angelopoulos, V., Phan, T., Lin, R. P., and Slavin, J. A.: Ionospheric current signatures of transient plasma sheet flows, J. Geophys. Res., 105, $10677-10690,2000$.

Kauristie, K., Weygand, J., Pulkkinen, T. I., Murphree, J. S., and Newell, P. T.: Size of the auroral oval: UV ovals and precipitation boundaries compared, J. Geophys. Res, 104, 2321-2331, 1999.

Kawano, H., Kokubun, S., and Takahashi, K.: Survey of transient magnetic field events in the dayside magnetosphere, J. Geophys. Res., 97, 10 677-10 692, 1992.

Kistler, L. M., Frey, H. U., Möbius, E., Mouikis, C., Quinn, J. M., Klecker, B., Rème, H., Bosqued, J. M., Dandouras, I., Sauvaud, J. A., Di Lellis, A. M., Formisano, V., Marcucci, M. F., Carlson, C. W., McFadden, J. P., Parks, G. K., McCarthy, M., Korth, A., Eliasson, L., Lundin, R., Paschmann, G., Popecki, M. A., Mende, S. B., Winningham, J. D., and Fazakerley, A. N.: Motion of auroral ion outflow structures observed with CLUSTER and IMAGE FUV, J. Geophys. Res., 107(A8), doi:10.1029/2001JA005075, 2002.

Lockwood M., Fazakerley, A., Opgenoorth, H., Moen, J., van Eyken, A. P., Dunlop, M., Bosqued, J-M., Lu, G., Cully, C., Eglitis, P., McCrea, I. W., Hapgood, M. A., Wild, M. N., Stamper, R., Denig, W., Taylor, M., Wild, J. A., Provan, G., Amm, O., Kauristie, K., Pulkkinen, T., Strømme, A., Prikryl, P., Pitout, F., Balogh, A., Rème, H., Behlke, R., Hansen, T., Greenwald, R., Frey, H., Morley, S. K., Alcayd, D., Blelly, P-L., Donovan, E., Engebretson, M., Lester, M., Watermann, J., and Marcucci, M. F.: Coordinated Cluster and ground-based instrument observations of transient changes in the magnetopause boundary layer during an interval of predominantly northward IMF: rela- tion to reconnection pulses and FTE signatures, Ann. Geophys., 19, 1613-1640, 2001b,

\section{SRef-ID: 1432-0576/ag/2001-19-1613.}

Lockwood M., McCrea, I. W., Milan, S. E., Moen, J., Cerisier J.C., and Thorolfsson, A.: Plasma structure with poleward-moving cusp/cleft auroral transients: EISCAT Svalbard Radar observations and explanation in terms of the local time extent of events, Ann. Geophys., 18, 1027-1042, 2000,

SRef-ID: 1432-0576/ag/2000-18-1027.

Lockwood, M. and Smith, M. F.: Low- and mid-altitude cusp particle signatures for general magnetopause reconnection rate variations: 1. Theory, J. Geophys. Res., 99, 8531-8553, 1994.

Lockwood, M. and Smith, M. F.: Low-altitude signatures of the cusp and flux transfer events, Geophys. R. L., 16, 879-882, 1989.

Lockwood, M., Davis, C. J., Smith, M. F., Onsager, T. G., and Denig, W. F.: Location and characteristics of the reconnection $\mathrm{X}$-line deduced from low-altitude satellite and ground-based observations: 2. Defense Meteorological Satellite Program and European Incoherent Scatter data, J. Geophys. Res., 100, $21803-$ $21813,1995$.

Lockwood, M.: Location and characteristics of the reconnection Xline deduced from low-altitude satellite and ground-based observations: 1. Theory, J. Geophys. Res., 100, 21 791-21 802, 1995.

Lockwood, M., Opgenoorth, H. J., van Eyken, A. P., Fazakerley, A., Bosqued, J.-M., Denig, W. F., Wild, J., Cully, C., Greenwald, R., Lu, G., Amm, O., Stromme, A., Prikryl, P., Hapgood, M. A., Wild, M. N., Stamper, R., Taylor, M., McCrea, I. W., Kauristie, K., Pulkkinen, T., Pitout, F., Balogh, A., Dunlop, M., Rème, H., Behlke, R., Hansen, T., Provan, G., Eglitis, P., Morley, S. K., Alcayde, D., Blelly, P.-L., Moen, J., Donovan, E., Engebretson, M., Lester, M., Watermann, J., and Marcucci, M. F.: Coordinated Cluster, ground-based instrumentation and low-altitude satellite observations of transient poleward-moving events in the ionosphere and in the tail lobe, Ann. Geophys., 19, 1589-1612, 2001a,

SRef-ID: 1432-0576/ag/2001-19-1589.

Lockwood, M., Wild, M. N., and. Opgenoorth, H. J.: Satellite - Ground Based Coordination Sourcebook, European Space Agency, SP-1198, 1997.

Lu, G., Holzer, T. E., Lummerzheim, D., Ruohoniemi, J. M., Stauning, P., Troshichev, O., Newell, P. T., Brittnacher, M., and Parks, G.: Ionospheric response to the interplanetary magnetic field southward turning: Fast onset and slow reconfiguration, J. Geophys. Res., 107, 1153, doi:10.1029/2001JA000324, 2002.

Lu, G., Lyons, L. R., Reiff, P. H., Denig, W. F., de la Beaujardiere, O., Kroehl, H. W., Newell, P. T., Rich, F. J., Opgenoorth, H., and Persson, M. A. L.: Characteristics of ionospheric convection and field-aligned current in the dayside cusp region, J. Geophys. Res., 100, 11 845-11 861, 1995.

Lui, A. T. Y.: Current disruption in the Earth's magnetosphere: Observations and models, J. Geophys. Res., 101, 1996, $13067-$ $13088,1996$.

Lyons, L. R.: Determinations of relative timing of near-Earth substorm onset and and tail reconnection, Proceedings of the Fifth International Conference on Substorms, 16-20 May 2000, ESA SP-443, 255-262, 2000.

Machida, S., Miyashita, Y., Ieda, A., Nishida, A., Mukai, T., Saito, Y., and Kokubun, S.: GEOTAIL observations of flow velocity and north-south magnetic field variations in the near and middistant tail associated with substorms onsets, Geophys. R. L., 26, 635-638, 1999.

Marchaudon A., Cerisier, J.-C., Amm, O., Lester, M., Carlson, C. 
W., and Parks, G. K.: Quantitative modelling of the closure of meso-scale parallel currents in the nightside ionosphere, Ann. Geophys., 22, 125-140, 2004a,

\section{SRef-ID: 1432-0576/ag/2004-22-125.}

Marchaudon, A., Cerisier, J.-C., Bosqued, J.-M., Dunlop, M. W., Wild, J. A., Dcreau, P. M. E., Förster, M., Fontaine, D., and Laakso, H.: Transient plasma injections in the dayside magnetosphere: one-to-one correlated observations by Cluster and SuperDARN, Ann. Geophys., 22, 141-158, 2004b,

SRef-ID: 1432-0576/ag/2004-22-141.

Marklund, G. T., Ivchenko, N., Karlsson, T., Fazakerley, A., Dunlop, M., Lindqvist, P. A., Buchert, S., Owen, C., Taylor, M., Vaivalds, A., Carter, P., André, M., and Balogh, A.: Temporal evolution of the electric field accelerating electrons away from the auroral ionosphere, Nature, 414, 724-727, 2001.

Maynard, N. C., Ober, D. M., Burke, W. J., Scudder, J. D., Lester, M., Dunlop, M., Wild, J. A., Grocott, A., Farrugia, C. J., Lund, E. J., Russell, C. T., Weimer, D. R., Siebert, K. D., Balogh, A., André, M., and Rème, H.: Polar, Cluster and SuperDARN evidence for high-latitude merging during southward IMF: temporal/spatial evolution, Ann. Geophys., 21, 2233-2258, 2003,

SRef-ID: 1432-0576/ag/2003-21-2233.

McCrea I. W., Lockwood, M., Moen, J., Pitout, F., Eglitis, P., Aylward, A. D., Cerisier, J.-C., Thorolfsson, A. and Milan, S.: ESR and EISCAT observations of the response of the cusp and cleft to IMF orientation changes, Ann. Geophys., 18, 9, 1009-1026, 2000 ,

\section{SRef-ID: 1432-0576/ag/2000-18-1009}

McPherron, R.: Growth phase of magnetospheric substorms, J. Geophys. Res., 75, 5592-5599, 1970.

McPherron, R. L., Kivelson, M. G., Khurana, K., Amm, O., Baker, J. B., Balogh, A., Rème, H., Coonors, M., Creutzberg, F., Dandouras, I., Mann, I., Milling, D., Moldwin, M. B., Rostoker, G., Russell, C. T., and Singer, H. J.: Cluster observations of the postmidnight plasma sheet at $18 R_{E}$ during substorms, Proceedings of Internatioinal Conference on Substorms, 283-290, (Ed.) Winglee, R. M., Washington University, 2002.

McWilliams, K. A., Yeoman, T. K., Sigwarth, J. B., Frank, L. A., and Brittnacher, M.: The dayside ultraviolet aurora and convection responses to a southward turning of the interplanetary magnetic field, Ann. Geophys., 19, 701-721, 2001b.

McWilliams, K. A., Yeoman, T. K., and Cowley, S. W. H: Twodimensional electric field measurements in the ionospheric footprint of a flux transfer event, Ann. Geophys., 18, 1584-1598, 2001a,

\section{SRef-ID: 1432-0576/ag/2000-18-1584}

Mende, S. B., Heetderks, H., Frey, H. U., Lampton, M., Geller, S. P., Habraken, S., Renotte, E., Jamar, C., Rochus, P., Spann, J., Fuselier, S. A., Gerard, J.-C., Gladstone, R., Murphree, S., and Cogger, L.: Far Ultraviolet Imaging from the IMAGE Spacecraft: 1 . System Design, IMAGE Special Issue, Space Sci. Rev., 91, 243-270, February, 2000

Miyashita, Y., Machita, S., Liou, K., Mukai, T., Saito, Y., Hayakawa, H., Meng, C.-I., and Parks, G. K.: Evolution of the magnetotail associated with substorm auroral breakups, J. Geophys. Res., 108, 1353, doi:10.1029/2003JA009939, 2003.

Moen, J., Holtet, J. A., Pedersen , A., Lybekk, B., Svenes, K., Oksavik, K., Denig, W. F., Lucek, E., Søraas, F., and André., M.: Cluster boundary layer measurements and optical observations at magnetically conjugate sites, Ann. Geophys., 19, 1655-1668, 2001,

SRef-ID: 1432-0576/ag/2001-19-1655
Mozer, F. S., Cattel, C. A., Hudson, M. K., Lysak, R. L., Temerin, M., and Torbert, R. B.: Satellite measurements and theories of low altitude auroral particle acceleration, Space Sci. Rev., 27, 155-213, 1980.

Murison, M., Richmond, A. D., and Matsushita, S.: Estimation of ionospheric electric fields and currents from a regional magnetometer array, J. Geophys. Res., 90, 3525-3530, 1985.

Nagai, T., Fujimoto, M., Saito, Y., Machida, S., Terasawa, T., Nakamura, R., Yamamoto, T., Mukai, T., Nishida, A., and Kokubun, S.: Structure and dynamics of magnetic reconnection for substorm onsets with Geotail observations, J. Geophys. Res., 103, 4419-4440, 1998.

Nakamura, R., Amm, O., Laakso, H., Draper, N., Lester, M., Grocott, A., Klecker, B., McCrea, I. W., Balogh, A., Rème, H., and André, M.: Localized fast flow disturbance observed in the plasma sheet and in the ionosphere, Ann. Geophys., 23, 553566,2005 ,

SRef-ID: 1432-0576/ag/2005-23-553.

Nakamura, R., Baumjohann, W., Klecker, B., Bogdanova, Y., Balogh, A., Rème, H., Bosqued, J.-M., Dandouras, I., Sauvaud, J.-A., Glassmeier, K.-H., Kistler, L., Mouikis, C., Zhang, T. L., Eichelberger, H., and Runov, A.: Motion of the dipolarization front during a flow burst event observed by Cluster, Geophys. R L., 29(20), doi:10.1029/2002GL015763, 2002.

Nakamura, R., Baumjohann, W., Mouikis, C., Kistler, L. M., Runov, A., Volwerk, M., Asano, Y., Vörös, Z., Zhang, T. L., Klecker, B., Rème, H., and Balogh, A.: Spatial scale of high-speed flows in the plasma sheet observed by Cluster, Geophys. R. L., 31(9), L09804, doi:10.1029/2004GL019558, 2004.

Nakamura, R., Baumjohann, W., Schoedel, R., Sergeev, V. A., Kubyshkina, M., Brittnacher, M., Mukai, T., and Liou, K.: Earthward flow bursts, auroral streamers and small expansions, J. Geophys. Res., 106, 10 791-10 802, 2001.

Newcomb, W. A.: Motion of lines of force, Annals of Physics, 3, 347-385, 1958.

Newell P. T and Meng, C. I.: Ion acceleration at the equatorward edge of the cusp: low altitude observations of patchy merging, Geophys. R. L., 18, 1829-1832, 1991.

Onsager T. G.: A quantitative model of magnetosheath plasma in the low-latitude boundary layer, cusp and mantle, in "Physical signatures of magnetopause boundary layer processes" (Eds.) Holtet, J. A., and Egeland, A., NATO ASI Series C, Vol. 425, Kluwer, 385-400, 1994.

Opgenoorth, H. J., Häggström, I., Williams, P. J. S., and Jones, G. O. L.: Regions of strongly enhanced perpendicular electric fields adjacent to auroral arcs, J. Atmos. Terr. Phys., 52, 449458, 1990.

Opgenoorth, H. J., Lockwood, M., Alcayde, D., Donovan, E., Engebretson, M. J., van Eyken, A. P., Kauristie, K., M.Lester, Moen, J., Waterman, J., Alleyne, H., Andre, M., Balogh, A., CornilleauWehrlin, N., Decreau, P. E., Fazerkerley, A., Rème, H., Andre, R., Amm, O., Behlke, R., Blelly, P.-L., Boholm, H., Boralv, E., Bosqued, J.-M., Buchert, S., Cerisier, J. C., Cully, C., Denig, W. F., Doe, R., Dunlop, M. W., Eglitis, P., Greenwald, R. A., Kelly, J. D., Krauklis, I., Lu, G., Mann, I. R., Marcucci, M. F., McCrea, I. W., Maksimovic, M., Massetti, S., Masson, A., Milling, D. K., Orsini, S., Pitout, F., Provan, G., Ruohoniemi, J. M., Samson, J. C., Schott, J. J., Sedgemore-Schulthess, F., Stamper, R., Stauning, P., Stromme, A., Taylor, M., Villain, J. P., Voronkov, I., Wild, J. A., and Wild, M.: Coordinated groundbased, low altitude satellite and Cluster observations on global and local scales during a transient postnoon sector excursion of 
the magnetospheric cusp, Ann. Geophys., 19, 1367-1398, 2001, SRef-ID: 1432-0576/ag/2001-19-1367.

Opgenoorth, H., J. and Lockwood, M.: Opportunities for magnetospheric research with coordinated cluster and ground-based observations: Space Sci. Rev., 79, 599-637, 1997.

Paschmann, G., and Daly, W. (Eds.): Analysis methods for multispacecraft data, International Space Science Institute (ISSI) Scientific Report SR-001, ESA Publications Division, Noordwijk, The Netherlands, 1998.

Paschmann, G., Quinn, J. M., Torbert, R. B., Vaith, H., McIlwain, C. E., Haerendel, G., Bauer, O. H., Bauer, T., Baumjohann, W, Fillius, W., Förster, M., Frey, S., Georgescu, E., Kerr, S. S., Kletzing, C. A., Matsui, H., Puhl-Quinn, P., and Whipple, E. C.: The Electron Drift Instrument on Cluster: overview of first results, Ann. Geophys., 19, 1273-1288, 2001,

SRef-ID: 1432-0576/ag/2001-19-1273.

Peterson, W. K., Collin, H. L., Boehm, M., Yau, A. W., Cully, C., and Lu, G.: Investigation into the spatial and temporal coherence of ionospheric outflow on 9-12 January 1997, J. Atmos. Sol. Terr. Phys., 64, 1659-1666, 2002.

Phan, T. D., Frey, H. U., Frey, S., Peticolas, L., Fuselier, S., Carlson, C., Rème, H., Bosqued, J.-M., Balogh, A., Dunlop, M., Kistler, L., Mouikis, C., Dandouras, I., Sauvaud, J.-A., Mende, S., McFadden, J., Parks, G., Moebius, E., Klecker, B., Paschmann, G., Fujimoto, M., Petrinec, S., Marcucci, M. F., Korth, A., and Lundin, R.: Simultaneous Cluster and IMAGE observations of cusp reconnection and auroral proton spot for northward IMF, Geophys. R. L., 30, 1509, doi:10.1029/2003GL016885, 2003.

Pinnock, M., Rodger, A. S., Dudeney, J. R., Rich, F., and Baker, K. B.: High spatial and temporal resolution observations of the ionospheric cusp, Ann. Geophys., 13, 919-925, 1995, SRef-ID: 1432-0576/ag/1995-13-919.

Pitout F., Bosqued, J. M., Alcayde, D., Denig, W. F., and Rème, H.: Observations of the cusp region under northward IMF, Ann. Geophys., 19, 1641-1653, 2001,

SRef-ID: 1432-0576/ag/2001-19-1641.

Powell, K. G., Roe, P. L., Linde, T. J., Gombosi, T. I., and DeZeeuw, D. L.: A solution-adaptive upwind scheme for ideal magnetohydrodynamics, J. Comput. Phys., 154, 284-309, 1999.

Pulkkinen, T. I., Baker, D. N., Fairfield, D. H., Pellinen, R. J., Murphree, J. S., Elphinstone, R. D., McPherron, R. L., Fennell, J. F., Lopez, R. E., and Nagai, T.: Modeling the growth phase of a substorm using the Tsyganenko model and multi-spacecraft observations: CDAW-9, Geophys. R. L., 18, 11, 1963-1966, 1991.

Pulkkinen, T. I., Koskinen, H. E. J., Pellinen, R. J., Sergeev, V. A., Opgenoorth, H. J., and Donovan, E.: Data based magnetic field models: present status and future prospects, in Satellite - Ground Based Coordination Sourcebook, (Eds.) Lockwood, M., Wild, M., and Opgenoorth, H., ESA SP-1198, 293-317, 1998.

Raeder, J., Berchem, J., and Ashour-Abdalla, M.: The geospace environment modelling grand challenge: Results from a Global Geospace Circulation Model, J. Geophys. Res., 103, 1478714797, 1998.

Rees, M. H. and Luckey, D.: Auroral electron energy derived from ratio of spectroscopic emissions, J. Geophys. Res., 79, 51815186, 1974.

Reiff, P. H. and Burch, J. L.: IMF BY-dependent plasma flow and Birkeland currents in the dayside magnetosphere, 2. A global model for northward and southward IMF, J. Geophys. Res., 90, 1595-1609, 1985.

Rème, H., Aoustin, C., Bosqued, J. M., Dandouras, I., Lavraud, B., Sauvaud, J. A., Barthe, A., Bouyssou, J., Camus, Th., Coeur-
Joly, O., Cros, A., Cuvilo, J., Ducay, F., Garbarowitz, Y., Medale, J. L., Penou, E., Perrier, H., Romefort, D., Rouzaud, J., Vallat, C., Alcayd, D., Jacquey, C., Mazelle, C., d'Uston, C., Möbius, E., Kistler, L. M., Crocker, K., Granoff, M., Mouikis, C., Popecki, M., Vosbury, M., Klecker, B., Hovestadt, D., Kucharek, H., Kuenneth, E., Paschmann, G., Scholer, M., Sckopke, N., Seidenschwang, E., Carlson, C. W., Curtis, D.W., Ingraham, C., Lin, R. P., McFadden, J. P., Parks, G. K., Phan, T., Formisano, V., Amata, E., Bavassano-Cattaneo, M.B., Baldetti, P., Bruno, R., Chionchio, G., Di Lellis, A., Marcucci, M.F., Pallocchia, G., Korth, A., Daly, P.W., Graeve, B., Rosenbauer, H., Vasyliunas, V., McCarthy, M., Wilber, M., Eliasson, L., Lundin, R., Olsen, S., Shelley, E.G., Fuselier, S., Ghielmetti, A.G., Lennartsson, Escoubet, C.P., Balsiger, H., Friedel, R., Cao, J.-B., Kovrazhkin, R. A., Papamastorakis, I., Pellat, R., Scudder, J., and Sonnerup, B.: First multispacecraft ion measurements in and near the Earth's magnetosphere with the identical Cluster ion spectrometry (CIS) experiment, Ann. Geophys., 19, 1303-1354, 2001,

SRef-ID: 1432-0576/ag/2001-19-1303.

Richmond, A. D. and Kamide, Y.: Mapping electrodynamic features of the high-latitude ionosphere from localized observations: Technique, J. Geophys. Res., 93, 5741-5759, 1988.

Rijnbeek, R. P., Cowley, S. W. H., Southwood, D. J., and Russell, C. T.: A survey of dayside flux transfer events observed by ISEE 1 and 2 magnetometers, J. Geophys. Res., 89, 786-800, 1984.

Robinson, R. M., Vondrak, R. R., Miller, K., Dabbs, T., and Hardy, D. A.: On calculating ionospheric conductivities from the flux and energy of precipitating electrons, J. Geophys. Res., 92, 2565-2569, 1987.

Rostoker, G., Samson, J. C., Creutzberg, F., Hughes, T. J., McDiarmid, D. R., McNamara, A. G., Vallance Jones, A., Wallis, D. D., Cogger, L. L.: CANOPUS - A ground based instrument array for remote sensing the high latitude ionosphere during the ISTP/CGS program, Space Sci. Rev., 71, 743-760, 1995.

Runov, A., Nakamura, R., Baumjohann, W., Treumann, R. A., Zhang, T. L., Volwerk, M., Vörös, Z., Balogh, A., Glassmeier, K.-H., Klecker, B., Réme, H., and Kistler, L.: Current sheet structure near magnetic X-line observed by Cluster, Geophys. R. L., 30(11), 1579, doi:10.1029/2002GL016730, 2003.

Ruohoniemi, J. M. and Baker, K. B.: Large-Scale Imaging of HighLatitude Convection with Super Dual Auroral Radar Network HF Radar Observations, J. Geophys. Res., 103, 20 797-20 811, 1998.

Ruohoniemi, J. M. and Greenwald, R. A.: Statistical Patterns of High-Latitude Convection Obtained from Goose Bay HF Radar Observations, J. Geophys. Res., 101, 21 743-21 764, 1996.

Russell, C. T., Le, G., and Kuo, H.: The occurrence rate of flux transfer events, Adv. Space. Res., 18, 197-205, 1996.

Russell, C. T. and Elphic, R. C.: Initial ISEE magnetometer results: Magnetopause observations, Space Sci. Rev., 22, 681-715, 1978.

Russell, C. T. and Elphic, R. C.: ISEE observations of flux transfer events at the dayside magnetopause, Geophys. R. L., 6, 33-36, 1979.

Sandholt P. E., Farrugia, C. J., Moen, J., Norberg, O., Lybekk, B., Sten, T. and Hansen, T.: A classification of dayside auroral forms as a function of IMF orientation, J. Geophys. Res., 103, 23 325$23346,1998$.

Semeter, J. and Doe, R.: On the proper interpretation of ionospheric conductance estimated through satellite photometry, J. Geophys. Res., 107(A8), 1200, doi:10.1029/2001JA009101, 2002.

Sergeev, V. A., Angelopoulos, V., Gosling, J. T., Cattell, C. A., and Russell, C. T.: Detection of localized, plasma-depleted flux tubes 
or bubbles in the midtail plasma sheet, J. Geophys. Res., 101, 10 817-10 826, 1996.

Sergeev, V. A., Liou, K., Meng, C.-I., Newell, P. T., Brittnacher, M., Parks, G., and Reeves, G. D.: Development of auroral streamers in association with localized impulsive injections to the inner magnetotail, Geophys. R. L., 26, 417-420, 1999.

Sergeev, V., Runov, A., Baumjohann, W., Nakamura, R., Zhang, T. L., Volwerk, M., Balogh, A., Rème, H., Sauvaud, J. A., André, M., and Klecker, B.: Current sheet flapping motion and structure observed by Cluster, Geophys. R. L., 30, 1327, doi:10.1029/2002GL016500, 2003.

Sergeev, V. A., Kubyshkina, M. V., Baumjohann, W., Nakamura, R., Amm, O., Pulkkinen, T., Angelopoulos, V., Mende, S. B., Klecker, B., Nagai, T., Sauvaud, J.-A., Slavin, J. A., and Thomsen, M. F.: Transition from substorm growth to substorm expansion phase as observed with a radial configuration of ISTP and Cluster spacecraft, Ann. Geophys., accepted, 2005.

Slavin, J. A., Owen, C. J., Dunlop, M. W., Borälv, E., Moldwin, M. B., Sibeck, D. G., Tanskanen, E., Goldstein, M. L., Fazakerley, A., Balogh, A., Lucek, E., Richter, I., Rème, H., and Bosqued, J. M.: Cluster four spacecraft measurements of small traveling compression regions in the near-tail, Geophys. R. L., 30(23), 2208, doi:10.1029/2003GL018438, 2003.

Sonnerup, B. U. O., Papamastorakis, I., Paschmann, G., and Lühr, H.: Magnetopause properties from AMPTE/IRM observations of the convection electric field: Method development, J. Geophys. Res., 92, 12 137-12 159, 1987.

Stasiewicz, K., Bellan, P., Chaston, C., Kletzing, C., Lysak, R., Maggs, J., Pokhotelov, O., Seyler, C., Shukla, P., Stenflo, L., Streltsov, A., and Wahlund, J.-E.: Small scale Alfvénic structures in the aurora, Space Sci. R., 92, 425-533, 2000.

Stubbe, P., Kopka, H., Lauche, H., Rietveld, M. T., Brekke, A., Holt, O., Jones, T. B., Robinson, T., Hedberg, A., Thide, B., Crochet M., and Lotz, H. J.: Ionospheric modification experiments in northern Scandinavia, J. Atmos. Terr. Phys., 44, 1025-1041, 1982.

Syrjäsuo, M. T., Pulkkinen, T. I., Janhunen, P., Viljanen, A., Pellinen, R. J., Kauristie, K., Opgenoorth, H. J., Wallman, S., Eglitis, P., Karlsson, P, Amm, O., Nielsen, E., and Thomas, C.: Observations of substorm electrodynamics using the MIRACLE network, Proceedings of the 4th International Conference on Substorms, S. Kokobun and Y. Kamide, eds., Astrophysics and Space Science Library, volume 238, Terra Scientific Publishing Company/ Kluwer Academic Publishers, 1998.

Torkar, K., Riedler, W., Escoubet, C. P., Fehringer, M., Schmidt, R., Grard, R. J. L., Arends, H., Rüdenauer, F., Steiger, W., Narheim, B. T., Svenes, K., Torbert, R., André, M., Fazakerley, A., Goldstein, R., Olsen, R. C., Pedersen, A., Whipple, E., and Zhao, H.: Active spacecraft potential control for Cluster - implementation and first results, Ann. Geophys., 19, 1289-1302, 2001,

SRef-ID: 1432-0576/ag/2001-19-1289.

Trattner, K. J., Fuselier, S. A., Peterson, W. K., and Carlson, C. W.: Spatial features observed in the cusp under steady solar wind conditions, J. Geophys. Res., 107, 1288, doi:10.1029/2001JA000262, 2002.

Trattner, K. J., Fuselier, S. A., Peterson, W. K., Sauvaud, J.-A., Stenuit, H., and Dubouloz, N.: On spatial and temporal structures in the cusp, J. Geophys. Res., 104, 28 411-28 421, 1999.

Trattner, K. J., Fuselier, S. A., Yeoman, T. K., Carlson, C., Peterson, W. K., Korth, A., Rème, H., Sauvaud, J. A., and Dubouloz, N.: Spatial and temporal cusp structures observed by multiple spacecraft and ground based observations, Space Sci. R., in press,
2005.

Trattner, K. J., Fuselier, S. A., Yeoman, T. K., Korth, A., Fraenz, M., Mouikis, C., Kucharek, H., Kistler, L. M., Escoubet, C.P., Reme, H., Dandouras, I., Sauvaud, J. A., Bosqued, J. M., Klecker, B., Carlson, C., Phan, T., McFadden, J. P., Amata, E., and Eliasson, L.: Cusp structures: combining multi-spacecraft observations with ground-based observation, Ann. Geophys., 21, 20312041, 2003,

SRef-ID: 1432-0576/ag/2003-21-2031.

Tsyganenko, N. A.: Global quantitative models of geomagnetic field in the cislunar magnetosphere for different disturbance levels, Planet Spac., 35, 1347-1358, 1987.

Tsyganenko, N. A.: A magnetospheric magnetic field model with a warped tail current sheet, Planet. Space Sci., 37, 5-20, 1989.

Tsyganenko, N. A.: A model of the near magnetosphere with a dawn-dusk asymmetry 1. Mathematical structure, J. Geophys. Res., 107(A8), 1179, doi:10.1029/2001JA000220, 2002a.

Tsyganenko, N. A.: A model of the near magnetosphere with a dawn-dusk asymmetry 2. Parameterization and fitting to observations, J. Geophys. Res., 107(A8), 1176, doi:10.1029/2001JA000220, 2002b.

Vaivads, A., André, M., Buchert, S., Eriksson, A. I., Olsson, A., Wahlund, J.-E., Janhunen, P., Marklund, G., Kistler, L. M., Mouikis, C., Winningham, D., Fazakerley, A., and Newell, P.: What high altitude observations tell us about the auroral acceleration: A Cluster/DMSP conjunction, Geophys. R. L., 30, 3, 1106, doi:10.1029/2002GL016006, 2003.

Vallance Jones, A.: Aurora, D. Reidel Pub., Dordrecht, 1974.

Wahlund, J.-E., Yilmaz, A., Backrud, M., Sundkvist, D., Vaivads, A., Winningham, D., André, M., Balogh, A., Bonnell, J., Buchert, S., Carozzi, T., Cornilleau, N., Dunlop, M., Eriksson, A.I., Fazakerley, A., Gustafsson, G., Parrot, M., Robert, P., and Tjulin, A.: Observations of auroral broadband emissions by CLUSTER, Geophys. R. L., 30(11), 1563, doi:10.1029/2002GL016335, 2003.

Watermann, J., de la Beaujardiere, O., Lummerzheim, D., Woch, J., Newell, P. T., Potemra, T. A., Rich F. J., and Shapshak, M.: The dynamic cusp at low altitudes: a case study utilising Viking, DMSP-D7 and Sondrestrom incoherent scatter radar observations, Ann. Geophys., 12, 1114-1157, 1994

Wild, J. A., Milan, S. E., Cowley, S. W. H., Dunlop, M. W., Owen, C. J., Bosqued, J. M., Taylor, M. G. G. T., Davies, J. A., Lester, M., Sato, N., Yukimatu, A. S., Fazakerley, A. N., Balogh, A., and Rème, H.: Coordinated interhemispheric SuperDARN radar observations of the ionospheric response to flux transfer events observed by the Cluster spacecraft at the high-latitude magnetopause, Ann. Geophys., 21, 1807-1826, 2003,

SRef-ID: 1432-0576/ag/2003-21-1807.

Wild, J. A., Cowley, S. W. H., Davies, J. A., Khan, H., Lester, M., Milan, S. E., Provan, G., Yeoman, T. K., Balogh, A., Dunlop, M. W., Fornacon, K.-H., and Georgescu, E.: First simultaneous observations of flux transfer events at the high-latitude magnetopause by the Cluster spacecraft and pulsed radar signatures in the conjugate ionosphere by the CUTLASS and EISCAT radars, Ann. Geophys., 19, 1491-1508, 2001,

SRef-ID: 1432-0576/ag/2001-19-1491.

Wild, J. A., Milan, S. E., Owen, C. J., Bosqued, J. M., Lester, M., Wright, D. M., Frey, H., Carlson, C. W., Fazakerley, A. N., and Rème, H.: The location of the open-closed magnetic field line boundary in the dawn sector auroral ionosphere, Ann. Geophys., 22, 3625-3639, 2004,

SRef-ID: 1432-0576/ag/2004-22-3625. 
Wilken, B., Daly, P. W., Mall, U., Aarsnes, K., Baker, D. N., Belian, R. D., Blake, J. B., Borg, H., Büchner, J., Carter, M., Fennell, J. F., Friedel, R., Fritz, T. A., Gliem, F., Grande, M., Kecskemety, K., Kettmann, G., Korth, A., Livi, S., McKenna-Lawlor, S., Mursula, K., Nikutowski, B., Perry, C.H., Pu, Z. Y., Roeder, J., Reeves, G. D., Sarris, E. T., Sandahl, I., F. Søraas, F., Woch, J., and Zong, Q.-G.: First results from the RAPID imaging energetic particle spectrometer on board Cluster, Ann. Geophys., 19, 1355-1366, 2001,

\section{SRef-ID: 1432-0576/ag/2001-19-1355.}

Wiltberger, M., Pulkkinen, T. I., Lyon, J. G., and Goodrich, C. C.: MHD simulation of the magnetotail during the December 10 , 1996, substorm, J. Geophys. Res., 105, 27 649-27 664, 2000.

Wooliscroft, L. J. C., H. Alleyne, H. St. C., Dunford, C. M., Sumner, A., Thompson, J. A., Walker, S. N., Yearby, K. H., Buckley, A., Chapman, S., and Gough, M.P.: The digital wave processing experiment on Cluster, Space Sci. R., 79, 209-231, 1997.
Wright, D. M., Davies, J. A., Robinson, T. R., Chapman, P. J., Yeoman, T. K., Thomas, E. C., Lester, M., Cowley, S. W. H., Stocker, A. J., Horne R. B., and Honary, F.: Space Plasma Exploration by Active Radar (SPEAR): An overview of a future radar facility, Ann. Geophys., 18, 1248-1255, 2000,

SRef-ID: 1432-0576/ag/2000-18-1248.

Wygant, J. R., Keiling, A., Cattell, C. A., Johnson, M., Lysak, R. L., Temerin, M., Mozer, F. S., Kletzing, C. A., Scudder, J. D., Peterson, W., Russell, C. T., Parks, G., Brittnacher, M., Germany, G., and Spann, J.: Polar spacecraft based comparisons of intense electric fields and Poynting flux near and within the plasma sheet-tail lobe boundary to UVI images: An energy source for the aurora, J. Geophys. Res., 105, 18 675-18 692, 2000. 